Aus der Poliklinik für Präventive Zahnmedizin, Parodontologie und Kariologie (Prof. Dr. med. dent. A. Wiegand) im Zentrum für Zahn-, Mund- und Kieferheilkunde der Medizinischen Fakultät der Universität Göttingen

\title{
Entfernung der medikamentösen Einlage aus Wurzelkanälen mit Hilfe unterschiedlicher Techniken
}

\author{
INAUGURAL-DISSERTATION \\ zur Erlangung des Doktorgrades \\ für Zahnmedizin \\ der Medizinischen Fakultät der \\ Georg-August-Universität zu Göttingen
}

vorgelegt von

Anna-Lena Zopfs

aus

Freiburg i. Brsg.

Göttingen 2021 
Dekan:

\section{Betreuungsausschuss}

Betreuer/in:

Ko-Betreuer/in:

\section{Prüfungskommission}

Referent/in:

Ko-Referent/in:

Drittreferent/in:
Prof. Dr. med. W. Brück

Prof. Dr. M. Hülsmann

Prof. Dr. M. Rödiger

Prof. Dr. M. Hülsmann

Prof. Dr. M. Rödiger

Prof. Dr. Thomas Meyer

Datum der mündlichen Prüfung: 25.11.2021 
Hiermit erkläre ich, die Dissertation mit dem Titel "Entfernung der medikamentösen Einlage aus Wurzelkanälen mit Hilfe unterschiedlicher Techniken" eigenständig angefertigt und keine anderen als die von mir angegebenen Quellen und Hilfsmittel verwendet zu haben.

Göttingen, den 25.11.2021 


\section{Inhaltsverzeichnis}

Abbildungsverzeichnis....................................................................II

Tabellenverzeichnis...............................................................................

Abkürzungsverzeichnis...........................................................................

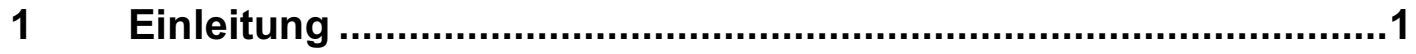

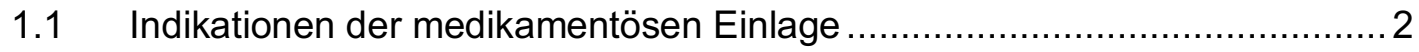

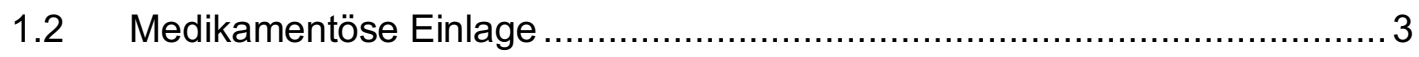

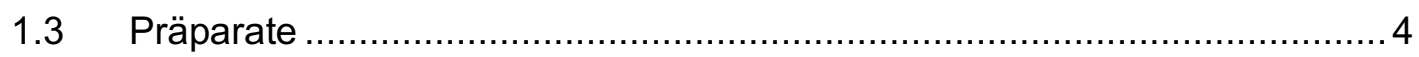

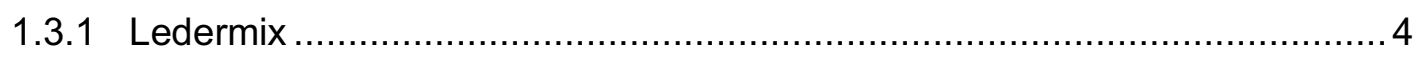

1.3.2 Odontopaste

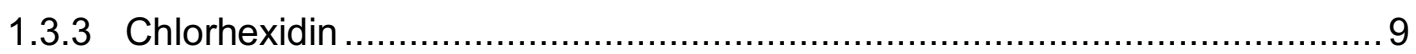

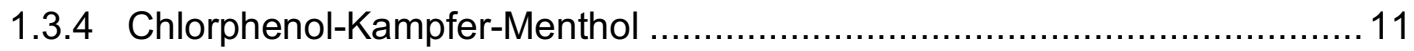

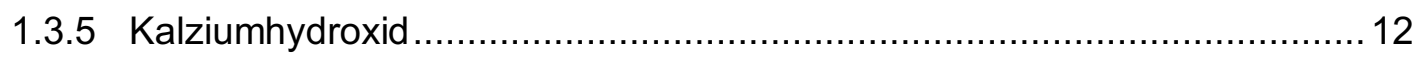

1.4 Applikation der medikamentösen Einlage …………............................... 15

1.5 Entfernung der medikamentösen Einlage ................................................ 15

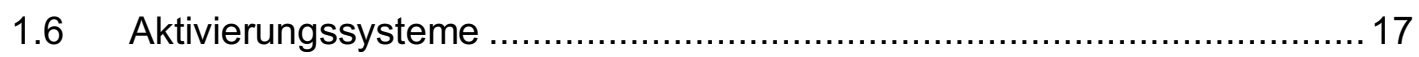

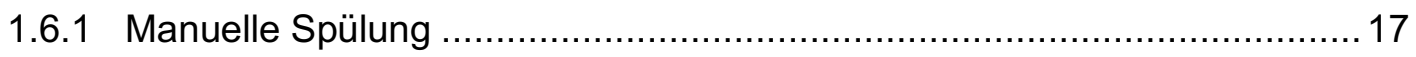

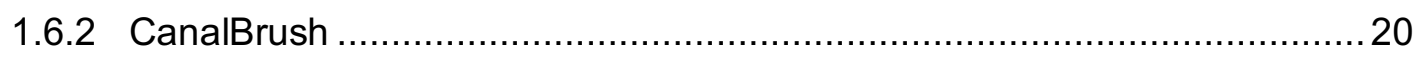

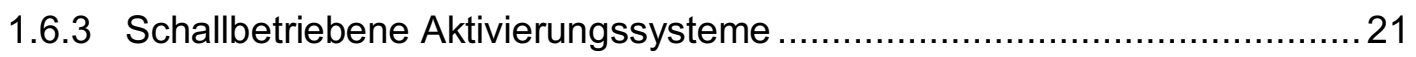

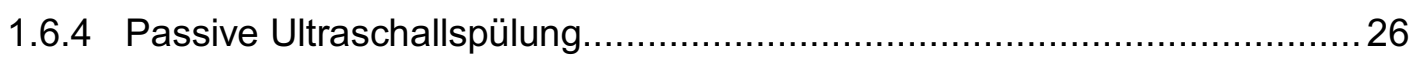

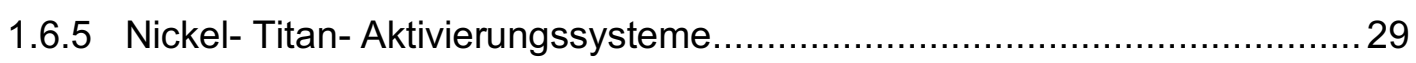

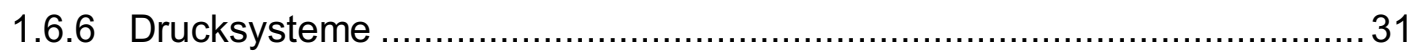

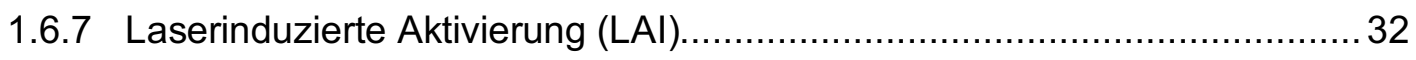

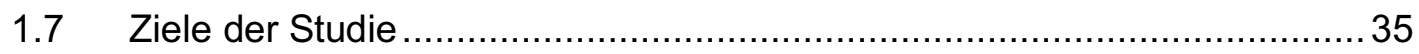

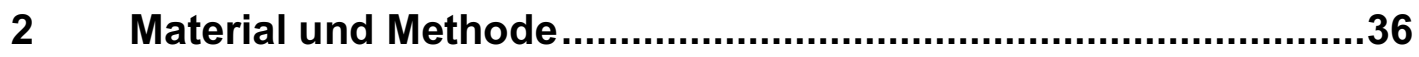

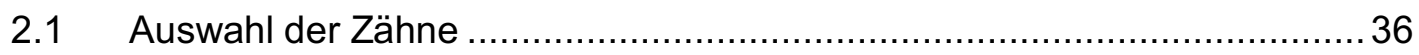

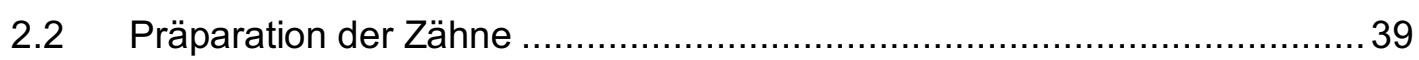

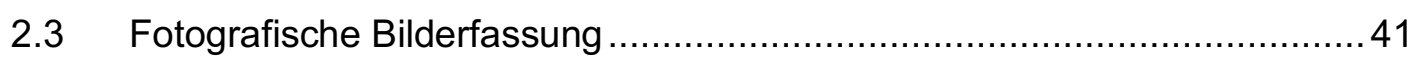

2.4 Befüllen der Vertiefungen .................................................................. 41

2.5 Entfernung der medikamentösen Ledermix-Einlage ................................. 44

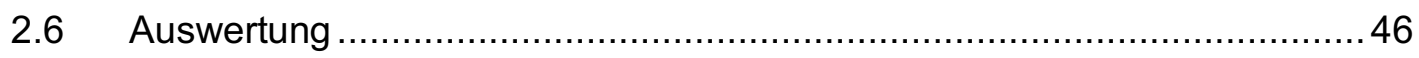

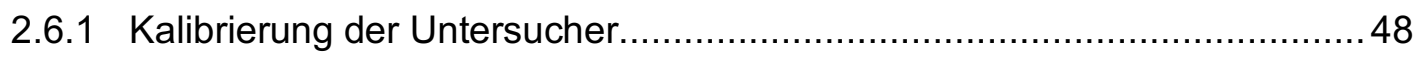

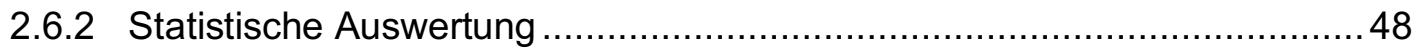

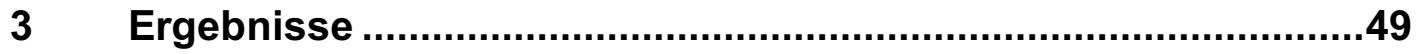

3.1 Reproduzierbarkeit der Ergebnisse ………………............................. 49 
3.1.1 Intraindividuelle Reproduzierbarkeit ................................................. 49

3.1.2 Interindividuelle Reproduzierbarkeit ................................................. 49

3.2 Ergebnisse der Hauptversuche .................................................... 50

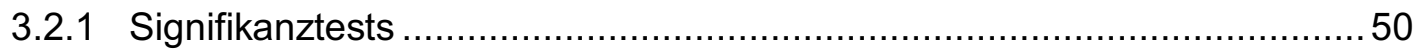

3.2.2 Unterschiede der Aktivierungsmethoden ......................................... 50

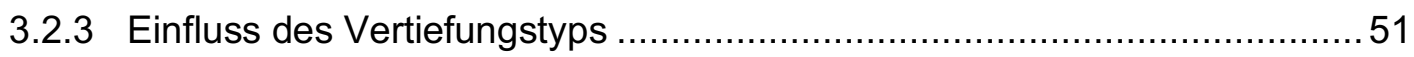

3.3 Absolute und relative Häufigkeit ................................................... 52

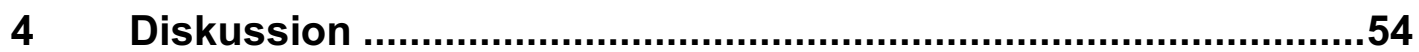

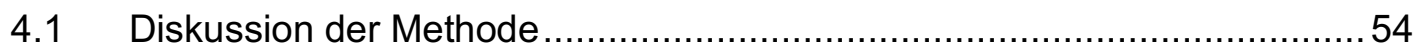

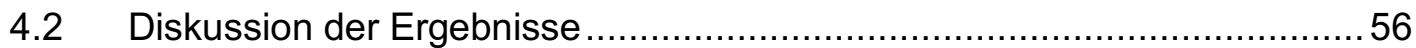

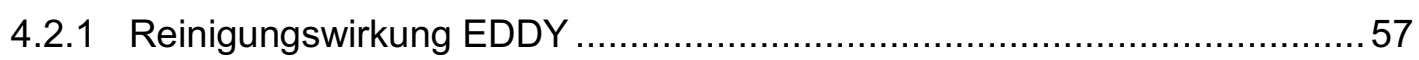

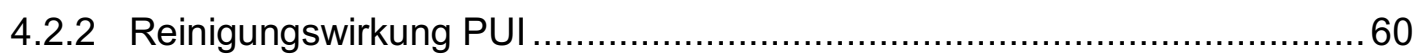

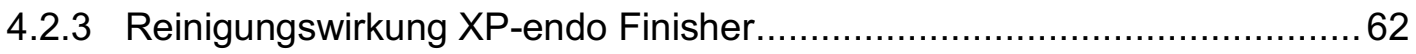

4.2.4 Reinigungswirkung weiterer Aktivierungsmethoden............................... 64

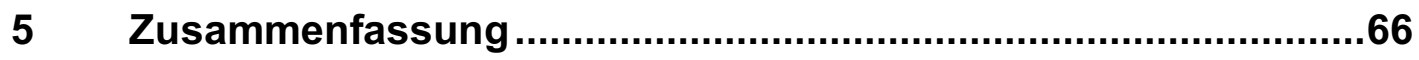

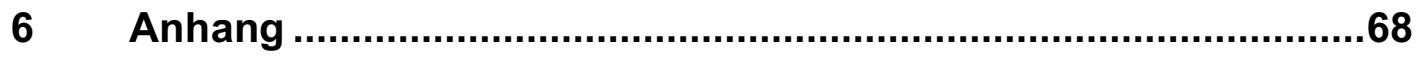

$7 \quad$ Literaturverzeichnis................................................................ 


\section{Abbildungsverzeichnis}

Abbildung 1: Überblick über gängige Aktivierungssysteme

Abbildung 2: Schematische Darstellung der Position von Gruben und Rillen in den Zahnwurzelhälften (angelehnt an Lee et al.

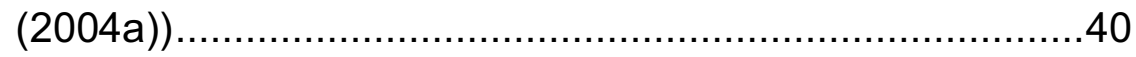

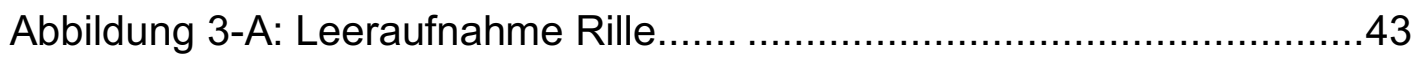

Abbildung 3-B: Leeraufnahme Gruben..................................................

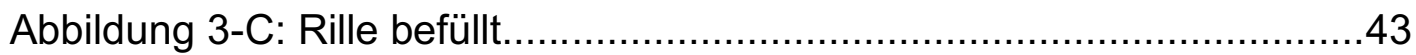

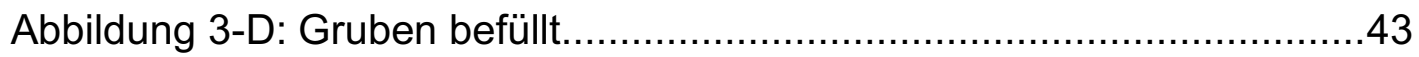

Abbildung 4: Röntgenkontrolle einer homogenen

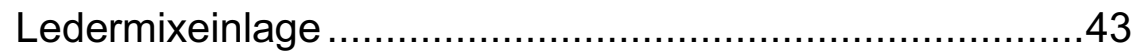

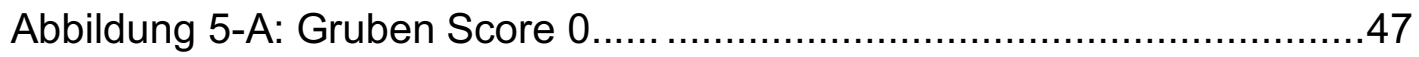

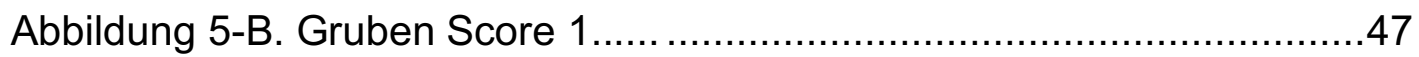

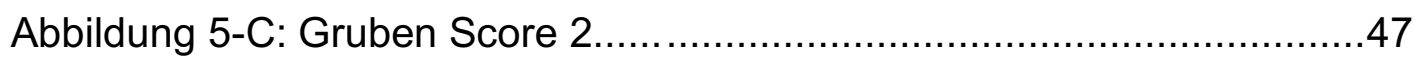

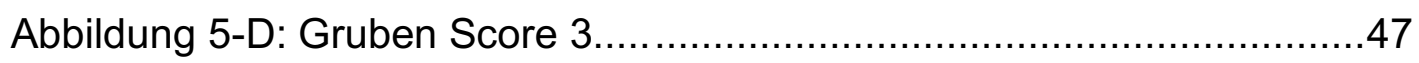

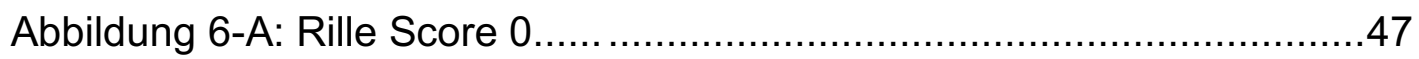

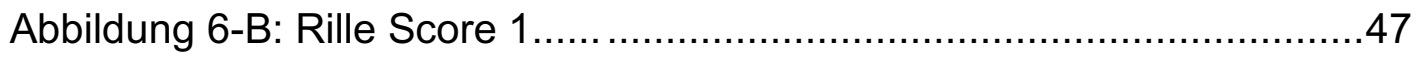

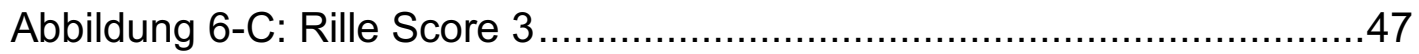

Abbildung 7: Übersicht der relativen Häufigkeit bei der Verteilung der Score-Werte 


\section{Tabellenverzeichnis}

Tabelle 1: Anforderungen an eine medikamentöse Einlage........................3

Tabelle 2: Applikation der medikamentösen Einlage ..............................15

Tabelle 3: Einschlusskriterien der verwendeten Zähne............................36

Tabelle 4: Ausschlusskriterien der verwendeten Zähne............................37

Tabelle 5: Spülprotokoll ..................................................................45

Tabelle 6: Darstellung der Score-Werte nach Lee et al. (2004a) ...............46

Tabelle 7: Kappa-Werte beider Untersucher für die intraindividuellen Reproduzierbarkeit......................................................50

Tabelle 8: Übersicht der absoluten Häufigkeit bei der Verteilung der ScoreWerte. 


\section{Abkürzungsverzeichnis}

C. albicans Candida albicans

CB CanalBrush

ChKM Chlorphenol-Kampfer-Menthol

$\mathrm{CHX} \quad$ Chlorhexidin

E. faecalis Enterococcus faecalis

EA EndoActivator

EDTA Ethylendiamintetraessigsäure

Er,Cr:YSSG Erbium-Chronium-Yttrium-Scandium-Garnett

ER:YAG Erbium-YAG

EV EndoVac

IRM intermediate restorative material

LAI laser activated irrigation

MDA manual dynamic agitation

PIPS photoneninduzierte photoakustische Spülmethode

PUI passive ultrasonic irrigation

RE RinsEndo

SAF self-adjusting file

SWEEPS shock wave enhanced emission photoacoustic streaming

VLE Vapor-Lock-Effekt 


\section{$1 \quad$ Einleitung}

Ziel einer endodontischen Behandlung ist es, ein möglichst keimarmes Wurzelkanalsystem mit einer suffizienten definitiven Wurzelfüllung zu versorgen. Hierzu sind eine ausreichende Präparation und Desinfektion des Wurzelkanals von Nöten. Da es sich bei Wurzelkanälen um komplexe Hohlraumsysteme mit schwerzugänglichen Abschnitten wie Isthmen und Seitenkanälen handelt, können Erreger trotz intensiver Desinfektion im Wurzelkanal verbleiben und einen Erfolg der Therapie verhindern. Ein großer Anteil endodontisch relevanter Mikroorgansimen wird während der chemomechanischen Präparation des Wurzelkanalsystems entfernt. Hierfür stehen unterschiedliche mechanische Präparationssysteme, wie beispielsweise Handinstrumente, schall- und ultraschallbetriebene Systeme oder neuartige Nickel-Titan-Instrumente zur Verfügung.

Bei der Präparation des Wurzelkanals entsteht durch das Abtragen von Dentin und verbliebenen Geweberesten der sogenannte smear layer. Da durch den smear layer Eingänge von Seitenkanälen und Dentintubuli verstopft werden, gilt es auch diese Schicht zu entfernen (Wauters und Wauters 2000). Hier setzt die Verwendung unterschiedlicher Spülflüssigkeiten an. So ist Natriumhypochlorit $(\mathrm{NaOCl})$ in der Lage, die organischen Bestandteile des smear layer aufzulösen. Ein Chelator, z. B. EDTA (= Ethylendiamintetraessigsäure) oder Zitronensäure, wiederum besitzt die Fähigkeit, die anorganischen Bestandteile des smear layer zu beseitigen. Eine suffiziente Entfernung des smear layer ist durch eine kombinierte Anwendung dieser beiden Spüllösungen am besten zu erreichen (Bystrom und Sundqvist 1985; Wauters und Wauters 2000).

Kann eine endodontische Maßnahme nicht in einer Sitzung abgeschlossen werden, wird die Verwendung einer medikamentösen Einlage empfohlen. Eine temporäre intrakanaläre Einlage sollte unter anderem eine breite antimikrobielle Wirksamkeit gegen die im Wurzelkanal anwesenden Mikroorganismen aufweisen. So kann zwischen den Behandlungsterminen eine zusätzliche Desinfektion des Wurzelkanals erreicht und eine Reinfektion während der 
gesamten Behandlungsdauer verhindert werden (Bystrom und Sundqvist 1985; Sjögren et al. 1991; Gomes et al. 2003b).

Da es sich bei einer medikamentösen Einlage nicht um eine definitive Füllung handelt, sollte das verwendete Material gut aus dem endodontischen System zu entfernen sein. Eine komplette Beseitigung der medikamentösen Einlage ist im Hinblick auf eine suffiziente definitive Wurzelkanalfüllung anzustreben. Verbleiben Reste der Einlage im Wurzelkanalsystem, wirken diese ähnlich wie der smear layer und verhindern ein Eindringen des Sealers in Dentinkanälchen. Eine weitere Problematik stellt das veränderte Abbindeverhalten von Sealern dar, welches in apikalen Undichtigkeiten der Wurzelkanalfüllung resultieren kann (Margelos et al. 1997; Hosoya et al. 2004; Böttcher et al. 2010). Eine vollständige Entfernung der intrakanalären Einlage stellt auch heute noch eine Herausforderung dar (Rödig et al. 2011; Arslan et al. 2015; Topçuoğlu et al. 2015b; Pabel und Hülsmann 2017; Kfir et al. 2018).

Die vorliegende Studie befasst sich mit drei unterschiedlichen Methoden zur Entfernung der medikamentösen Einlage Ledermix aus Wurzelkanälen. Sie prüft die Effektivität der Reinigungskraft des schallbetriebenen EDDY (VDW, München, Deutschland), der passiven Ultraschallspülung unter Verwendung der IRRI Safe Feile (VDW, München, Deutschland) und des neuartige Nickel-TitanInstruments XP-endo Finisher (FKG Dentaire SA, La Chaux-de-Fonds, Schweiz).

\subsection{Indikationen der medikamentösen Einlage}

Ist es nicht möglich, eine Wurzelkanalbehandlung in einer Sitzung zu beenden, sollte der Wurzelkanal in der Zwischenzeit mit einem temporären Füllmaterial versorgt werden.

Die Gründe für ein zwei- oder mehrzeitiges Vorgehen können unterschiedlich sein. So ist es möglich, dass bei Vorliegen einer irreversiblen Pulpitis ohne infiziertes Endodont eine definitive Füllung des Wurzelkanals aus zeitlichen Gründen in derselben Sitzung nicht erfolgen kann. Oder es liegt eine infizierte nekrotische Pulpa vor, welche vor einer definitiven Wurzelfüllung zunächst mit einer intrakanalären Einlage versorgt werden sollte, um eine weitere Eliminierung von Mikroorganismen im Wurzelsystem und somit eine zusätzliche Desinfektion 
zu erreichen. Auch ist es möglich, durch die Anwendung einer medikamentösen Einlage eine Linderung des Schmerzempfindens zu erreichen. Ein weiterer großer Vorteil einer zweizeitigen Behandlung gegenüber einem einzeitigen Vorgehen ist eine verbesserte Reaktionsmöglichkeit bei Flare-Ups.

Dennoch sollte bei jeder endodontischen Maßnahme abgewogen werden, ob eine medikamentöse Einlage von Nöten ist. Kann ein Wurzelkanal erst nach mehreren Sitzungen gefüllt werden, sollte aufgrund der unterschiedlichen Eigenschaften der vorhandenen Präparate die Wahl der medikamentösen Einlage bei jedem Termin neu getroffen werden.

\subsection{Medikamentöse Einlage}

Bei einer medikamentösen Einlage handelt es sich zumeist um eine pastenartige oder flüssige Substanz. Sie kommt zur Anwendung bei einem zweizeitigen Vorgehen einer endodontischen Behandlung und verbleibt zur zeitlichen Überbrückung zwischen den Behandlungsterminen im Wurzelkanal, um eine (Re-) Infektion des Wurzelkanalsystems zu verhindern. An jede medikamentöse Einlage werden bestimmte Anforderungen bezüglich ihrer Eigenschaften gestellt. Diese sind in Tabelle 1 zusammengefasst.

Tabelle 1: Anforderungen an eine medikamentöse Einlage

- gute Biokompatibilität

- Auflösung im Wurzelkanal zurückgebliebener Gewebereste

- Neutralisierung von Endotoxinen

- Verhinderung einer Vermehrung bzw. einer Rekolonisation verbliebener

- Mikroorganismen im Wurzelkanalsystem

- Desinfektion des angrenzenden Wurzeldentins

- antibakterielle Wirksamkeit

- Entzündungshemmung

- Schmerzlinderung

- nicht zahnverfärbend

- temporäres Füllmaterial

- einfache Applikation und Entfernung

- gute Lagerungsstabilität

- geringer Preis

- Resorptionshemmung bei Trauma

- Förderung der Hartsubstanzbildung im Falle einer Apexifikation. 
Keine der momentan erhältlichen medikamentösen Einlagen ist in der Lage, alle genannten Anforderungen gleichermaßen gut zu erfüllen. Vor jeder Anwendung einer intrakanalären Einlage sollte abgewogen werden, welches Präparat die besten Eigenschaften für die vorgefundene Situation bietet.

\subsection{Präparate}

\subsubsection{Ledermix}

Ledermix wird von der Firma Riemser (Greifswald, Insel Riems, Deutschland) hergestellt und wurde im Zusammenhang mit endodontischen Maßnahmen das erste Mal in einer Studie von Schroeder und Triadan im Jahre 1962 genannt (Schroeder und Triadan 1962).

Es handelt sich um ein Kombinationspräparat mit zwei Wirkstoffen: Zum Einen Demeclocyclin als antibiotischer Anteil aus der Gruppe der Tetrazycline und zum Anderen Triamcinolon als Kortikosteriod. Ledermix gibt es sowohl pastenförmig in den Verhältnissen von Demeclocyclin-Calcium $(30,21 \mathrm{mg} / \mathrm{g})$ und Triamcinolonacetonid (10 mg/g). Dies entspricht $30 \mathrm{mg} / \mathrm{g}$ Demeclocyclinhydrochlorid. Ledermix kann auch als Dentalpulver mit Eugenollösung in den Verhältnissen von Demeclocyclinhydrochlorid $(20 \mathrm{mg} / \mathrm{g})$ und Triamcinolonacetonid $(6,7 \mathrm{mg} / \mathrm{g})$ erworben werden. Die fertige Ledermixpaste besitzt mit einer Verwendungsdauer von zwei Monaten nach Anbruch eine verringerte Haltbarkeit gegenüber dem Pulver (drei Monate), ist jedoch einfacher und schneller anzuwenden.

Laut Herstellerangaben ist Ledermix ein Präparat zur Notversorgung bei einer akuten Entzündung der Pulpa.

Der Kortikosteroidanteil bewirkt eine Unterdrückung der Entzündungsreaktion und verhindert die Freisetzung von Entzündungsmediatoren, was zu einer schnellen Schmerzreduktion beziehungsweise einer Unterdrückung der Schmerzsymptome führt. Willershausen et al. (2012) zeigten, dass der postoperative Schmerz nach einer Anwendung von Ledermix innerhalb der ersten Stunde geringer war als bei einer Kalziumhydroxid-basierten Einlage. Auch Ehrmann et al. (2003) zeigten in ihrer Studie eine Überlegenheit von Ledermix in Kombination mit Präparation und Desinfektion des Wurzelkanals 
gegenüber Kalziumhydroxid $\left(\mathrm{Ca}(\mathrm{OH})_{2}\right)$ in Bezug auf die postoperative Schmerzlinderung.

Im Hinblick auf postoperative Flare-Ups zeigten Ehrmann et al. (2007), dass es keinen signifikanten Unterschied bezüglich der Schmerzreduktion zwischen Ledermix- und Kalziumhydroxideinlagen gab. Notiert wurden die Veränderungen nach $4 \mathrm{~h}$ sowie nach $24 \mathrm{~h}$. Ledermix erreichte innerhalb der ersten vier Stunden eine bessere Schmerzreduktion, sie war jedoch nicht signifikant. Diese Erkenntnis deckt sich mit den Ergebnissen von Abbott et al. (1988), die zeigten, dass die Diffusionsrate von Triamcinolonmolekülen in das umliegende Gewebe innerhalb der ersten $3-8 \mathrm{~h}$ am höchsten ist. Auch Trope (1990) untersuchte verschiedene medikamentöse Einlagen hinsichtlich postoperativer Flare-Ups. Es wurde kein signifikanter Unterschied zwischen einer Ledermix- oder einer Kalziumhydroxideinlage festgestellt. Jedoch muss erwähnt werden, dass ein postoperativer Schmerzzuwachs erst als Flare-Up gewertet wurde, sobald eine merkliche Schwellung auftrat beziehungsweise auch nach der Einnahme eines Schmerzmittels der Schmerz nicht nachließ.

Da Triamcinolone die Osteoklastenaktivitäten herabsetzen, gilt Ledermix als erfolgversprechende Einlage, um entzündlichen Wurzelresorptionen nach dentalen Traumata entgegenzuwirken (Chen et al. 2008).

Demeclocyclin wirkt als bakteriostatisches Breitbandantibiotikum einem durch die kortikosteroidbedingte Immunsuppression verstärkten Bakterienwachstum im Wurzelkanal entgegen.

Die antibakterielle Effektivität von Ledermix wird im Hinblick auf die Keimreduktion innerhalb des Wurzelkanals kontrovers diskutiert. Tetrazykline wirken in erster Linie gegen gram-positive Erreger, im Wurzelkanal sind jedoch gramnegative Spezies vorherrschend. Ledermix zeigt in wurzelkanalnahen Dentinbereichen eine antibakterielle Wirksamkeit, welche jedoch nach einigen Tagen Liegedauer nachlässt (Abbott et al. 1988). Ursprünglich wurde das Antibiotikum der Paste jedoch nur zugegeben, um die immunkomprimierende Wirkung des Kortikosteroids zu kompensieren. Es war nicht Ziel des Herstellers, mit Hilfe des Antibiotikumanteils eine Kanaldesinfektion durch die medikamentöse Einlage zu erreichen. 
Athanassiadis et al. (2010) überprüften in ihrer Studie die Wirksamkeit eines Kalziumhydroxidpräparates, von Ledermix und einer Mischung der beiden Präparate gegenüber Enterococcus faecalis (E. faecalis). Ledermix war in alleiniger Anwendung erst nach drei Tagen in der Lage, eine signifikante Reduzierung der Bakterienanzahl von E. faecalis zu erreichen, während Kalziumhydroxid und eine 50:50 Mischung der beiden Einlagen schon nach einer Stunde eine vollständige Eliminierung von $E$. faecalis herbeiführten. Zusammenfassend ist festzustellen, dass Ledermix wirksam gegen $E$. faecalis ist, jedoch in alleiniger Anwendung einen längeren Zeitraum als Kalziumhydroxid zur Inaktivierung benötigt. Taylor et al. (1989) überprüften die bakterizide Wirkung von Ledermix, Kalziumhydroxid und einer 1:1 Mixtur der beiden Präparate im Hinblick auf Streptococcus mutans und Lactobacillus casei. Beide Präparate zeigten eine antibakterielle Wirkung, welche bei Ledermix bei geringeren Konzentrationen sank, während Kalziumhydroxid auch noch in geringeren Konzentrationen ähnlich stark wirksam war. Die Mixtur der beiden Präparate zeigte eine ähnliche bakterizide Wirksamkeit wie Ledermix in alleiniger Anwendung. Jedoch handelt es sich bei den untersuchten Bakterienstämmen um die Leitkeime einer Karieserkrankung und weniger um die im Wurzelkanal anwesenden Stämme. Seow (1990) zeigten in ihrer Studie, dass die bakterizide Wirkung von Ledermix in Bezug auf Streptococcus sanguis und Staphylococcus aureus schon durch eine $25 \%$-ige Beimischung von Kalziumhydroxid signifikant nachlässt. Eine Gegenkontrolle durch Verdünnung der Wirkstoffkonzentration des Ledermix um 25\% zeigte keine signifikante Änderung der antibakteriellen Effekte. Athanassiadis et al. (2011; 2013) überprüften ein mögliches Wechselspiel zwischen $\mathrm{Ca}(\mathrm{OH})_{2}$ und den Hauptbestandteilen von Ledermix. Sie zeigten, dass es durch Zugabe von $\mathrm{Ca}(\mathrm{OH})_{2}$ sowohl zu einer Destruktion des Triamcinolons als auch des Demeclocyclins kommt. Daraus schlossen sie, dass eine Beimengung des $\mathrm{Ca}(\mathrm{OH})_{2}$ die initiale Entzündungshemmung des Ledermix verringert.

Heling und Pecht (1991) untersuchten die Wirksamkeit von Ledermix und Chlorphenol-Kampfer-Menthol (ChKM) gegenüber Staphylococcus aureus. Während CHKM innerhalb der ersten $24 \mathrm{~h}$ eine signifikante Reduzierung der Bakterien bewirkte, zeigte Ledermix zu diesem Zeitpunkt noch keine Minimierung des Bakterienbefalls. Nach sieben Tagen zeigten ChKM und Ledermix einen 
gleichermaßen guten Erfolg in der Bekämpfung von Staphylococcus aureus. Zusammenfassend ist festzuhalten, dass die antibakterielle Wirksamkeit von Ledermix konzentrations- und zeitabhängig ist, dann jedoch ein breites Spektrum an Keimen erfasst.

Der Tetrazyklinanteil in Ledermix kann bei dauerhafter Anwendung zu Verfärbungen der Zahnhartsubstanz führen. Kim et al. (2000), Chen et al. (2012) und Thomson et al. (2012) zeigten in ihren Studien, dass Ledermix im Vergleich zu anderen intrakanalären Einlagen die höchste Verfärbungsrate aufweist. So zeigt Ledermix schon nach zweiwöchiger Liegedauer eine deutliche Verfärbung der Zahnhartsubstanz, während Odontopaste erst nach einer vierwöchigen Liegedauer einen signifikanten Farbunterschied herbeiführt (Chen et al. 2012). $\mathrm{Ca}(\mathrm{OH})_{2}$ zeigt nach zwölfmonatiger Liegedauer kaum Veränderungen in der Farbe der Zahnhartsubstanz, wohingegen Ledermix bereits bei der Kontrolle nach einem Monate deutliche Farbveränderungen induziert (Thomson et al. 2012). In beiden Studien wurde nachgewiesen, dass es auch ohne eine indirekte Lichtquelle während der Liegedauer der medikamentösen Einlagen zu Verfärbungen kommt. Diese Erkenntnis ist gegenteilig zu den Erkenntnissen von Kim et al. (2000), die ohne Lichtexposition keine Farbänderungen der Zahnhartsubstanz feststellten. Lenherr et al. (2012) untersuchten die Verfärbungstendenz von Ledermix an bovinen Zähnen. Diese waren in den ersten drei Untersuchungsmonaten keinem Licht ausgesetzt, während sie in den folgenden neun Monaten indirektem Sonnenlicht ausgesetzt waren. Die Ledermixeinlage führte am Ende der zwölf Monate zu deutlichen Farbveränderungen in der Hartsubstanz, wobei diese in den ersten drei Monaten nicht signifikant waren. Diese gegenteiligen Ergebnisse lassen darauf schließen, dass neben einer Lichtquelle weitere Prozesse an der Verfärbungstendenz von Ledermix beteiligt sein müssen. Weiter zeigten einige Studien, dass das Ausmaß der Verfärbungen geringer ist, wenn der koronale Anteil des Wurzelkanals nicht mit Ledermix bestückt wird (Kim et al. 2000; Kim und Abbott 2000; Lenherr et al. 2012). Es sollte - vor allem in ästhetisch anspruchsvollen Regionen - darauf geachtet werden, dass der Wurzelkanal nur im apikalen Bereich mit Ledermix befüllt wird.

Ledermix sollte während der Schwangerschaft und Stillzeit keine Anwendung finden (Fatori Popovic et al. 2016). Laut Herstellerangaben zeigt Triamcinolon vor 
allem innerhalb der ersten fünf Schwangerschaftsmonate eine teratogene Wirkung. Demeclocyclin ist in der Lage, die Plazentaschranke zu passieren und tritt somit in die Muttermilch über. Diese Faktoren sprechen gegen eine Verwendung von Ledermix während der Schwangerschaft und Stillzeit.

Die Gewebeverträglichkeit von Ledermix gilt allgemein als gut. Barker und Lockett (1972) stellten auch drei Monate nach der Anwendung von Ledermix keine pathologischen Gewebeveränderungen fest. Es wurde allerdings auch über eine verstärkte periapikale Entzündungsreaktion nach Ledermixanwendung berichtet (Tepel et al. 1994). Die Verstärkung könnte durch die Unterdrückung der Phagozytose durch das Kortikoid auftreten.

\subsubsection{Odontopaste}

Odontopaste wird von der Firma Australian Dental Manufacturing (Kenmore Hills, Australien) hergestellt und in Deutschland über die Firma Henry Schein Dental Deutschland (Langen, Deutschland) vertrieben.

Es handelt sich um eine weiße, pastenartige Substanz auf Zinkoxidbasis. Ähnlich wie Ledermix handelt es sich um ein Kombinationspräparat mit zwei Hauptwirkstoffen: Zum Einen Clindamycinhydrochlorid (5\%) als Breitbandantibiotikum aus der Gruppe der Lincosamid-Antibiotika und zum Anderen Triamcinolonacetonid (1\%) als Kortikosteroid. Weiter beinhaltet die Zusammensetzung 0,5\% Kalziumhydroxid.

Laut Herstellerangaben findet Odontopaste Anwendung als Notfallmedikation bei irreversibler Pulpitis. Auch soll Odontopaste durch den Kortikosteroidanteil postoperativ zur Schmerzlinderung beitragen. Eftekhar et al. (2013) zeigten in ihrer Studie, dass die Behandlung mit Odontopaste nach $24 \mathrm{~h} \mathrm{zu}$ einer signifikanten Reduzierung von spontan auftretenden Schmerzen sowie einer signifikanten Reduzierung der Perkussionsempfindlichkeit führt.

Die Verwendung von Clindamycin als antibiotischer Bestandteil gegenüber Tetrazyklin bei Ledermix hat den Vorteil geringerer Verfärbungen der Zahnhartsubstanz. Chen et al. (2012) untersuchten die Verfärbungstendenz unterschiedlicher medikamentöser Einlagen und kamen zu dem Schluss, dass Odontopaste die geringsten Verfärbungen zeigte. Ledermix zeigte bereits nach zwei Wochen eine deutliche Verringerung der Helligkeit der Zahnhartsubstanz, 
während bei Odontopaste zu diesem Zeitpunkt keine signifikante Änderung zu erkennen war.

Plutzer et al. (2018) überprüften die Effektivität verschiedener medikamentöser Einlagen gegenüber E. faecalis. Odontopaste war in einer 50:50 Mischung mit Kalziumhydroxid, genauso wie Ledermix mit Kalziumhydroxid (50:50), in der Lage, die Überlebensrate von E. faecalis um über $99 \%$ zu verringern. Jedoch war Kalziumhydroxid auch ohne Zugabe von Odontopaste oder Ledermix in über $99 \%$ effektiv gegenüber $E$. faecalis. Athanassiadis et al. $(2011 ; 2013)$ überprüften ein mögliches Wechselspiel zwischen $\mathrm{Ca}(\mathrm{OH})_{2}$ und den Hauptbestandteilen von Odontopaste. Sie zeigten, dass es durch Zugabe von $\mathrm{Ca}(\mathrm{OH})_{2}$ sowohl zu einer Destruktion des Triamcinolons als auch des Clindamycinhydrochlorids kommt. Eine Beimengung von $\mathrm{Ca}(\mathrm{OH})_{2}$ zu Odontopaste bewirkte innerhalb der ersten Stunden eine geringere Zerstörung der Steroidkomponente als es bei Ledermix der Fall war. Nach $72 \mathrm{~h}$ zeigten jedoch beide Präparate unter Zugabe von $\mathrm{Ca}(\mathrm{OH})_{2}$ eine ähnlich stark ausgeprägte Zerstörung des Triamcinolons. Ebenfalls wurde nach sieben Tagen eine Verringerung des Antibiotikumanteils festgestellt. Eine Mixtur aus den beiden medikamentösen Einlagen bietet folglich keine verbesserte Wirkung von Odontopaste.

Lin et al. (2003) überprüften die antibakterielle Wirksamkeit von Clindamycin und Ledermix gegenüber Streptococcus sanguis. Clindamycin zeigte höhere Erfolge in der bakteriziden Wirkung und war besser in der Lage, in umliegende Dentinkanälchen zu diffundieren als Ledermix.

Die Anwendung von Odontopaste ist in der Schwangerschaft und Stillzeit kontraindiziert, da Clindamycin in die Muttermilch übergehen kann. Auch sollte Odontopaste nicht zeitgleich mit Erythromycin beziehungsweise Makrolidantibiotika angewandt werden, da Clindamycin und Makrolidantibiotika in ihrer Wirkungsweise gleich agieren und sich so gegenseitig in ihrer Effektivität behindern würden.

\subsubsection{Chlorhexidin}

Davies et al. (1954) beschrieben erstmals die Verwendung von Chlorhexidin (kurz CHX) als Desinfektionsmittel in der Medizin. Seither gilt es als Antiseptikum 
für Haut und Hände mit guten antimikrobiellen Eigenschaften, weshalb $\mathrm{CHX}$ seit Jahren auch als Mundspüllösung Anwendung findet.

Chlorhexidin schädigt über eine Inaktivierung bakterieller Enzyme den Zellmetabolismus von Bakterien. Ab einer Konzentration von 0,19 ppm gilt $\mathrm{CHX}$ als bakteriostatisch, ab etwa 100 ppm als bakterizid (Hennessey 1973). Durch diese antibakteriellen Eigenschaften findet es in der Endodontie auch Verwendung als medikamentöse Einlage und Spülmedium. Für eine Nutzung als intrakanaläre Einlage sind Konzentrationen von mindestens $1 \%$ nötig, wobei eine Intensität von $2 \%$ bei geleeartiger Beschaffenheit in der Literatur empfohlen wird (Basrani et al. 2002; Sassone et al. 2003; Vianna et al. 2004).

$\mathrm{CHX}$ ist gegenüber den meisten endodontisch ausschlaggebenden Keimen wirksam, gram-positive sowie gram-negative (Hülsmann und Rödig 2005). Weiter besitzt es antifugale Wirkung und wird somit erfolgreich angewandt in der Bekämpfung von Infektionen des Wurzelkanals mit E. faecalis oder Candida albicans (Waltimo et al. 1999; Basrani et al. 2003; Schäfer und Bössmann 2005). Durch diesen erweiterten Anwendungsbereich findet Chlorhexidin vor allem in Revisionsbehandlungen Verwendung. Eine alleinige Anwendung von $\mathrm{CHX}$, sowohl als Spülmedium und auch als medikamentöse Einlage sollte nicht erfolgen, da Chlorhexidin nicht in der Lage ist, Endotoxine zu eliminieren und Gewebe aufzulösen (Naenni et al. 2004).

Da sich Chlorhexidinmoleküle an das Dentin adsorbieren können, verfügt $\mathrm{CHX}$ nach einwöchiger intrakanalärer Anwendung über eine Reservoirwirkung (White et al. 1997). So kann eine 2\%-ige CHX-Einlage eine antimikrobielle Wirkdauer von bis zu zwölf Wochen erreichen (Rosenthal et al. 2004). Jedoch sollte eine maximale Liegedauer von zwei Wochen in der Regel nicht überschritten werden, da ab diesem Zeitpunkt eine deutliche Verringerung der Effektivität eintritt (Gomes et al. 2003a). Um ein nicht gewolltes Bakterienwachstum zu umgehen, sollte eine medikamentöse Einlage mit Chlorhexidin in der Regel alle zwei Wochen erneuert werden. 


\subsubsection{Chlorphenol-Kampfer-Menthol}

Otto Walkhoff führte 1905 Chlorphenol-Kampfer-Mischungen für endodontische Zwecke in die Zahnmedizin ein (Möller 1934), nachdem er sich schon zuvor für eine Nutzung von Chlorphenol bei pulpalen Erkrankungen ausgesprochen hatte. Lange Zeit wurden Chlorphenole sowohl als Spülmedium als auch als medikamentöse Einlage genutzt. Heutzutage findet es, wenn überhaupt, noch als medikamentöse Einlage Anwendung, wobei einige Autoren von einer Verwendung aufgrund biokompatiblerer Alternativen abraten (Walton 1984; Tronstad 1991; Spångberg 1994; Spångberg 2002). In Deutschland wird Chlophenol in Kombination mit Kampfer und Menthol (kurz ChKM) über den Vertrieb der Firma Adolf Haupt (Würzburg, Deutschland) angeboten.

Parachlorphenolpräparate besitzen in direktem Kontakt mit vitalem Gewebe lokal schmerzstillende Eigenschaften und zeigen weiter eine eiweißfällende und ätzende Wirkung. In erhöhter Konzentration führt dieser Effekt zu einer Denaturierung von Zellproteinen (Siqueira und Lopes 2002). Durch die Zugabe von Kampfer sollten die ätzenden und zytotoxischen Eigenschaften des Chlorphenols herabgesetzt werden. Durch Zugabe von Kampfer wird die Zytotoxizität von Chlorphenol durch die zytotoxische Wirkung des Kampfers vielmehr noch weiter erhöht (Soekanto et al. 1996). Der weitere Zusatz von Menthol soll laut Walkhoff (1928) in passender Konzentration die ätzende Wirkung des Chlorphenols minimieren. Menthol wirkt in dieser Kombination lokal schmerzstillend und entzündungshemmend.

Bei Chlorphenol-Kampfer-Menthol-Präparaten stehen den guten antiseptischen Fähigkeiten toxische Einflüsse des Chlorphenols und Kampfers gegenüber, wobei Tronstad (1991) nur einen zeitlich begrenzten antiseptischen Nutzen feststellen konnte. Diese Erkenntnis sollte eine Verwendung von ChKM kritisch hinterfragen.

Eine Anwendung von ChKM sollte in Form getränkter Papierspitzen oder Wattefäden stattfinden, da in diesem Fall ein direkter Kontakt des ChKMs und infizierten Dentinabschnitten besteht und eine ausreichend hohe Konzentration zur Nutzung der antiseptischen Effekte von ChKM erreicht wird (Wall et al. 1972). Von einem alleinigen Einlegen eines getränkten Watte- oder Kunststoffpellets in die Pulpakammer wird abgeraten, da dieses nur zu einem Nutzen des Vapors 
führen würde, welcher jedoch keine ausreichende antibakterielle Wirksamkeit zeigt (Ellerbruch und Murphy 1977; Spångberg 1994).

Chlorphenol-Kampfer-Präparate zeigen sich in ihrer antibakteriellen Wirksamkeit als hocheffektive Agenzien. Orstavik und Haapasalo (1990) überprüften unter anderem die Wirkung von Chlorphenol-Kampfer auf $E$. faecalis. Nach zweiwöchigem direktem Kontakt zu infiziertem Dentin zeigte sich ChlorphenolKampfer in der desinfizierenden Wirkung als sehr effizient. Auch Tanriverdi et al. (1997) stellten eine hohe Wirksamkeit von ChKM gegenüber E. faecalis fest, wobei es der Einlage mit Kalziumhydroxid überlegen war. In anderen Studien wurde die antibakterielle Wirksamkeit von ChKM und Kalziumhydroxid, sowohl in alleiniger Anwendung als auch als Kombinationspräparat, überprüft mit dem Ergebnis, dass die Kombination der beiden medikamentösen Einlagen in ihrer desinfizierenden Wirkung der jeweils alleinigen Anwendung deutlich überlegen war (Siqueira und de Uzeda 1996; Sukawat und Srisuwan 2002). Diesen Effekt deuteten Siqueira und de Uzeda (1996) in ihrer Untersuchung so, dass ChKM die bakteriziden Eigenschaften des Kalziumhydroxids steigert. Roach et al. (2001) wiesen jedoch nach, dass eine Rekontamination des Wurzelkanals durch Kalziumhydroxid gleichermaßen gut verhindert werden kann, wie durch die Kombination mit ChKM. Eine Überlegenheit im Hinblick auf die bakterizide Wirkung verschiedener medikamentöser Einlagen von Kalziumhydroxid gegenüber Chlorphenol-Kampfer zeigten Bystrom et al. (1985). Auch Barbosa et al. (1997) stellten keine bessere antibakterielle Wirksamkeit von ChKM gegenüber Kalziumhydroxid fest. So steht mit Kalziumhydroxid ein deutlich biokompatibleres und weniger toxisches Medium als medikamentöse Einlage zur Verfügung. Diese Ergebnisse stützen die Aussage von Spångberg (Spångberg 1994; Spångberg 2002), dass die Verwendung von ChKM bei heutigem Wissensstand als „inkompatibel mit einem biologisch orientierten Behandlungskonzept" anzusehen ist.

\subsubsection{Kalziumhydroxid}

Kalziumhydroxid wurde 1920 von Hermann zur Behandlung der vitalen Pulpa eingeführt (Hermann 1920). Wurde Kalziumhydroxid zu Beginn vor allem zur Überkappung der Pulpa genutzt, wird es heute auch noch in anderen Bereichen 
der Zahnheilkunde eingesetzt. So gilt es bei der Suche nach einer passenden medikamentösen Einlage häufig als Mittel der Wahl. Durch die Fähigkeit, eine Hartgewebsneubildung zu stimulieren, kommt es ebenfalls bei weiteren zahnmedizinischen Behandlungen wie beispielweise einer Apexifikation sowie bei der Behandlung interner oder externer Resorptionen zur Anwendung (Farhad und Mohammadi 2005). Auch kann es, wie schon von Hermann empfohlen, zur indirekten oder direkten Überkappung der Pulpa verwendet werden (Hermann 1930; Farhad und Mohammadi 2005).

Es handelt sich hierbei um ein weißes geruchloses Pulver mit der chemischen Formel $\mathrm{Ca}(\mathrm{OH})_{2}$. Kalziumhydroxid gilt als schlecht wasserlöslich, wobei sich die Löslichkeit mit steigender Temperatur erhöht. Die schlechte Löslichkeit bedingt bei Kontakt mit vitalem Gewebe oder Gewebeflüssigkeiten eine längere Wirkdauer des Kalziumhydroxids, was klinisch von Vorteil sein kann (Fava und Saunders 1999).

In wässrigem Medium dissoziiert $\mathrm{Ca}(\mathrm{OH})_{2} \mathrm{zu} \mathrm{OH}^{-}$- und $\mathrm{Ca}^{2+}$-Ionen. Kommen Hydroxylionen ( $\mathrm{OH}^{-}$-lonen) mit vitalem Gewebe in Kontakt, führt dieses aufgrund ihrer hohen Reaktionsfreudigkeit als freiem Radikal zu einer Denaturierung von Proteinen und der Zerstörung von Zellmembranen. Diese Effekte bewirken eine gute antibakterielle Wirksamkeit. Weiter wird durch diese Hydroxylionen anhand alkalischer Phosphatasen eine Hartgewebsneubildung induziert (Estrela et al. 1995; Carrotte 2004).

Bei einem pH-Wert von etwa 12,5 verfügt Kalziumhydroxid über eine hohe Alkalinität. In einem solchen alkalischen Medium können die meisten endodontisch relevanten Pathogene nicht überleben und werden zerstört, wenn sie in direkten Kontakt mit $\mathrm{Ca}(\mathrm{OH})_{2}$ kommen (Heithersay 1975; Estrela et al. 1995). Neben guten antibakteriellen Eigenschaften ist Kalziumhydroxid auch in der Lage, Gewebe aufzulösen (Hasselgren et al. 1988). Diese Kombination bietet einen entscheidenden Vorteil bei der Wahl einer medikamentösen Einlage gegenüber anderen Wirkstoffen, welche alleine nicht in der Lage sind, im Wurzelkanal verbliebene Gewebereste aufzulösen.

Gomes et al. (2003a) untersuchten die Dauer einer Rekontamination des Wurzelkanals nach dem Einbringen einer medikamentösen Einlage. Bei der Verwendung von Kalziumhydroxid bei koronalem Verschluss mit IRM 
(intermediate restorative material) war nach 17,2 Tagen eine Rekontamination nachweisbar. Ohne einen koronalen Verschluss konnte Kalziumhydroxid lediglich 1,8 Tage eine erneute Kontamination des Wurzelkanals verhindern. Es kann daraus geschlossen werden, dass ein Wurzelkanal nach Einbringen einer medikamentösen Einlage temporär verschlossen werden muss, um möglichst lange ein keimarmes Wurzelkanalsystem erhalten zu können.

Kalziumhydroxid gilt als gut antimikrobiell wirksam gegenüber dem Großteil der endodontisch relevanten Keime (Sjögren et al. 1991; Stuart et al. 1991; Estrela et al. 1998; Tanomaru et al. 2007). Podbielski et al. (2003) wiesen eine gute Wirksamkeit von $\mathrm{Ca}(\mathrm{OH})_{2}$ gegenüber gram-negativen Pathogenen wie beispielsweise Fusobacterium nucleatum und Porphyromonas gingivalis nach. Auch gegenüber gram-positiven Keimen zeigte sich Kalziumhydroxid als effektiv, jedoch in deutlich geringerem Maße. Zu diesen Ergebnissen kamen auch Gomes et al. (2002). Georgopoulou et al. (1993) untersuchten die Effizienz von $\mathrm{Ca}(\mathrm{OH})_{2}$ im Hinblick auf gram-positive und gram-negative Anaerobier. Nach fünfminütiger Testzeit zeigten sich 64,3\% der gram-positiven und 62,59\% der gram-negativen Bakterienstämme resistent gegenüber Kalziumhydroxid. Nach 15 Minuten konnten keine resistenten Keime der gram-negativen Gruppe nachgewiesen werden, wobei sich noch $7,1 \%$ der gram-positiven Keime als resistent erwiesen. Nach einer Testdauer von 30 Minuten war auch kein Nachweis resistenter grampositiver Stämme mehr möglich. Diese Ergebnisse lassen den Schluss zu, dass Kalziumhydroxid gegenüber gram-negativen endodontisch relevanten Keimen eine bessere antimikrobielle Wirksamkeit als gegenüber gram-positiven zeigt.

E. faecalis oder Candida albicans (C. albicans) gelten als resistent gegenüber Kalziumhydroxid, weshalb es im Falle einer Revisionsbehandlung nicht als Mittel der Wahl gilt (Siqueira und de Uzeda 1996; Waltimo et al. 1999). Basrani et al. (2003) belegten, dass Kalziumhydroxid in der Bekämpfung von E. faecalis keine Wirksamkeit zeigte, wohingegen sich $\mathrm{CHX}$ als effektiv erwies. Diese Ergebnisse decken sich mit denen von Ballal et al. (2007). Waltimo et al. (1999) untersuchten den antimikrobiellen Effekt von $\mathrm{Ca}(\mathrm{OH})_{2}$ und $\mathrm{CHX}$ gegenüber $\mathrm{C}$. albicans. $\mathrm{CHX}$ erwies sich als effizient, während $C$. albicans gegenüber Kalziumhydroxid unempfindlich war. 


\subsection{Applikation der medikamentösen Einlage}

Kommt es während einer endodontischen Behandlung zur Applikation einer medikamentösen Einlage, sollte diese vorzugsweise alle Hohlräume eines Wurzelkanalsystems ausfüllen, wobei eine homogene Verteilung der jeweiligen Substanz anzustreben ist. Hierbei sollte ein Überpressen über das apikale Foramen hinaus vermieden werden. Über die optimale Technik zur Applikation gibt es in der Literatur keine eindeutigen Aussagen. In Tabelle 2 werden die am häufigsten genutzten Techniken genannt.

Tabelle 2: Applikation der medikamentösen Einlage

- Einrotieren der medikemantösen Einlage mit Hilfe eines Lentulos (DENTSPLY Maillefer - USA, Tulsa, Oklahoma)

- Injizieren gebrauchsfertiger Präparate mit dünnen Injektionskanülen

- Applikation mit Hilfe von Ultraschallfeilen

- Einbringen der Substanz mit Hilfe einer Amalgampistole

- Nutzung von Pastinject (Micro- Mega SA - Frankreich, Besancon).

Um eine möglichst homogene Applikation zu erreichen, ist ein Nachkondensieren mit Hilfe von Papierspitzen, Wattepellets oder eines Pluggers hilfreich.

Bei der Nutzung eines Lentulos oder von Ultraschallfeilen besteht bei nicht sachgemäßer Nutzung die Gefahr einer Instrumentenfraktur, was bei der Wahl des passenden Applikationsmediums bedacht werden sollte.

\subsection{Entfernung der medikamentösen Einlage}

Eine möglichst vollständige Entfernung der medikamentösen Einlage vor der Verwendung von Guttapercha sollte angestrebt werden. Befinden sich Rückstände der temporären Einlage im Wurzelkanalsystem, kann dieses - 
ähnlich wie bei einem Verbleib des smear layer - zu Beeinträchtigungen der Qualität der definitiven Füllung eines Wurzelkanals führen. Calt und Serper (1999) sowie Uzunoglu-Özyürek et al. (2018) zeigten, dass ein Belassen von Resten medikamentöser Einlagen zu einer unzureichenden Penetration des Sealers in die Dentinkanälchen führt. Weiter können Überreste von Kalziumhydroxid ein verändertes Abbindeverhalten und Dichtungsvermögen des Sealers bedingen (Margelos et al. 1997; Hosoya et al. 2004; Böttcher et al. 2010). Sealer auf Zinkoxid-Eugenol-Basis zeigen eine beschleunigte Abbindezeit, was das Einbringen der Guttaperchastifte auf die richtige Arbeitslänge erschweren kann. Auch kann eine unvollständige Beseitigung medikamentöser Einlagen im weiteren Verlauf die Dichtigkeit der definitiven Wurzelkanalfüllung beeinflussen und in apikalen Leakages resultieren (Margelos et al. 1997; Kim und Kim 2002; Hosoya et al. 2004). Ähnliche Ergebnisse in Hinblick auf den Einfluss von Überresten einer temporären Einlage auf das Abbinde- sowie Abdichtungsverhalten wurde bei Sealern auf Basis von Glasionomerzementen nachgewiesen (Hosoya et al. 2004).

Eine vollständige Entfernung einer medikamentösen Einlage aus dem Wurzelkanal ist von mehreren Faktoren abhängig. Neben dem verwendeten Spülmedium spielt auch die dabei angewandte Aktivierungsmethode eine Rolle. In jedem Falle sollte bei der Nutzung einer temporären Einlage die Präparation eine Feilengröße vor der endgültigen Instrumentengröße enden, um mit Hilfe des verbleibenden Instrumentes Reste der Einlage mechanisch zu entfernen. Eine Aktivierung der Spülflüssigkeiten resultiert in besseren Ergebnissen als eine passive Spülung. Hierfür findet sich eine Vielzahl an unterschiedlichen Methoden, wie beispielsweise Schall- und Ultraschallinstrumente oder aber auch Nickel-Titan-Instrumente (Abbildung 1). 


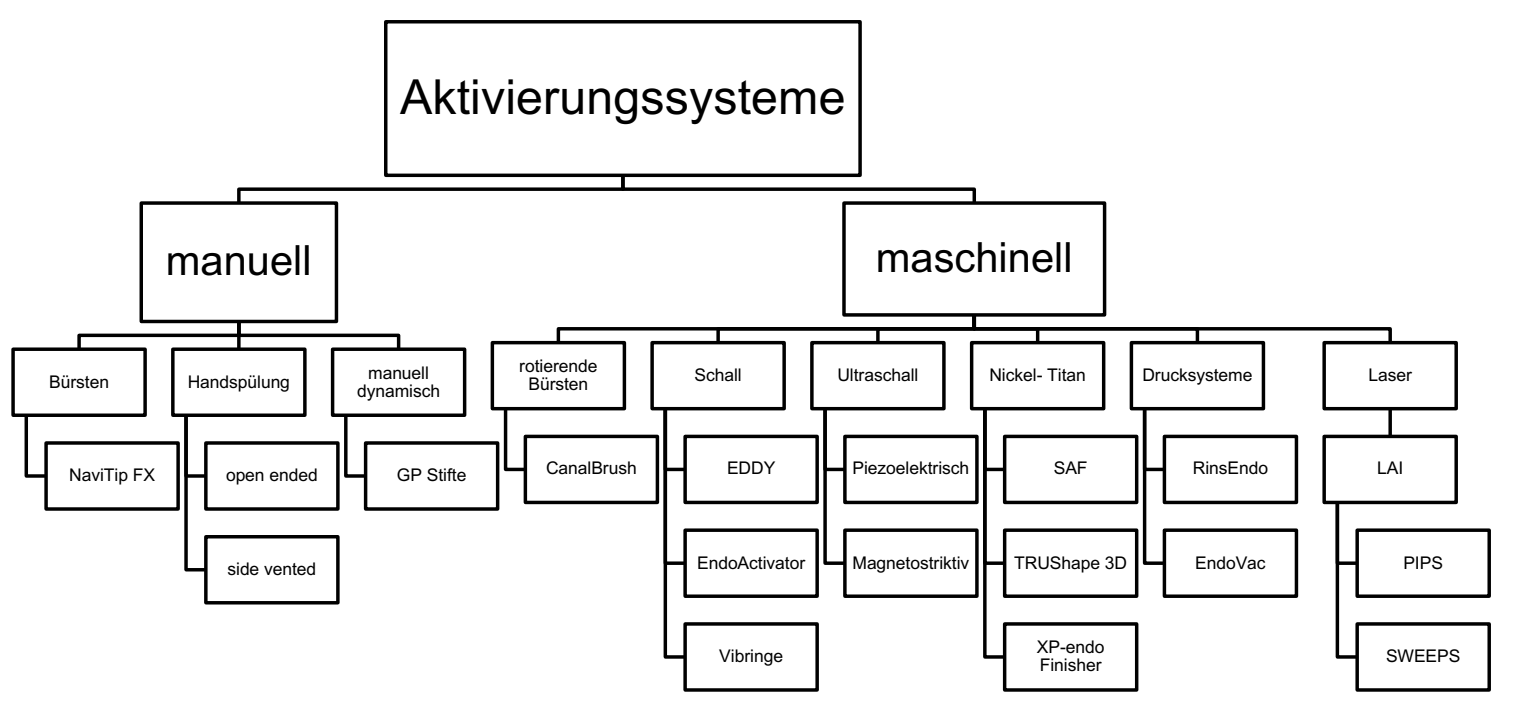

Abbildung 1: Überblick über gängige Aktivierungssysteme

\subsection{Aktivierungssysteme}

\subsubsection{Manuelle Spülung}

Die Handspülung oder konventionelle Spülung gehört auch heutzutage noch zu den weitverbreitetsten Techniken in der Zahnarztpraxis (Peters 2004; Boutsioukis et al. 2010a). Zum Einen ist es eine effektive Methode, um Spülflüssigkeiten in den Kanal einzubringen, und zum Anderen ist sie sicher in der Anwendung. Die Sicherheit für den Anwender resultiert aus der guten Kontrolle der Insertionstiefe, des Spüldrucks und des genutzten Volumens an Spülflüssigkeit, sowie der einfach zu erlernenden Technik (van der Sluis et al. 2006). Verwendet werden handelsübliche Spritzen mit unterschiedlichen Aufsätzen. Aufgrund des Nadelaußendurchmessers von 0,3 mm bei konventionellen Injektionskanülen ist eine apikale Präparation des Wurzelkanals auf ISO-Größe 35 - 40 notwendig, um eine adäquate Reinigungswirkung im apikalen Wurzelbereich zu erzielen. Ram (1977) zeigte, dass ein Erweitern des Wurzelkanals auf ISO 40 gegenüber ISO 25 einen enormen Zuwachs in der 
Effektivität der Spülung erreichte. Diese Ergebnisse werden durch neuere Studien bestätigt (Wu und Wesselink 1995; Hsieh et al. 2007; Boutsioukis et al. 2010b). Chang et al. (2015) zeigten, dass durch eine Präparation bis zur ISOGröße 40 das Risiko apikaler Extrusionen verringert wird. Der Erfolg einer manuellen Spülung ist neben der Größe der apikalen Präparation noch von weiteren Faktoren abhängig. So spielen die Insertionstiefe der Spülnadel, aber auch die Nadelgröße und -form eine bedeutende Rolle. Je näher die Öffnung der Spülkanüle an das Foramen apicale inseriert werden kann, desto besser sind die Spülleistungen und der Austausch mit frischer Spüllösung (Sedgley et al. 2005; Hsieh et al. 2007). Hsieh et al.( 2007) zeigten, dass das Strömungsverhalten von Spülflüssigkeiten durch einen großen Durchmesser der Injektionskanüle nachteilig beeinflusst wird. Um diesen Nachteil ausgleichen zu können, sind neben konventionellen Spülnadeln auch solche mit einem apikalen Durchmesser von ISO 30 und geringer erhältlich. Moser und Heuer (1982) weisen jedoch auf ein erhöhtes Frakturrisiko bei kleineren Spülkanülen hin. Senia et al. (1971) geben zu bedenken, dass bei kleinerem Durchmesser das Lumen der Spülnadel leichter durch $\mathrm{NaOCl}-K$ ristalle verschlossen werden kann. Beides könnte die Spülleistung negativ beeinflussen. Neben unterschiedlichen Nadelgrößen gibt es auch Unterschiede in der Kanülenöffnung. Es werden frontoffene (open ended) Spülnadeln von denen mit seitlichen Fensterungen (side vented) abgegrenzt. Bei der Verwendung einer open ended Kanüle wird eine Insertionstiefe von 2 bis 3 mm kürzer als die Arbeitslänge empfohlen, da ein Austausch der Spülflüssigkeit bis über $2 \mathrm{~mm}$ apikal der Nadel nachzuweisen ist. Auch würde der entstehende apikale Druck bei tieferem Einbringen die Gefahr von Extrusionen über das Foramen apicale hinaus erhöhen (Hsieh et al. 2007; Boutsioukis et al. 2010a; Boutsioukis et al. 2010c). Wird die Nutzung einer side vented Kanüle bevorzugt, ist zu beachten, dass sich die Nadelspitze in einem Abstand von etwa $1 \mathrm{~mm}$ koronal der Arbeitslänge befindet, da ansonsten kein Austausch von Spülflüssigkeiten und somit keine adäquate Reinigung erfolgen kann. Durch die seitlichen Öffnungen wird ein geringerer apikaler Druck aufgebaut, wodurch trotz der Nähe zum Foramen apicale nur eine minimale Gefahr ungewollter Extrusionen besteht (Zehnder 2006; Boutsioukis et al. 2009; Boutsioukis et al. 2010a; Boutsioukis et al. 2010c). Die mechanische Spülleistung manueller Spülmethoden ist somit vor allem abhängig von der Insertionstiefe sowie dem 
Durchmesser der Spülkanüle und folglich von der apikalen Präparationsgröße (Abou-Rass und Piccinino 1982; Chow 1983; Walters et al. 2002; Boutsioukis et al. 2010b).

Ein bei der Spülung auftretendes Phänomen ist der sogenannte Vapor-LockEffekt (VLE). Der Vapor-Lock-Effekt beschreibt das Auftreten apikaler Luft- oder Gaseinschlüsse beim Einbringen einer Spülflüssigkeit in einen leeren Wurzelkanal (Gu et al. 2009; Boutsioukis et al. 2014). Senia et al. (1971) und Gu et al. (2009) hingegen führen die Entstehung von Gasbläschen im apikalen Wurzelbereich auf die Reaktion von $\mathrm{NaOCl}$ mit den organischen Bestandteilen der Dentinwand zurück. In jedem Fall ist eine adäquate Reinigung und Desinfektion aufgrund des Vapor-Lock-Effektes nicht möglich, da Spülflüssigkeiten nicht in der Lage sind, die apikale Gasblase zu verdrängen und somit nicht in den apikalen Bereich vordringen können (Tay et al. 2010). Es wird berichtet, dass sich der VLE nach einer gewissen Zeitspanne minimiert. Da es sich hier aber um eine Dauer von mehreren Stunden bis zu Tagen handelt, welche die Dauer einer Wurzelkanalbehandlung weit überschreitet, sollte der VLE gezielt eliminiert werden (Gu et al. 2009). Da die konventionelle statische Spülung nicht in der Lage ist, die eingeschlossene Luft zu verdrängen, bedarf es einer manuellen dynamischen Aktivierung (manual dynamic agitation, MDA) der Spülflüssigkeit. Hierfür wird ein in Größe und Konizität angepasster Guttaperchastift auf Arbeitslänge in den Wurzelkanal eingebracht und mit einer Frequenz von 3,3 Hz auf- und abbewegt (Huang et al. 2008; McGill et al. 2008). Durch die gute Passung des Guttaperchastiftes wird bei der Insertion der zuvor luftgefüllte Hohlraum durch diesen ausgefüllt und somit aufgelöst. Zeitgleich erreicht ein dünner Film von Spülflüssigkeit den apikalen Wurzelbereich und verhindert eine erneute Entstehung des Vapor-Lock-Effekts. Durch die regelmäßigen Hubbewegungen wird zusätzlich der Austausch der Spülflüssigkeit verbessert. Auch Devi und Abbott (2012) zeigten ein durch dynamische Hubbewegungen verbessertes Eindringen von Spülmedien in apikale Bereiche. Boutsioukis et al. zeigten, dass der VLE bei der Verwendung einer apikal offenen Kanüle geringer ausfällt als bei der Nutzung einer seitlich geöffneten Spülnadel (Boutsioukis et al. 2014).

Bei der Handspülung sollte der Spülvorgang langsam und ohne Druck erfolgen. Auch sollte eine Friktion der Spülkanüle im Wurzelkanal vermieden werden, um 
einen Abtransport von Spülflüssigkeit und Debris sowie die Vermeidung zu hoher apikaler Druckverhältnisse zu gewährleisten (Gu et al. 2009).

Obwohl die konventionelle Handspülung im Praxisalltag häufig Anwendung findet, ist ihre Effektivität aufgrund einer unzureichenden Entfernung von Debris und der smear layer aus unzugänglichen Bereichen stark limitiert (Cunningham et al. 1982).

Auch wurde eine deutliche Überlegenheit von schall- oder ultraschallbasierten Aktivierungsmethoden gegenüber der konventionellen Handspülung aufgezeigt (Cunningham et al. 1982; Rödig et al. 2010a; Chou et al. 2014; Grischke et al. 2014).

\subsubsection{CanalBrush}

Bei der CanalBrush handelt es sich um ein flexibles Mikrobürstchen aus Polypropylen (Coltène/Whaledent, Langenau, Deutschland). Der Einsatz kann sowohl manuell durch drehende Bewegungen als auch eingespannt in ein Winkelstück bei 600 Umin $^{-1}$ erfolgen, wobei letzteres laut Herstellerangaben eine höhere Effektivität zeigt. Der zentrale Schaft des Mikrobürstchens ist mit jeweils 30 Bürsten pro Seite besetzt, welche gegenüberliegend zueinander arrangiert sind (Plotino et al. 2009; Salman et al. 2010).

Bei der Entfernung von smear layer und Debris aus dem Wurzelkanal zeigt CanalBrush (CB) eine signifikant bessere Reinigungswirkung als die manuelle Aktivierung von Spüllösungen. Die Effektivität der CB ist hierbei vergleichbar mit der einer passiven ultraschallgestützten Reinigung (Al-Ali et al. 2012). Auch Rödig et al. (2010b) zeigten keinen signifikanten Unterschied zwischen der Reinigungsleistung von CB und PUI (passive ultrasonic irrigation), wobei beide signifikant schlechtere Ergebnisse erzielten als der EndoActivator (EA).

Bei der Entfernung von Kalziumhydroxid aus dem Wurzelkanal ist die CanalBrush der Aktivierung mit Hilfe der PUI unterlegen (Topçuoğlu et al. 2015b; Gokturk et al. 2017; Keskin et al. 2017; Pabel und Hülsmann 2017). Auch die Reinigungsleistung von Nickel-Titan-Aktivierungssystemen wie XPEndo finisher und self-adjusting file (SAF) sind denen der CanalBrush überlegen (Topçuoğlu et al. 2015b; Keskin et al. 2017). Pabel und Hülsmann (2017) zeigten eine 
Überlegenheit der CB gegenüber der konventionellen Handspülung bei der Entfernung von Kalziumhydroxid aus lateralen Gruben sowohl im apikalen als auch koronalen Bereich. Gokturk et al. (2017) stellten eine leichte Überlegenheit der CanalBrush gegenüber der manuellen Spülung fest, sowohl bei der Verwendung frontoffener als auch seitlich geöffneter Spülnadeln. Diese Ergebnisse decken sich nicht mit denen von Keskin et al. (2017) und Topçuoğlu et al. (2015b), welche keine Überlegenheit der CB gegenüber der manuellen Aktivierung feststellten.

\subsubsection{Schallbetriebene Aktivierungssysteme}

Schallaktivierte Spülmetechniken arbeiten in einem Frequenzbereich von unter $20 \mathrm{kHz}$. Für den endodontischen Gebrauch wird ein Frequenzbereich von 1 bis $8 \mathrm{kHz}$ angegeben (Walmsley et al. 1989; van der Sluis et al. 2007). Schallinstrumente oszillieren bei freier Schwingung elliptisch mit einer deutlich sichtbaren lateralen Bewegungsamplitude (Walmsley et al. 1989). In Flüssigkeiten sind ein Schwingungsbauch am Ende des Instruments und ein Schwingungsknoten an der Basis zu beobachten (van der Sluis et al. 2007). Kann eine schallbetriebene Feile nicht frei schwingen, sondern ist beispielsweise durch Kontakt mit der Wurzelkanalwand in ihrer Bewegung eingeschränkt, ändert sich das Schwingungsmuster von einer lateralen zu einer longitudinalen Bewegung (Walmsley et al. 1989). Die Reinigungswirkung schallgestützter Aktivierungsmethoden basiert vor allem auf dem Phänomen des acoustic streaming. Acoustic streaming beschreibt in Flüssigkeiten die Entstehung von Schwingungsknoten und -bäuchen entlang einer Längsachse. Hierbei kommt es zu Verwirbelungen der den oszillierenden Körper umgebenden Flüssigkeit. Im Schallbereich entsteht entlang einer Längsachse nur ein Schwingungsknoten mit einer großen Amplitudenauslenkung, wodurch es sich vom Schwingungsmuster des Ultraschalls unterscheidet, bei dem mehrere Schwingungsknoten mit kleinerer Amplitudenauslenkung zu beobachten sind. 


\subsubsection{EDDY ${ }^{\circledR}$}

EDDY (VDW, München, Deutschland) ist eine schallaktivierte Polyamidspitze, welche in einem Frequenzbereich von 5000 bis $6000 \mathrm{~Hz}$ arbeitet. Sie wird zur Verwendung auf einen Airscaler aufgeschraubt. Die während der Aktivierung erzeugten Schwingungen werden auf die Polymerspitze übertragen, was zu einer oszillierenden Bewegung des Instruments mit einer starken Amplitudenauslenkung führt. Hierdurch entstehen neben Verwirbelungen der Spülflüssigkeit, das sogenannte acoustic streaming, laut Herstellerangaben auch Kavitationen. Unter Kavitation versteht man das Implodieren der durch den (Ultra) Schall gebildeten Bläschen an einer Instrumentenspitze. Durch das Auftreten dieser Effekte soll sich eine verbesserte Reinigungskraft des EDDY ergeben. Brandt und Sonntag (2016) erwähnen in ihrer Übersichtsarbeit ein Auftreten mehrerer Schwingungsknoten bei der Anwendung des EDDY gegenüber einem Schwingungsbauch bei der Verwendung des EndoActivator, was ein Auftreten von Kavitation begünstigen könnte.

Erhältlich ist EDDY in einer Universalgröße (ISO 25/.04), welche für jegliche Kanalanatomien kompatibel sein soll. VDW nennt als weiteren Vorteil bei der Nutzung des EDDY die Risikominimierung von Instrumentenfrakturen oder Dentinschäden aufgrund der hohen Flexibilität der Polyamidspitzen.

Urban et al. (2017) überprüften die Entfernung von smear layer und Debris aus geraden Wurzelkanälen durch Anwendung von EDDY, EndoActivator, PUI und der konventionellen Handspülung. Bei der Entfernung der smear layer gab es keine signifikanten Unterschiede in der Reinigungswirkung von EDDY, EA und PUI. Jedoch waren lediglich PUI und EDDY der konventionellen Handspülung signifikant überlegen. Bei der Reduzierung von Debris im Wurzelkanal waren EDDY, EA und PUI signifikant erfolgreicher als die manuelle Spülung, ohne dabei Unterschiede untereinander aufzuweisen. Die Sauberkeit der Kanäle nahm von apikal nach koronal zu, unabhängig von der angewandten Methode. Zu ähnlichen Ergebnissen kamen auch Haupt et al. (2020). Sie überprüften ebenfalls die Reinigungseffektivität von EDDY, EA, PUI und der Handspülung in Bezug auf Debris und smear layer, jedoch in gekrümmten Wurzelkanälen. Im Hinblick auf den smear layer erzielten EDDY, EA und PUI ähnlich gute Ergebnisse und waren der manuellen Spülung signifikant überlegen. Bei der Entfernung von Debris 
erreichten nur EDDY und EA signifikant bessere Resultate als die konventionelle Spülung. Haupt et al. (2020) beobachteten hingegen keine Unterschiede hinsichtlich der Reinigungsleistung in apikalen und koronalen Bereichen. Plotino et al. (2019) studierten die Eliminierung von Debris aus künstlich geschaffenen Wurzelkanälen und untersuchten neben der Reinigungswirkung von EDDY und PUI auch zeitliche Unterschiede in der jeweiligen Aktivierungsdauer. EDDY konnte signifikant bessere Resultate in der Reinigung der Kanäle erzielen als PUI. Im Hinblick auf die Nutzungsintervalle zeigten Plotino et al. (2019), dass es bei einer 60-sekündigen Anwendung von PUI keinen signifikanten Unterschied in der Leistung gegenüber einer 20-sekündigen Anwendung von EDDY gab. Weiter gab es bei EDDY keine signifikanten Vorteile einer 60-sekündigen gegenüber einer 40-sekündigen Nutzungsdauer. Diese Ergebnisse lassen vermuten, dass für ein ähnlich effizientes Reinigungsergebnis bei der Verwendung von EDDY eine kürzere Anwendungsdauer als bei PUI ausreichend sein könnte. Conde et al. (2017) untersuchten die Auflösung organischer Gewebe aus simulierten Rillen in geraden Wurzelkanälen mit Hilfe von EDDY, EA und PUI. Die Wurzelkanäle wiesen eine laterale Rille im apikalen Bereich auf, welche mit organischem Material aus der Gaumenmukosa von Schweinen befüllt wurde. Gewichtskontrollen der Proben erfolgten jeweils vor und nach der Anwendung der jeweiligen Aktivierungsmethode, wobei es keinen signifikanten Unterschied in der Gewichtsabnahme und somit der Fähigkeit, organisches Gewebe aufzulösen zwischen EDDY, PUI und EA gab. Zusammenfassend lässt sich vermuten, dass EDDY mindestens so effektiv wie PUI, wenn nicht sogar in einzelnen Fällen der PUI überlegen ist. Auch bei der Entfernung von Kalziumhydroxid aus artifiziellen Rillen erzielten EDDY und PUI ähnlich gute Ergebnisse, ohne dabei signifikante Unterschiede untereinander aufzuweisen (Reus 2018; Donnermeyer et al. 2019). Die Resultate der vorliegenden Studien in Hinblick auf die Reinigungsleistung schall- und ultraschallbetriebener Aktivierungsmethoden unterscheiden sich von denen früherer Studien, in denen schallbasierte Instrumente der PUI gemeinhin unterlegen waren.

Diese konträren Ergebnisse können darauf zurückzuführen sein, dass zumeist die Effektivität des EndoActivator mit der der PUI verglichen wurde. Der EndoActivator arbeitet jedoch in einem deutlich niedrigeren Frequenzbereich (33 
- $170 \mathrm{~Hz}$ ) als EDDY (Grischke et al. 2014; Neuhaus et al. 2016; Keskin et al. 2017; Pabel und Hülsmann 2017; Urban et al. 2017).

\subsubsection{EndoActivator}

Der EndoActivator (Dentsply Maillefer, Ballaigues, Schweiz) ist ein schallbetriebenes Gerät zur hydrodynamischen Aktivierung von Spülflüssigkeiten. Es arbeitet in einem Frequenzbereich von 33 bis $166 \mathrm{~Hz}$, wobei sich drei unterschiedliche Frequenzen des Schallmotors einstellen lassen: Stufe 1 = low arbeitet laut Herstellerangaben bei 2.000 Umin $^{-1}(33 \mathrm{~Hz})$, Stufe $2=$ medium bei $6.000 \mathrm{Umin}^{-1}(100 \mathrm{~Hz})$ und Stufe $3=$ high bei $10.000 \mathrm{Umin}^{-1}(166 \mathrm{~Hz})$. Der EndoActivator besteht aus einem batteriebetriebenen Handstück, auf welches Spülansätze aus Polymer aufgesteckt werden. Auch bei den Aufsätzen stehen mit den Größen klein (ISO 15/.02), mittel (ISO 25/.04) und groß (ISO 35/.04) drei Varianten zur Verfügung. Der EndoActivator wird zur Aktivierung von Spülflüssigkeiten ohne Friktion auf Arbeitslänge $-2 \mathrm{~mm}$ in den Wurzelkanal inseriert.

Jiang et al. (2010) und Macedo et al. (2014) konnten bei der Verwendung des EndoActivators keine Kavitationen nachweisen und führten dies auf eine zu geringe Geschwindigkeit zurück, die deutlich niedriger ist als die des EDDY.

Bei der Entfernung von Debris und smear layer aus gekrümmten Wurzelkanälen ist der EndoActivator der konventionellen Handspülung signifikant überlegen, zeigt dabei aber keine verbesserten Reinigungsleistung gegenüber EDDY, PUI oder dem XP-endo finisher (Rödig et al. 2010b; Elnaghy et al. 2017; Haupt et al. 2020). Rödig et al. (2010b) stellten jedoch bei der Beseitigung von smear layer eine bessere Effizienz des EndoActivators gegenüber PUI und der CanalBrush fest. Urban et al. (2017) untersuchten die Fähigkeit unterschiedlicher Aktivierungssysteme zur Eliminierung von Debris und smear layer aus geraden Wurzelkanälen. Auch sie stellten eine Überlegenheit von EA, PUI und EDDY gegenüber der manuellen Spülung fest, die aber keine signifikanten Unterschiede untereinander aufwiesen. Bei der Entfernung von Kalziumhydroxid aus dem Wurzelkanalsystem ist der EndoActivator anderen Aktivierungsmethoden wie PUI, XP-endo finisher oder der self-adjusting file unterlegen (Arslan et al. 2015; Topçuoğlu et al. 2015b; Keskin et al. 2017). Der 
Vergleich von EA und der konventionellen Handspülung liefert kontroverse Ergebnisse. So wiesen mehrere Studien (Arslan et al. 2015; Topçuoğlu et al. 2015b; Keskin et al. 2017) keine verbesserte Reinigungswirkung des EA nach, wohingegen Pabel und Hülsmann (2017) bei der Entfernung von Kalziumhydroxid aus apikal und koronal gelegenen Rillen eine signifikante Überlegenheit des EndoActivators im koronalen Bereich gegenüber der manuellen Spülung feststellten. Kirar et al. (2017) stützen die Ergebnisse von Pabel und Hülsmann (2017) und beschrieben sogar eine Überlegenheit des EA gegenüber der PUI. Chou et al. (2014) demonstrierten bei der Beseitigung von Ledermix aus dem Wurzelkanal ebenfalls eine bessere Reinigungswirkung des EndoActivator gegenüber der manuellen Spülung, stellten jedoch keinen Vorteil bei der Nutzung des EA zur Entfernung von Kalziumhydroxid fest. Zusammenfassend ist festzuhalten, dass der EndoActivator eine erfolgreiche Methode zur Aktivierung von Spülflüssigkeiten ist und trotz kontroverser Studienergebnisse oftmals eine verbesserte Reinigungswirkung gegenüber der konventionellen Handspülung aufweist.

\subsubsection{Vibringe}

Vibringe (Vibringe B.V. Corp., Amsterdam, Niederlande) arbeitet bei einer Frequenz von $150 \mathrm{~Hz}$ und setzt dabei Vibrationen frei. Das Handstück ist kabellos und besteht aus einem Kunststoffhandgriff sowie einem Körper aus Aluminium. Hier befindet sich auch der integrierte Akku, welcher über Induktion zu laden ist. Das Handstück wird auf speziell angefertigte $10 \mathrm{ml}$ Luer-Lock-Spritze aufgesetzt und übermittelt so die Schallwellen direkt an die Flüssigkeit. Somit ermöglicht Vibringe eine Zufuhr und Aktivierung von Spülmedien in einem Schritt.

Rödig et al. (2010a) verglichen Vibringe, PUI und die Handspülung hinsichtlich ihrer Effizienz bei der Entfernung von Debris aus geraden Kanälen mit je einer künstlich geschaffenen Rille im koronalen und apikalen Wurzelbereich. Vibringe erzielte im apikalen Bereich signifikant bessere Reinigungsleistungen als die Handspülung, war PUI jedoch in allen Abschnitten signifikant unterlegen. Auch 
Johnson et al. (2012) verglichen die Fähigkeit von Vibringe und der manuellen Handspülung zur Eliminierung von Debris, stellten jedoch keine Überlegenheit von Vibringe gegenüber der konventionellen Handspülung fest. Zu ähnlichen Ergebnissen kamen Gokturk et al. (2016) bei der Entfernung von double antibiotic paste aus dem Wurzelkanal. In Studien zur Entfernung von Kalziumhydroxid aus dem Wurzelkanalsystem unterlag Vibringe der PUI, konnte jedoch eine Überlegenheit gegenüber der Reinigungsleistung von NaviTip FX-Kanülen und der konventionellen Handspülung demonstrieren (Gokturk et al. 2017; Küçükkaya Eren et al. 2017)

\subsubsection{Passive Ultraschallspülung}

Ultraschall findet in der Endodontie Anwendung seit der Einführung durch Richman (1957), wobei es erst später durch den Einsatz ultraschallaktivierter KFeilen während der Wurzelkanalpräparation weitreichende Akzeptanz fand (Plotino et al. 2007). Ultraschall arbeitet bei Frequenzen über $20 \mathrm{kHz}$, welche für das menschliche Gehör nicht mehr wahrnehmbar sind. Im endodontischen Bereich werden Ultraschallfrequenzen zwischen 25 und $40 \mathrm{kHz}$ genutzt (Brandt und Sonntag 2016). Die Erzeugung von Ultraschall kann anhand zweier unterschiedlicher Methoden erfolgen. Zum Einen über Magnetostriktion, welche das Prinzip der Deformation magnetischer Werkstoffe nach Anlegen einer magnetischen Spannung verfolgt, währenddessen kommt es zu einer Umwandlung elektrischer zu mechanischer Energie und es werden Vibrationen in der Spülflüssigkeit hervorgerufen, und zum Anderen über Piezoelektrizität, bei der die Beschaffenheit spezieller Kristalle ausgenutzt wird, durch die es zu Verformungen eben dieser Kristalle kommt, sobald eine elektrische Spannung angelegt wird. Als Folge der Deformation kommt es zu einer Freisetzung mechanischer Vibrationen. Für den endodontischen Gebrauch wird die Verwendung piezoelektrischer Ultraschallgeber bevorzugt, da sie deutlich weniger Wärme als magnetrostriktive Varianten freisetzen, was den Schutz vor thermischen Schädigungen umgebender Hart- und Weichgewebe erhöht (Plotino et al. 2007). Durch das Auftreten von Vibrationen kommt es bei der Anwendung von Ultraschall zu den Phänomenen des acoustic streaming und von (Mikro-) Kavitationen, welche maßgeblich an der Effektivität ultraschallgestützter 
Aktivierungsmethoden beteiligt sind. Acoustic streaming beschreibt die Entstehung von Schwingungsknoten und -bäuchen entlang einer Längsachse. Hierbei kommt es zu Verwirbelungen von Flüssigkeiten, welche einen oszillierenden Körper umgeben. Entsteht im Schallbereich entlang einer Längsachse lediglich nur ein Schwingungsknoten mit einer großen Amplitudenauslenkung, sind im Bereich des Ultraschalls mehrere Schwingungsknoten kleinerer Amplitudenauslenkung zu beobachten (Walmsley et al. 1989; Walmsley und Williams 1989). Unter Kavitation versteht man die Entstehung und das anschließende rapide Implodieren von Blasen im Bereich der Instrumentenspitze. Durch den Kollaps der Blasen werden Druckwellen innerhalb der Spülflüssigkeit freigesetzt, wodurch es zu einer verstärkten Entwicklung von Scherkräften an der Wurzelkanalwand kommt (van der Sluis et al. 2007; Walmsley et al. 2013; Macedo et al. 2014). Um die Vorteile von acoustic streaming und Mikrokavitationen bestmöglich ausnutzen zu können, sollten die Ultraschallfeilen während der Anwendung nur geringen Kontakt zur Kanalwand haben. Kommt es zu einem Kontakt des Instruments mit dem Wurzelkanal, wird die Effektivität dieser beiden Phänomene herabgesetzt, was in einer reduzierten Reinigungsleistung resultiert (van der Sluis et al. 2007). Unter anderem deswegen sollte ein passiver Einsatz von Ultraschallfeilen erfolgen. Die passive Ultraschallspülung (PUI, passive ultrasonic irrigation) wurde erstmals von Weller et al. (1980) erwähnt. Der Einsatz der Ultraschallfeile soll möglichst ohne Wandkontakt und somit ohne Dentinschädigungen erfolgen. Bei der Beseitigung von Debris und smear layer aus dem Wurzelkanal ist die PUI der konventionellen Spülung überlegen (Rödig et al. 2010c; Mozo et al. 2014; Urban et al. 2017; Haupt et al. 2020). Silva et al. (2019) untersuchten die Reinigungswirkung der PUI hinsichtlich der Entfernung von Debris, wobei es keine signifikanten Unterschiede zwischen den Aktivierungsmethoden PUI, SAF und EndoVac gab. Auch Leoni et al. (2017) überprüften die Spüleffizienz der PUI in Unterkiefermolaren, wobei sie der SAF signifikant überlegen war, ohne sich in ihrer Reinigungsleistung vom XP-endo Finisher zu unterscheiden. Urban et al. (2017) verglichen die Effektivität von PUI und den schallbetriebenen Systemen EDDY und EndoActivator hinsichtlich der Entfernung von Debris und smear layer. Sie stellten keine signifikanten Unterschiede zwischen den Aktivierungsmethoden 
fest. Diese Erkenntnisse werden durch die Ergebnisse der Studie von Haupt et al. (2020) unterstützt.

Bei der Beseitigung von Kalziumhydroxid aus dem Wurzelkanalsystem ist die PUI der manuellen Spülung ebenfalls überlegen (Topçuoğlu et al. 2015b; Keskin et al. 2017; Pabel und Hülsmann 2017; Wigler et al. 2017; Kfir et al. 2018; Donnermeyer et al. 2019). Rödig et al. (2011) verglichen die PUI mit dem SaugDruck-System RinsEndo hinsichtlich der Entfernung von Ledermix und $\mathrm{Ca}(\mathrm{OH})_{2}$ aus dem Wurzelkanal. Für keine der medikamentösen Einlagen wurden Unterschiede zwischen den Aktivierungsmethoden festgestellt. Pabel und Hülsmann (2017) konnten diese Ergebnisse für RinsEndo nicht bestätigen. Sie beobachteten eine signifikante Überlegenheit der passiven Ultraschallspülung. Auch EndoVac war bei der Eliminierung von Kalziumhydroxid der PUI unterlegen (Capar et al. 2014; Topçuoğlu et al. 2015b). Donnermeyer et al. (2019) verglichen die Reinigungsleistung von PUI und dem schallbetriebenen EDDY, wobei sie keine signifikanten Unterschiede zwischen beiden Aktivierungssystemen erkennen konnten. Bei der Untersuchung des EndoActivator, ebenfalls ein schallbetriebenes Instrument, wurde hingegen in mehreren Studien eine Überlegenheit der PUI nachgewiesen (Topçuoğlu et al. 2015b; Keskin et al. 2017; Pabel und Hülsmann 2017). Wigler et al. (2017) überprüften die Reinigungsleistung von XP-endo Finisher und PUI, auch hier wurden keine Unterschiede in der Effektivität gefunden. Diese Erkenntnisse bestätigen die Studien von Keskin et al. (2017), Uygun et al. (2017) und Kfir et al. (2018). Gokturk et al. (2017) wiesen jedoch, ebenso wie Donnermeyer et al. (2019), eine Überlegenheit wer PUI nach, wobei Hamdan et al. (2017) die bessere Effektivität dem XP-endo Finisher zuordneten.

PUI stellt eine sehr effektive Methode zur Reinigung von Wurzelkanälen dar. Neuartige Aktivierungssysteme wie der schallbetriebe EDDY, der XP-endo Finisher oder auch laserinduzierte Spültechniken können jedoch ähnlich effiziente Ergebnisse erzielen (Arslan et al. 2015; Gokturk et al. 2017; Keskin et al. 2017; Wigler et al. 2017; Kfir et al. 2018; Donnermeyer et al. 2019; Haupt et al. 2020). 


\subsubsection{Nickel- Titan- Aktivierungssysteme}

\subsubsection{XP-endo Finisher}

Der XP-endo Finisher gehört (FKG Dentaire, La Chaux-de-Fonds, Schweiz) zu der Familie der Nickel-Titan-Instrumente. Sie zeichnen sich durch die Verwendung der MaxWire-Legierung aus, welche es den Instrumenten ermöglicht, auf einen Temperaturwechsel mit einer Formänderung zu reagieren. Während sich der XP-endo Finisher bei Raumtemperatur in der M-Phase (Martensit) befindet und eine gerade Form aufweist, wechselt er bei Körpertemperatur in die A-Phase (Austenit) und nimmt aufgrund des Formgedächtnisses eine Sichelform an. Wird das sichelförmige Instrument nun in Rotation versetzt, schwingt es bis zum Wandkontakt lateralwärts und passt sich so der Wurzelkanalanatomie an. Laut Herstellerangaben sollte der XP-endo Finisher bei einer Drehzahl von 800 bis $1000 \mathrm{~min}^{-1}$ und erst nach einer Kanalerweiterung bis mindestens zur ISO-Größe 25 verwendet werden.

Leoni et al. (2017) überprüften die Effektivität des XP-endo Finishers hinsichtlich der Reinigung gekrümmter Wurzelkanäle von Debris. Das Instrument war signifikant effektiver als die SAF oder die manuelle Spülung und gleichermaßen erfolgreich wie die PUI. Auch De-Deus et al. (2019) stellten gleich gute Ergebnisse von XP und PUI bei der Entfernung von Debris aus ovalen Wurzelkanälen fest. Elnaghy et al. (2017) untersuchten die Reinigungswirkung in Bezug auf smear layer und Debris, wobei der XP-endo Finisher ebenso effizient war wie der EndoActivator, während beide der konventionellen Spülung signifikant überlegen waren. Zu konträren Ergebnissen bei der Eliminierung von Debris und smear layer aus ovalen Kanälen kamen Alakshar et al. (2020). Sie wiesen eine Überlegenheit von EA und der manuellen Spülung nach.

Wigler et al. (2017) überprüften die Fähigkeit von des XP-endo Finishers, Kalziumhydroxid aus apikalen Rillen zu beseitigen. Hierbei war der XP der manuellen Spülung signifikant überlegen, wohingegen zur PUI kein Unterschied festgestellt wurde. Diese Ergebnisse werden von Keskin et al. (2017) und Kfir et al. (2018) gestützt. In Untersuchungen zur Entfernung aus koronal gelegenen Rillen wurden keine Unterschiede zwischen PUI oder EDDY und XP aufgezeigt (Gokturk et al. 2017; Donnermeyer et al. 2019). Hinsichtlich der Reinigung von Rillen im apikalen Bereich waren PUI und EDDY jedoch signifikant überlegen 
(Gokturk et al. 2017; Donnermeyer et al. 2019). Nasab Mobarakeh et al. (2020) studierten die Entfernung unterschiedlicher Kalziumhydroxidpräparate aus Resorptionskavitäten, wobei der XP-endo Finisher in beiden Fällen der PUI signifikant unterlegen, jedoch deutlich effektiver als die manuelle Spülung war. Insgesamt gesehen ist der XP-endo Finisher eine effektive Methode zur Reinigung von Wurzelkanälen.

\subsubsection{Self-adjusting file (SAF)}

Die self-adjusting file (ReDent-Nova, Ra'anana, Israel) ist ein Nickel-TitanInstrument zur chemomechanischen Präparation des Wurzelkanals (Metzger et al. 2010a). Die SAF besteht aus einem $120 \mu \mathrm{m}$ dicken komprimierbaren NiTiGitter, welches sich nach Einführen in den Wurzelkanal aufgrund des Formgedächtnisses wieder ausdehnt und sich so der Kanalgeometrie anpasst. Der Hohlkörper bietet die Möglichkeit eines kontinuierlichen Flüssigkeitsaustauschs während der Aktivierung. Die Flüssigkeitszufuhr erfolgt über einen Spülansatz, welcher in das speziell für die SAF angefertigte Winkelstück integriert ist. Mit einem Durchmesser von 1,5 mm zur Verwendung bei Aufbereitungsgrößen bis ISO-Größe 20 oder einem Durchmesser von 2,0 mm bei einer Präparation bis ISO-Größe 30 stehen zwei Größen der SAF zur Verfügung. Die Insertion in den Wurzelkanal sollte bis auf Arbeitslänge erfolgen, wobei während der Anwendung Hubbewegungen von 3 bis $5 \mathrm{~mm}$ auszuführen sind.

In der Kombination mit NaOCl und EDTA als Spülmedien zeigten Metzger et al. (2010b), dass die SAF die Wurzelkanäle komplett von Debris befreite. Auch war die SAF in der Lage, den koronalen Bereich komplett von smear layer zu säubern, im apikalen Bereich waren 65\% der Kanalwand gereinigt. Topçuoglu et al. (2015a) und Silva et al. (2019) wiesen keine komplette Entfernung von Debris durch die SAF nach, jedoch zeigten ihre Untersuchungen, dass sie ebenso effektiv arbeitet wie die PUI. Auch bei der Entfernung von Kalziumhydroxid aus geraden Wurzelkanälen war die SAF gleichermaßen erfolgreich wie die PUI, wobei sie der Handspülung deutlich überlegen war (Topçuoğlu et al. 2015b; Kfir et al. 2018). 
Ahmetoğlu et al. (2013) fanden hingegen bei der Reinigung von Unterkieferprämolaren eine Überlegenheit der PUI gegenüber der SAF. Die Ergebnisse der vorliegenden Studien zeigen, dass die SAF eine effektive Variante ist, um Wurzelkanäle von Debris und Kalziumhydroxid zu befreien.

\subsubsection{Drucksysteme}

Drucksysteme arbeiten in ihrer Funktionsweise dem während eines Spülvorgangs natürlicherweise im Wurzelkanal vorherrschendem positiven apikalwärts gerichteten Druck entgegen. So kommt es bei der Anwendung des EndoVac zur Erzeugung eines negativen apikalen Drucks oder bei RinsEndo zur Nutzung einer simultanen Saug-Druck-Technik.

\subsubsection{EndoVac (EV)}

EndoVac (Discus Dental, Culver City, CA, USA) erzeugt einen intrakanalären apikalen Unterdruck und inseriert somit Spülflüssigkeiten bis auf Arbeitslänge in den Wurzelkanal, ohne dabei die Gefahr einer Extrusion über das Foramen apicale hinaus einzugehen. Bei der Entfernung von Debris aus Wurzelkanälen erzielte EndoVac signifikant bessere Reinigungsleistungen als die Handspülung (Ribeiro et al. 2012). Gade et al. (2013) stützen diese Erkenntnis für die Reinigung des apikalen Wurzelkanalabschnitts. Bei der Entfernung von Kalziumhydroxid wiesen Yücel et al. (2013) und Alturaiki et al. (2015) eine gesteigerte Effizienz des EndoVac gegenüber der konventionellen Handspülung nach. Capar et al. (2014) und Topçuoğlu et al. (2015b) stellten jedoch keinen signifikanten Unterschied hinsichtlich der beiden Aktivierungsmethoden fest. EndoVac bietet mit deutlich geringeren Extrusionen von Spülflüssigkeiten über das apikale Foramen hinaus einen großen Vorteil gegenüber der Handspülung (Desai und Himel 2009; Mitchell et al. 2010; Venumbaka et al. 2018). So kann EndoVac in der Gesamtheit zumindest als sicherer in der Anwendung bezeichnet werden und somit der manuellen Spülung überlegen, auch wenn für die Reinigungswirkung kontroverse Ergebnisse vorliegen. 


\subsubsection{RinsEndo (RE)}

Bei RinsEndo (DÜRR DENTAL SE, Bietigheim-Bissingen, Deutschland) handelt es sich um ein Spülhandstück, welches über eine Saug-Druck-Technologie Spülflüssigkeiten in den Wurzelkanal einbringt, sie dort aktiviert und wieder absaugt. Diese Technik führt zu einer hydrodynamischen Spülung von Wurzelkanälen. In der „Druckphase“ werden über einen im Handstück befindlichen Taktgeber bei einer Frequenz von 1,6 Hz je 65 Mikroliter der Spülflüssigkeit in den Wurzelkanal gepumpt und dabei oszillierend aktiviert. Während der „Saugphase“ wird die Spülflüssigkeit durch die Erzeugung eines kurzzeitigen Unterdrucks wieder aus dem Kanal entfernt. So erfolgt ein permanenter Austausch des Spülmediums während des Spülvorgangs.

Bei der Entfernung von Debris aus Wurzelkanälen untersuchten Rödig et al. (2010c) die Reinigungswirkung von RinsEndo, PUI und der konventionellen Handspülung bei unterschiedlich apikalen Präparationsgrößen. RinsEndo war PUI signifikant unterlegen. Lediglich bei der kleinsten überprüften Präparationsgröße von 30/.02 wurde keine Überlegenheit der PUI gegenüber RinsEndo festgestellt. Der konventionellen Handspülung war RE bei allen Größen signifikant überlegen. Vivan et al. (2010) fanden keine verbesserten Ergebnisse durch die Anwendung von RinsEndo gegenüber der manuellen Handspülung. Pabel und Hülsmann (2017) zeigten, dass bei der Beseitigung von Kalziumhydroxid aus dem Wurzelkanal RinsEndo signifikant schlechtere Reinigungsergebnisse erzielte als PUI, jedoch gleichermaßen gut abschnitt wie der EndoActivator.

Rödig et al. (2011) stellten keine Unterschiede in der Effektivität von RinsEndo und PUI bei der Entfernung medikamentöser Einlagen aus dem Wurzelkanal fest. RinsEndo und PUI entfernten Ledermix effizienter aus dem Kanal als Kalziumhydroxid.

\subsubsection{Laserinduzierte Aktivierung (LAl)}

LAl wandelt durch Absorption in Spülmedien Laserenergie in physikalische Energie um. Hierbei kommt es zu Phänomenen der Kavitation, welche eine effektive Reinigung von Wurzelkanälen unterstützen. Zumeist handelt es sich bei 
dem zur Anwendung kommenden Laser entweder um einen Er,Cr:YSGG(Erbium-Chromium-Yttrium-Scandium-Garnett) oder einen Er:YAG(ErbiumYAG)-Laser. Die Laserstrahlung wird durch das Spülmedium absorbiert, wodurch dieses zum Sieden gebracht wird. Die so entstandenen Gasbläschen können sich solange ausdehnen wie Laserstrahlung zugeführt wird. Stoppt der Laserimpuls, schrumpft die Gasblase bis sie implodiert, wodurch Spülflüssigkeiten innerhalb kürzester Zeit die entstehenden Hohlräume auffüllen und Kavitationseffekte freigesetzt werden. Aufgrund der rapiden Flüssigkeitsverschiebungen bilden sich zudem Druckwellen aus, welche einen mechanischen Reinigungseffekt auslösen. Da die Laserspitze für eine effiziente Reinigungswirkung bis weit in den Wurzelkanal eingebracht werden muss und diesen dabei fast komplett ausfüllt, kann es zu negativen Effekten wie Extrusion von Spülflüssigkeiten über das apikale Foramen hinaus oder zu thermischen Schädigungen der Kanalwand kommen (Schlichting 2018). Diese doch gravierenden Nachteile bei der Anwendung von LAl führten zu der Entwicklung der Photonen induzierten, photoakustischen Strömungsaktivierung, kurz PIPS.

\subsubsection{Photonen induzierte, photoakustische Strömungsaktivierung - PIPS}

Bei der PIPS-Methode handelt es sich unter der Verwendung eines Er:YAGLasers um eine Weiterentwicklung der laserunterstützten Aktivierung von Spülflüssigkeiten. Um die bei der LAl vorherrschenden Probleme einer thermischen Schädigung von Zahnhartsubstanz und apikaler Extrusion von Spülflüssigkeiten zu beheben, arbeitet PIPS mit einer speziell entwickelten konischen Spitze, welche lediglich in das Pulpakavum und nicht wie bei der LAI in den Wurzelkanal eingebracht wird (Schlichting 2018). PIPS entsendet einen einzelnen Laserimpuls mit einer Pulsdauer von $50 \mu \mathrm{s}$, wodurch es zu den gewünschten Kavitationseffekten und zur Entstehung von Druckwellen innerhalb der Spülflüssigkeiten kommt.

Bei der Entfernung von Debris aus geraden Wurzelkanälen stellten Arslan et al. (2014) eine deutliche Überlegenheit von PIPS gegenüber PUI, EA und der Handspülung fest. Auch in Unterkiefermolaren ist PIPS effektiver in der Beseitigung von Debris als die manuelle Spülung (Lloyd et al. 2014). Ozbay und 
Erdemir (2018) überprüften die Reinigungswirkung von PIPS hinsichtlich der smear layer und erzielten mit dem Er:YAG-Laser unabhängig von der verwendeten Spülflüssigkeit gute Ergebnisse. Arslan et al. (2015) wiesen bei der Eliminierung von Kalziumhydroxid aus geraden Wurzelkanälen mit apikal platzierten Rillen bei der Anwendung von PIPS eine vollständige Beseitigung der medikamentösen Einlage nach. PUI, EA und die Handspülung waren signifikant unterlegen. Li et al. (2015) zeigten bei der Verwendung von PIPS und PUI in den Wurzeln von Oberkieferprämolaren im Vergleich zu EA und der manuellen Spülung deutlich geringere Kalziumhydroxidrückstände. Auch in gekrümmten Wurzelkanälen von Unterkiefermolaren war PIPS bei der Entfernung von Kalziumhydroxid PUI und der manuellen Handspülung im apikalen Bereich signifikant überlegen (Lloyd et al. 2016). Diese Ergebnisse lassen darauf schließen, dass die Aktivierung mittels PIPS eine effektive Methode zur Reinigung von Wurzelkanälen darstellt.

\subsubsection{Shock Wave Enhanced Emission of Photoacustic Streaming - SWEEPS}

Mit SWEEPS steht ein neuer Ansatz zur Verbesserung der PIPS-Methode zur Verfügung. Anders als bei der PIPS-Methode, welche mit einem einzigen Laserimpuls arbeitet, wird bei SWEEPS ein zweiter laseraktivierter Impuls ausgelöst. Dieser wird zeitlich so gesetzt, dass er während der Implosionsphase der ersten Pulsung weitere Blasen erzeugt, welche das Kollabieren der primären Gasblasen beschleunigen. Aufgrund der explosionsartigen Implosion entstehen verstärkte Kavitationseffekte sowie eine Potenzierung der Druckwellen, welche stärkere mechanische Reinigungswirkungen zur Folge haben (Schlichting 2018).

Die Anzahl an Studien zur Effektivität von SWEEPS ist momentan noch sehr gering. Jezeršek et al. (2020) untersuchten die Entfernung simulierter Debrisansammlungen aus artifiziell hergestellten Wurzelkanälen und wiesen für SWEEPS eine bessere Reinigungswirkung nach als für die Aktivierung durch einen einzelnen Laserimpuls. Auch Yang et al. (2020) studierten die Effektivität von SWEEPS, PIPS und ultraschallgestützter Aktivierung hinsichtlich der Beseitigung von Debris aus Wurzelkanälen. 
SWEEPS konnte auch hier die Debrisrückstände besser reduzieren als PIPS. Diese Ergebnisse lassen darauf schließen, dass die Weiterentwicklung laseraktivierter Spülungen mit SWEEPS eine effektive und der PIPS überlegene Methode zur Reinigung von Wurzelkanälen darstellt.

\section{$1.7 \quad$ Ziele der Studie}

Ziel dieser Studie ist es, die Effektivität der Reinigung von mit Ledermix gefüllten Wurzelkanälen mit Hilfe einer schallgestützten Spültechnik, einer ultraschallgestützten Spülmethode und eines neuartigen Nickel-TitanInstrumentes zu erproben, sowie die angewandten Spültechniken untereinander zu vergleichen.

Folgende Spültechniken werden untersucht:

- XP-endo Finisher (FKG): ein Instrument aus MaxWire; eine von FKG exklusiv entwickelte Nickel-Titan-Legierung

- EDDY (VDW): schallgestützte Spülung mit einem vibrierenden Polymerstab

- IRRI Ultraschallfeile (VDW): passiv ultraschallgestützte Spülung.

Als Nullhypothese wurde formuliert:

Bei der Entfernung einer Ledermixeinlage aus allen Dritteln von geraden Wurzelkanälen besteht hinsichtlich der Reinigungswirkung kein Unterschied zwischen dem XP-endo Finisher, dem EDDY und der IRRI Ultraschallfeile. 


\section{Material und Methode}

Das Studienprotokoll wurde am 29.08.2016 unter der Nummer DOK_128_2016 von der Ethik-Kommission der UMG genehmigt.

\subsection{Auswahl der Zähne}

Die in der Studie verwendeten Zähne wurden alle innerhalb eines Jahres gesammelt und in Wasser gelagert. Die bei der Auswahl der Zähne zu Grunde liegenden Einschlusskriterien sind in Tabelle 3 und die Ausschlusskriterien in Tabelle 4 zusammengefasst.

Tabelle 3: Einschlusskriterien der verwendeten Zähne

\section{Einschlusskriterien}

- Mittlere und seitliche Oberkieferinzisivi oder einwurzelige Prämolaren

- Gerader Wurzelverlauf

- Unbeschädigter Apex

- Keine früheren endodontischen Maßnahmen

- Keine Wurzelkaries oder Zahnfrakturen

- Keine überkronten Zähne

- Vorlage einer Patenteneinwilligung zur Verwendung ihrer nicht zu Studienzwecken extrahierten Zähne zu wissenschaftlichen Zwecken. 
Tabelle 4: Ausschlusskriterien der verwendeten Zähne

\section{Ausschlusskriterien}

- Mehrwurzelige Zähne

- Nicht abgeschlossenes Wurzelwachstum

- Ungerader Wurzelverlauf

- Bereits erfolgte endodontische Maßnahmen

- Wurzelkaries oder Zahnfrakturen

- Überkronte Zähne

- Fehlende Patienteneinwilligung.

Alle 62 in die Studie einbezogenen Zähne wurden zunächst gereinigt und desinfiziert sowie die Wurzeloberflächen mit einem Scaler (HLW-Germany, Wernberg-Köblitz, Deutschland) von harten und weichen Belägen befreit. Anschließend erfolgte die Präparation der Zugangskavität mit hochtourig rotierenden und diamantierten Schleifern (Komet Dental, Lemgo, Deutschland).

Wurde das Pulpakammerdach erreicht, wurden die restlichen Dentinüberhänge mit einem Rosenbohrer entfernt (Komet Dental, Lemgo, Deutschland) und die Pulpakammerwände mit Hilfe eines diamantierten Ultraschallansatzes (KaVo Dental $\mathrm{GmbH}$, Bieberach/ Riß, Deutschland) geglättet.

Um die Durchgängigkeit des Foramen apicale eines jeden Zahnes zu überprüfen, erfolgte mit einem Reamer der ISO-Größe 10 (VDW GmbH, München, Deutschland) eine leichte Überinstrumentierung des Wurzelkanals. Die Überinstrumentierung erfolgte gerade soweit, dass die Spitze des Reamers apikal sichtbar wurde.

Da die Gesamtlängen der Zähne im Bereich von 20 bis $24 \mathrm{~mm}$ lagen, wurden eine Einheitslänge von $19 \mathrm{~mm}$ festgelegt und die Zähne mit einem Diamantschleifer auf diese Länge eingekürzt. 
Um eine koronale Erweiterung und somit einen Gleitpfad für die nachfolgende maschinelle Instrumentierung der Wurzelkanäle zu schaffen, wurde der Wurzelkanaleingang mit Gates-Glidden-Bohrern (Komet Dental, Lemgo, Deutschland) der Größen II und III erweitert. Die Arbeitslänge wurde ab einem definierten koronalen Referenzpunkt für den Gates- Glidden- Bohrer der Größe II auf $6 \mathrm{~mm}$ und den der Größe III auf $4 \mathrm{~mm}$ festgelegt.

Die maschinelle Präparation der Wurzelkanäle erfolgte mit dem Mtwo-System (VDW GmbH, München, Deutschland) in der Crown-Down-Technik bis zur Größe $40 / .04$

Die Abfolge der genutzten Nickel-Titan-Instrumente erfolgte nach Herstellerangaben, wobei aufgrund der Empfehlung des Herstellers jedes Instrument nach achtmaligem Gebrauch verworfen wurde. Die Arbeitslänge wurde auf 18 mm festgesetzt.

Nach jeder Instrumentierung erfolgte eine Spülung der Wurzelkanäle mit einem Volumen von $2 \mathrm{ml}$ einer 3\%-igen $\mathrm{NaOCl}$-Spüllösung (Hedinger, Stuttgart, Deutschland). Die Spülung wurde, zur Sicherstellung eines gleichbleibenden Spülvolumens während der einzelnen Spülvorgänge, manuell mit Hilfe einer 5 ml-Spritze (BD Discardit II, Becton, Dickinson and Company, Franklin Lake, USA) und einer Spülkanüle der Größe 30 (Endoneedle, Vedefar, Dilbeek, Belgien) durchgeführt.

Um möglichst gleiche Verhältnisse zu schaffen, wurden sowohl Präparation als auch Spülung von demselben Behandler durchgeführt.

Die Abschlussspülung erfolgte mit $5 \mathrm{ml}$ 17\%-igem EDTAs (Lege artis pharma, Dettenhausen, Deutschland) und $5 \mathrm{ml}$ einer 3\% NaOCl-Lösung.

Abschließend wurde der Wurzelkanal mit Hilfe von Papierspitzen (ORBIS Dental, Münster, Deutschland) getrocknet.

Für ein späteres exaktes Repositionieren der Wurzelhälften erfolgte pro Zahn in einem röhrenförmigen Acrylglasbehälter (Alt-intech, Neresheim, Deutschland) die Herstellung einer Silikonform aus Silaplast (Detax, Ettlingen, Deutschland). Die Zähne wurden dabei in Gänze in die noch verformbare Silaplastmasse geschoben, wobei das Acrylrohr der Stabilisierung und Formgebung diente. 


\subsection{Präparation der Zähne}

Es wurden standardisierte halbkugelförmige Gruben und Rillen in die Wurzelhälften präpariert. Hierbei wurde der Versuchsaufbau an den von Lee et al. (2004a) angelehnt, der schon in einigen vergleichbaren Studien angewandt wurde (Rödig et al. 2011; Capar et al. 2014; Wigler et al. 2017).

Um die Dimension des Wurzelkanals besser abschätzen zu können, wurde ein Guttaperchastift der ISO-Größe 40/.02 (VDW GmbH, München, Deutschland) in den Wurzelkanal eingebracht, ehe außen entlang der distalen und mesialen Längsachse mit Hilfe einer diamantierten Trennscheibe (Horico, Berlin, Deutschland) eine Rille angelegt wurde, ohne dabei das Kanallumen zu eröffnen. Anschließend wurde der Zahn longitudinal gespalten.

Ein spaltfreies Reponieren der Zahnhälften wurde mit einem Mikroskop (OPMI pico, Carl Zeiss, Jena, Deutschland) überprüft. War ein lückenloses Zusammensetzen nicht sichergestellt, wurden die Zähne aus der Studie ausgeschlossen. Ebenfalls aus der Studie ausgeschlossen wurden diejenigen Zähne, bei denen sich das Kanallumen lateral als eröffnet zeigte, da dies ansonsten zu einem späteren Zeitpunkt den Austritt von Spülflüssigkeit zur Folge gehabt hätte.

Für die Präparation der Vertiefungen in der jeweiligen Zahnhälfte wurde zunächst deren Ausmaß abgemessen und mit Bleistift auf den Zahnwurzelhälften markiert. Um nicht instrumentierte Unregelmäßigkeiten des Wurzelkanals imitieren zu können, wurden drei halbkugelförmige Gruben in eine Zahnhälfte präpariert. Hierfür wurden mit Hilfe eines Rosenbohrers (H71.104.003, Komet Dental, Lemgo, Deutschland) mit einem Durchmesser von 0,3 mm im Abstand von 2, 4 und $6 \mathrm{~mm}$ koronal der festgelegten Arbeitslänge drei Kavitäten in die Zahnhälfte präpariert (Abbildung 3-B). Die Positionierung der halbkugelförmigen Gruben wurde hierbei von Lee et al. (2004a) übernommen (Abbildung 2).

In die gegenüberliegende Zahnhälfte wurde mit einem Fingerspreader der ISOGröße 35 (VDW GmbH, München, Deutschland) eine Rille präpariert (Abbildung 3-A). Dies dient der Imitation von nicht direkt der normalen Spülung zugänglichen Bereichen beziehungsweise nicht effizient zu spülenden Bereichen. 
Für die Präparation wurde zunächst der Handgriff des Fingerspreaders abgetrennt, ehe die Spitze mit Hilfe einer diamantierten Trennscheibe in die Form eines "Vs" abgeändert wurde. Somit konnte eine einheitliche Präparation der Rillen erfolgen. Hierzu wurde die Spitze des Fingerspreaders in den Nadelhalter eines Ultraschallgerätes (VDW Ultra, VDW GmbH, München) eingesetzt und bei niedriger Frequenz gearbeitet. Der Beginn der Rille liegt $2 \mathrm{~mm}$ koronal der Arbeitslänge und wurde auf eine Gesamtlänge von $6 \mathrm{~mm}$ koronal der Arbeitslänge präpariert. Somit entstanden Rillen mit einer Länge von $4 \mathrm{~mm}$, einer Tiefe von 0,5 mm und einer Breite von 0,2 mm (Abbildung 2).
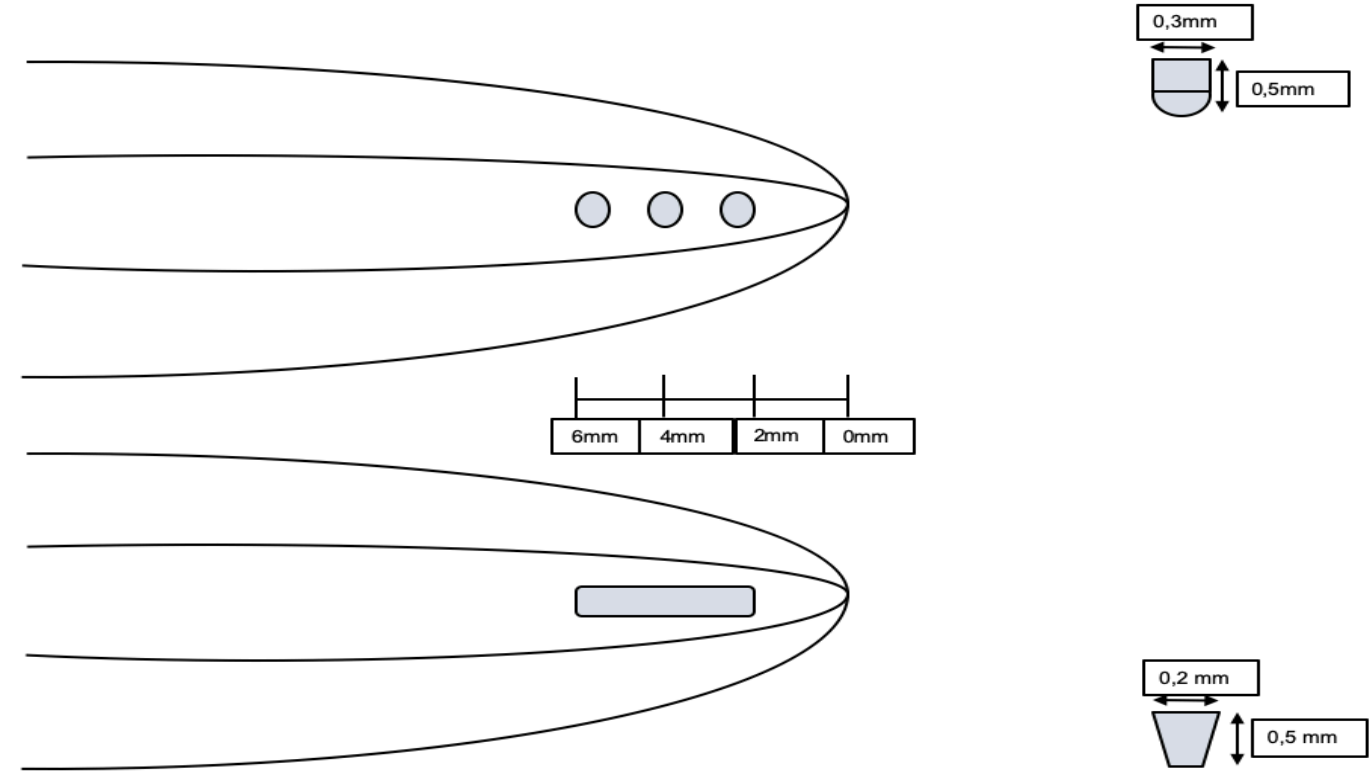

Abbildung 2: Schematische Darstellung der Position von Gruben und Rillen in den Zahnwurzelhälften (angelehnt an Lee et al. (2004a)) 


\subsection{Fotografische Bilderfassung}

Die fotografische Bilderfassung aller Zahnproben diente einer genauen Auswertung der Rillen und halbkugelförmigen Gruben nach dem Spülvorgang. Um eine exakte Repositionierung der Zahnhälften zu ermöglichen, wurde für jede Zahnprobe mit je zwei Zahnhälften ein Silaplastschlüssel angefertigt. Dies diente weiter einer reproduzierbaren und gut ausgeleuchteten Positionierung während der Aufnahme unter dem Mikroskop. So entstanden mit einer Kamera (Leica MC 170 HD, Leica Camera AG, Wetzlar, Deutschland) und einem Auflichtmikroskop (Stemi SV 11, Carl Zeiss, Jena, Deutschland) bei standardisierter Vergrößerung pro Zahn sieben digitale Aufnahmen.

1. Eine Übersichtsaufnahme beider Zahnhälften zusammen

2. Je eine Leeraufnahme der Rillen und halbkugelförmigen Gruben

3. Je eine Aufnahme der gefüllten Rillen und halbkugelförmigen Gruben

4. Je eine Aufnahme der Rillen und halbkugelförmigen Gruben nach dem Reinigungsvorgang mit Hilfe der unterschiedlichen Methoden.

Alle Aufnahmen erfolgten unter denselben Lichtverhältnissen und standardisierter Einstellung von Kamera und Auflichtmikroskop.

\subsection{Befüllen der Vertiefungen}

Das Befüllen der Vertiefungen im Wurzelkanal erfolgte unter standardisierter Vergrößerung unter einem Mikroskop. Die Rillen und halbkugelförmigen Gruben wurden mit Ledermix (RIEMSER Pharma $\mathrm{GmbH}$, Greifswald, Deutschland) befüllt, das unter geringem Druck mit einer Injektionskanüle (Ultradent Products, Inc., South Jordan, Utah, USA) in die jeweilige Kavität eingebracht wurde. Überschüsse wurden mit Hilfe von Papierspitzen aus dem Wurzelkanallumen entfernt. Nachfolgend wurde bei standardisierter Vergrößerung unter einem Auflichtmikroskop ein digitales Bild der befüllten Kavitäten erstellt (Abbildung 3C und 3-D). 
Anschließend erfolgte unter einem Mikroskop das spaltfreie Zusammensetzen der Zahnhälften. Um die Situation zu stabilisieren und ein späteres Austreten der Spülflüssigkeit zu vermeiden, wurde, ebenfalls unter einem Mikroskop, Zervikalwachs (Renfert $\mathrm{GmbH}$, Hilzingen, Deutschland) in die Längsrillen eingebracht und der apikale Bereich mit Klebewachs verschlossen (Renfert $\mathrm{GmbH}$, Hilzingen, Deutschland). Die Zähne wurden in die zuvor angefertigten Acrylröhrchen mit individuellen Silaplastschlüsseln eingegliedert. Dies diente einer weiteren Sicherung der spaltfreien Zuordnung der Zahnhälften zueinander. Mit Hilfe einer Injektionskanüle wurde das Ledermix in den gesamten Wurzelkanal eingebracht. Das Einbringen erfolgte unter leichtem Druck und einer flüssigen Bewegung von apikal nach koronal. Um das Ledermix im Wurzelkanal zu verdichten, wurde ein Wattekügelchen (Pluradent $\mathrm{GmbH}$ \& Co. KG, Offenbach, Deutschland) im Bereich des Wurzelkanal-einganges positioniert. Für einen koronal dichten Verschluss des Wurzelkanals wurde abschließend Cavit (3M ESPE, Neuss, Deutschland) in einer Schichtstärke von $2 \mathrm{~mm}$ appliziert.

Weiter wurde von jeder Zahnprobe ein digitales Röntgenbild (Heliodent Plus, Sirona, Bensheim; Einstellung: $7 \mathrm{~mA}, 60 \mathrm{kV}, 0,16 \mathrm{sec}$ ) erstellt, um beurteilen zu können, ob der Wurzelkanal in seiner Gesamtheit mit Ledermix befüllt wurde (Abbildung 4). War dies nicht der Fall, wurde die jeweilige Zahnprobe wieder gereinigt, erneut mit Ledermix befüllt und einer weiteren Röntgenkontrolle unterzogen.

Anschließend wurden die Zähne für 10 Tage bei $37^{\circ} \mathrm{C}$ und $100 \%$-iger Luftfeuchtigkeit im Inkubator (Climacell 111, MMM Medcenter, München, Deutschland) gelagert. Die Zahnproben wurden in einem mit aqua dest. (B. Braun, Melsungen, Deutschland) befüllten Kunststoffbehälter aufbewahrt. 


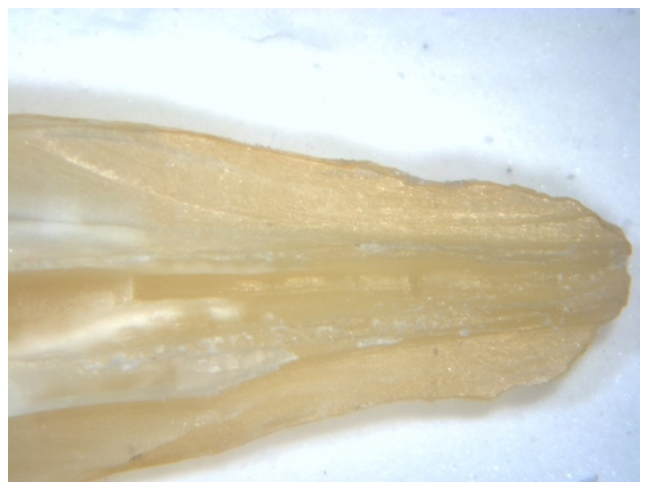

Abbildung 3-A: Leeraufnahme Rille

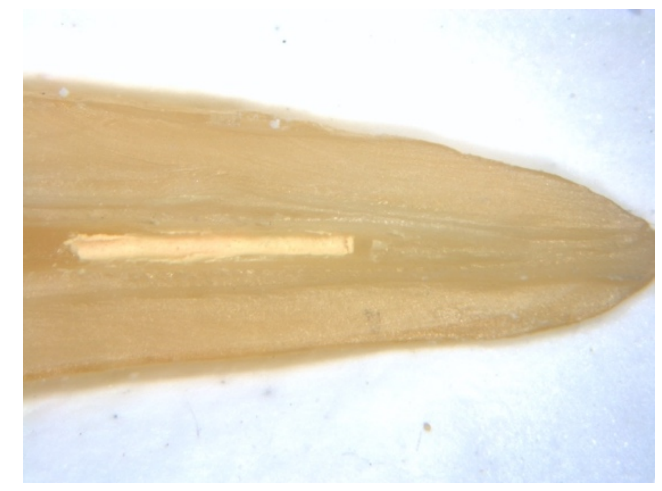

Abbildung 3-C: Rille befüllt

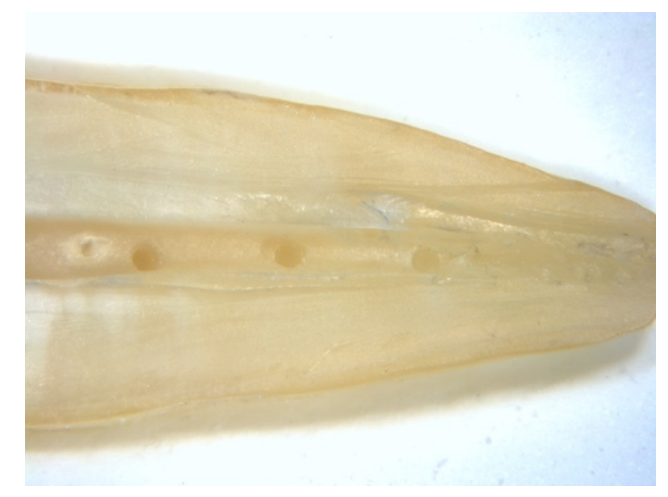

Abbildung 3-B: Leeraufnahme Gruben

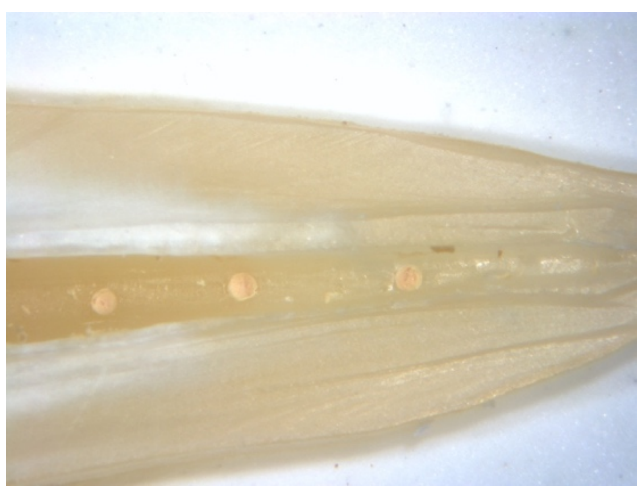

Abbildung 3-D: Gruben befüllt

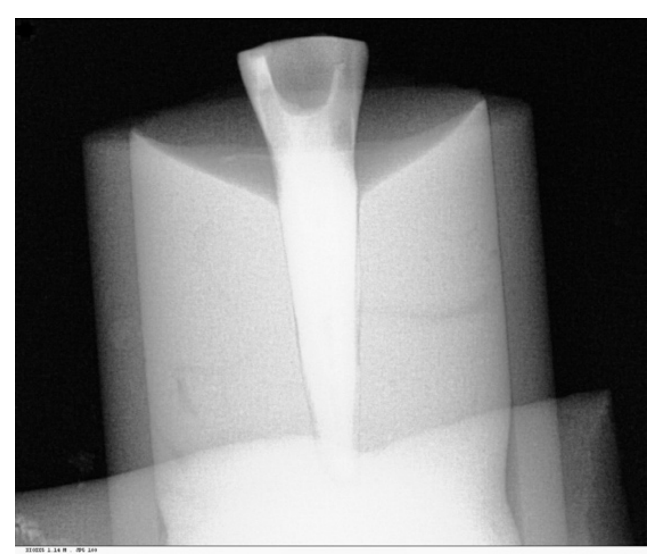

Abbildung 4: Röntgenkontrolle einer homogenen Ledermixeinlage 


\subsection{Entfernung der medikamentösen Ledermix-Einlage}

Zur Entfernung der Ledermix-Einlage kamen unter Verwendung von aqua dest. als Spülmedium unterschiedliche Spültechniken zum Einsatz.

Die Spülflüssigkeit wurde manuell in die Wurzelkanäle eingebracht. Dies erfolgte mit einer 5 ml-Spritze und einer 30gauge NaviTip-Kanüle (Endoneedle, Vedefar N.V, Dilbeek, Belgien). Es war darauf zu achten, dass die Spülkanüle ohne Wandkontakt auf Arbeitslänge minus $2 \mathrm{~mm}$ in den Wurzelkanal eingebracht wurde.

Zur Aktivierung der Spülflüssigkeit dienten in dieser Studie entweder das schallgestützte System EDDY (VDW GmbH, München, Deutschland), IRRI S Ultraschallspitzen (VDW GmbH, München, Deutschland) oder der XP-endo® Finisher (FKG Dentaire SA, La Chaux-de-Fonds, Schweiz). Die Spülung der Zahnproben folgte einem standardisierten Protokoll.

Je 15 der extrahierten Zähne wurden randomisiert der Versuchsgruppe I: EDDY, II: IRRI S Ultraschallspitzen und III: XP-endo Finisher zugeteilt. 10 Zähne dienten als Kontrollgruppe und sieben Zähne wurden für die Vorversuche verwendet.

Nach der Lagerung der Proben im Inkubator wurde zunächst das Cavit mit Hilfe einer nicht-diamantierten Ultraschallspitze und einem SonicFlex (beide KaVo Dental $\mathrm{GmbH}$, Biberach/Riß, Deutschland) entfernt. Auch das Wattekügelchen wurde aus dem Wurzelkanaleingang entfernt.

Anschließend folgte die Reinigung der Wurzelkanäle mit den bereits aufgeführten Spültechniken. Die jeweiligen Spülprotokolle für die Versuchsgruppen EDDY, IRRI S Ultraschallspitzen und XP-endo Finisher sind in Tabelle 5 dargestellt. 
Tabelle 5: Spülprotokoll

\section{EDDY}

- Spülung manuell mit $1 \mathrm{ml}$ aqua dest. mit einer $5 \mathrm{ml}$-Spritze und einer 30gauge NaviTip-Kanüle für $30 \mathrm{sec}$

- Penetration des Wurzelkanals auf Arbeitslänge mit einem Reamer ISO 10

- Einbringen des EDDY in den Wurzelkanal auf Arbeitslänge minus $2 \mathrm{~mm}$

- Aktivierung des schallgestützten EDDY bei 3,0 bar und $5.000 \mathrm{~Hz}$ nach Einbringen von $2 \mathrm{ml}$ aqua dest.

- in Zyklen von 3x $20 \mathrm{sec}$ und je 10 vertikalen Bewegungen von 2 bis $3 \mathrm{~mm}$

- Abschlussspülung manuell mit $2 \mathrm{ml}$ aqua dest. und einer $5 \mathrm{ml}$-Spritze mit einer 30gauge NaviTip-Kanüle

\section{IRRI S Ultraschallspitze}

- Spülung manuell mit $1 \mathrm{ml}$ aqua dest. mit einer $5 \mathrm{ml}$-Spritze und einer 30 gauge NaviTip-Kanüle für $30 \mathrm{sec}$

- Penetration des Wurzelkanals auf Arbeitslänge mit einem Reamer ISO 10

- Einbringen der Ultraschallspitze in den Wurzelkanal

- Aktivierung der schallgestützten Ultraschallspitze nach Einbringen von $2 \mathrm{ml}$ aqua dest.: VDW.Ultra Geräteeinstellung IRRI (im Bereich 0 bis 30)

- in Zyklen von 3x $20 \mathrm{sec}$ bei kontinuierlicher Bewegung der Ultraschallspitze

- Abschlussspülung manuell mit $2 \mathrm{ml}$ aqua dest. und einer $5 \mathrm{ml}$-Spritze mit 30gauge NaviTip-Kanüle

\section{XP-endo Finisher}

- Spülung manuell mit $1 \mathrm{ml}$ aqua dest. mit einer $5 \mathrm{ml}$-Spritze und einer 30 gauge NaviTip-Kanüle für $30 \mathrm{sec}$

- Penetration des Wurzelkanals auf Arbeitslänge mit einem Reamer ISO 10

- Einbringen des XP-endo Finishers in den Wurzelkanal

- Aktivierung des XP-endo Finishers nach Einbringen von $2 \mathrm{ml}$ aqua dest. in den Wurzelkanal

- Befüllen der koronalen Zugangskavität mit aqua dest. nach Aktivierung des XP-endo Finishers, Zyklen von 3x $20 \mathrm{sec}$

- Abschlussspülung manuell mit $2 \mathrm{ml}$ aqua dest. und einer $5 \mathrm{ml}$-Spritze mit 30gauge NaviTip-Kanüle. 
Die Spülung mit dem XP-endo Finisher erfolgte in einem auf $35^{\circ} \mathrm{C}$ erwärmten Wasserbad, um die Situation der in vivo vorherrschenden Temperaturen im Wurzelkanal zu gewährleisten und somit die Fähigkeiten der MaxWire- Legierung ausnutzen zu können. Dabei musste darauf geachtet werden, dass während des Spülvorganges keine weitere Flüssigkeit aus dem Wasserbad in die Zahnprobe gelangte.

\subsection{Auswertung}

Die Auswertung der gereinigten Zahnhälften erfolgte anhand eines ScoreSystems. Dieses wurde mit Hilfe der angefertigten Bildaufnahmen erhoben. Der Score wurde auf die Aufnahmen der gereinigten Gruben und Rillen angewandt, wobei im Falle einer schwierigen Entscheidungsfindung die jeweilige Leeraufnahme zur Hilfe gezogen werden konnte.

Die Auswertung wurde von zwei unabhängigen Untersuchern durchgeführt, welche zuvor kalibriert wurden. Die Beurteilung der Bildaufnahmen erfolgte an einem farbkalibrierten Monitor und unter standardisierten Bedingungen.

Als Score diente eine abgeänderte Form des von Lee et al. (2004a) publizierten Score-Systems, welches in Tabelle 6 dargestellt ist. Es beinhaltet vier Abstufungen, wobei die Intervalle gleich groß sind.

Tabelle 6: Darstellung der Score-Werte nach Lee et al. (2004a)

- Score 0: Gruben oder Rillen sind zwischen 0\%-25\% mit Ledermix gefüllt (Abbildung 5-A und 6-A)

- Score 1: Gruben oder Rillen sind zwischen 26\% - 50\% mit Ledermix gefüllt (Abbildung 5-B und 6-B)

- Score 2: Gruben oder Rillen sind zwischen 51\% - 75\% mit Ledermix gefüllt (Abbildung 5-C)

- Score 3: Gruben oder Rillen sind zwischen $76 \%$ - 100\% mit Ledermix gefüllt (Abbildung 5-D und 6-C). 


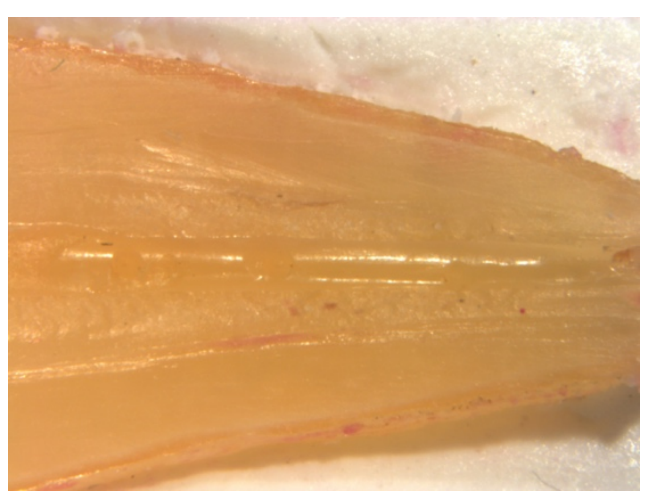

Abbildung 5-A: Gruben Score 0

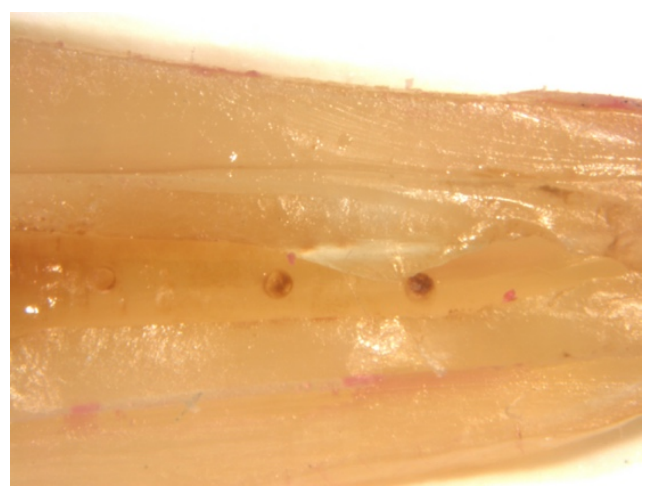

Abbildung 5-C: Gruben Score 2

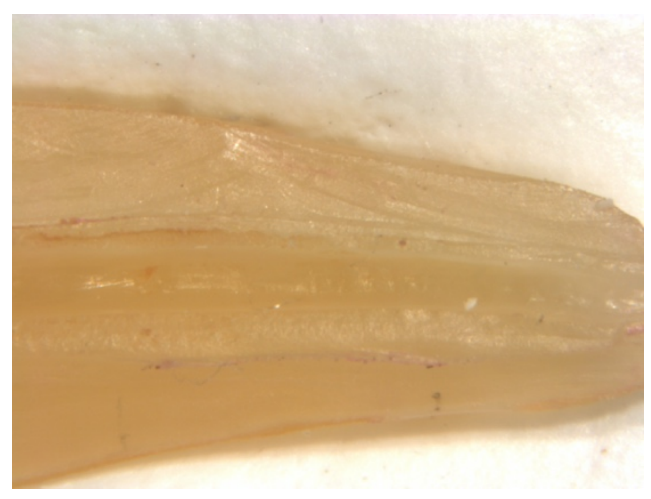

Abbildung 6-A: Rille Score 0

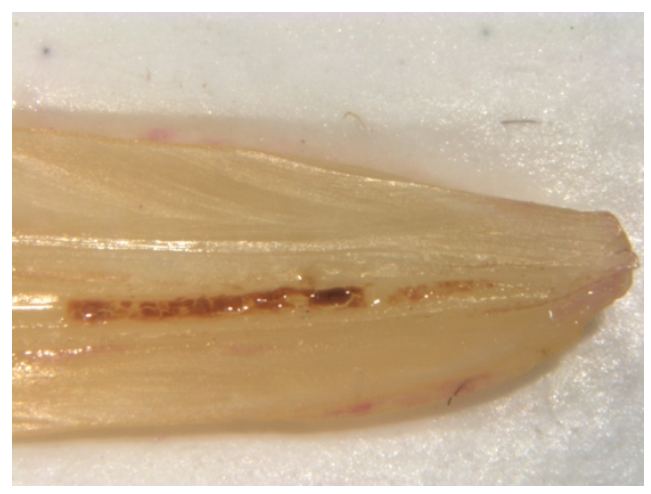

Abbildung 6-C: Rille Score 3

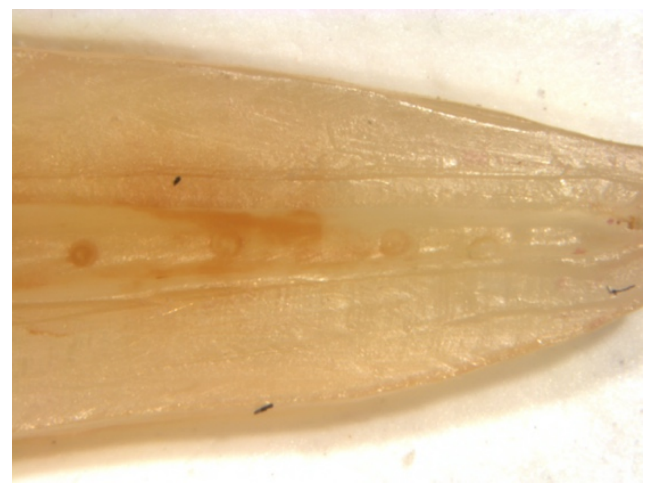

Abbildung 5-B: Gruben Score 1

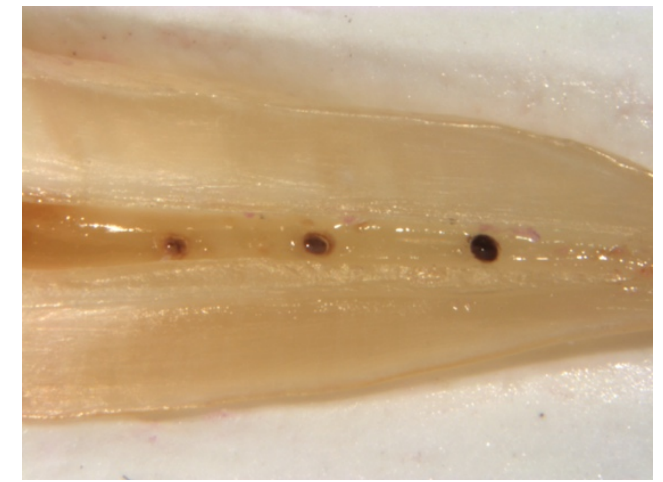

Abbildung 5-D: Gruben Score 3

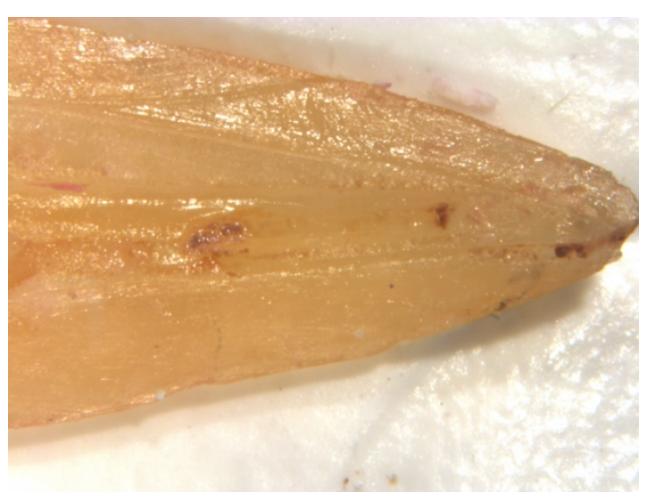

Abbildung 6-B: Rille Score 1 


\subsubsection{Kalibrierung der Untersucher}

Die Kalibrierung der Untersucher erfolgte anhand des oben beschriebenen Score-Systems. Als Grundlage dienten zufällig ausgewählte Bildaufnahmen der Vorversuche. Die beiden Untersucher nahmen die Auswertung der Aufnahmen separat voneinander vor. Kam es zu Unstimmigkeiten bezüglich der ScoreZugehörigkeit, wurden diese im Nachhinein besprochen. Dieses Procedere wurde nach weiteren sieben Tagen wiederholt.

\subsubsection{Statistische Auswertung}

Zur Überprüfung der Reliabilität der Ergebnisse wurde die intra- und interindividuellen Reproduzierbarkeit ermittelt. Hierzu diente die Berechnung der Cohens-Kappa-Werte.

Es kamen für die statistische Auswertung nicht parametrische Analyseverfahren zur Anwendung.

Zur Bestimmung der Signifikanzunterschiede zwischen den drei Aktivierungsmethoden wurde als Testverfahren ein Median-Vergleich bestimmt. Um festzustellen, ob die jeweilige apikale Vertiefung einen Einfluss auf das Reinigungsverhalten der jeweiligen Spülmethode hat, wurde zur Bestimmung der Signifikanzunterschiede innerhalb jeder Aktivierungsmethode der Wilcoxon-Test durchgeführt.

Anhand paarweiser Vergleiche wurden signifikante Unterschiede zwischen den Spültechniken festgestellt. Die Durchführung erfolgt mit der Bonferroni-Korrektur.

Das Signifikanzniveau wurde auf $\alpha \leq 0,05$ festgelegt.

Die statistische Auswertung wurde mit Statistika 12.0 durchgeführt. Diagramme und Tabellen wurden mit Statistica 12.0 und Excel Microsoft Office 365 angefertigt. 


\section{Ergebnisse}

\subsection{Reproduzierbarkeit der Ergebnisse}

Nach abgeschlossener Kalibrierung der Untersucher wurden die Reproduzierbarkeit der Ergebnisse zwischen jedem Untersucher für sich (intraobserver reproducibility) und die Übereinstimmung zwischen den beiden Untersuchern betrachtet (interobserver agreement).

\subsubsection{Intraindividuelle Reproduzierbarkeit}

Nach zweifacher Bewertung der Zahnproben wurde die Reproduzierbarkeit der Bewertung für den jeweiligen Untersucher überprüft. Hinsichtlich der intraindividuellen Reproduzierbarkeit ergab sich zwischen der ersten und zweiten Kalibrierung für den Untersucher A für die Zahnhälften mit den Rillen ein KappaWert von $\mathrm{k}=$ 0,917 (Tabelle 7) und für die Zahnhälften mit den halbkugelförmigen Gruben ein Kappa-Wert von k = 1,000 (Tabelle 7). Untersucher B erreichte für die Zahnhälften mit den Rillen einen Kappa-Wert von $k=0,683$ (Tabelle 7) und für die Zahnhälften mit den halbkugelförmigen Gruben einen Kappa-Wert von $\mathrm{k}=0,833$ (Tabelle 7).

Ein Wert des Cohens-Kappa-Koeffizienten von $\geq 0,8$ wird als eine (fast) vollständige Übereinstimmung gewertet, ein Wert von $k>0,6$ gilt als eine starke Übereinstimmung. Somit ist für beide Untersucher eine gute intraindividuelle Reproduzierbarkeit gewährleistet.

\subsubsection{Interindividuelle Reproduzierbarkeit}

Auch bei der Überprüfung der interindividuellen Übereinstimmung wurden sowohl die Zahnhälften mit den Rillen als auch die mit den Gruben von beiden Untersuchern bewertet. Für die interindividuelle Reproduzierbarkeit der beiden Untersucher ergab sich bei allen Bewertungsdurchgängen ein Kappa-Wert von $\geq 0,8$ wobei der niedrigste Wert bei $k=0,841$ lag. Die interindividuelle Übereinstimmung kann damit ebenfalls als gut bezeichnet werden. 
Tabelle 7: Kappa-Werte beider Untersucher für die intraindividuelle Reproduzierbarkeit

\begin{tabular}{|l|c|c|c|}
\hline & Kappa-Wert & $\begin{array}{c}\text { Asymptomatischer } \\
\text { Standardfehler }\end{array}$ & $\begin{array}{c}\text { Anzahl gültige } \\
\text { Fälle }\end{array}$ \\
\hline $\begin{array}{l}\text { Rillen } \\
\text { Untersucher A }\end{array}$ & 0,917 & 0,082 & 30 \\
\hline $\begin{array}{l}\text { Rillen } \\
\text { Untersucher B }\end{array}$ & 0,683 & 0,148 & 30 \\
\hline $\begin{array}{l}\text { Gruben } \\
\text { Untersucher A }\end{array}$ & 1,000 & 0,000 & 30 \\
\hline $\begin{array}{l}\text { Gruben } \\
\text { Untersucher B }\end{array}$ & 0,833 & 0,086 & 30 \\
\hline
\end{tabular}

\subsection{Ergebnisse der Hauptversuche}

\subsubsection{Signifikanztests}

Da die Proben anhand eines Score-Systems bewertet wurden und die Daten nicht normalverteilt vorlagen, wurde zur Bestimmung der Signifikanz ein nichtparametrisches Verfahren gewählt. Dabei wurde das Signifikanzniveau auf $\alpha \leq 0,05$ festgelegt.

\subsubsection{Unterschiede der Aktivierungsmethoden}

Zur Bestimmung der Signifikanzunterschiede zwischen allen drei Spültechniken wurde als Testverfahren ein Median-Vergleich gewählt. Der Test wurde für beide Arten der Vertiefungen durchgeführt.

Als Nullhypothese wurde angenommen, dass sich die Mediane der Spültechniken nicht unterscheiden. Nach der Auswertung der Stichproben ergab sich für beide Arten der Vertiefungen ein $p$-Wert kleiner als 0,05. Dieses Ergebnis zeigt das Vorhandensein eines signifikanten Unterschiedes innerhalb der drei Testgruppen an. 
Zur Feststellung, zwischen welchen Spülmethoden ein signifikanter Unterschied vorliegt, wurden paarweise Vergleiche durchgeführt. Die Durchführung erfolgte mit der Bonferroni- Korrektur.

Diese Vergleiche ergaben zwischen der Testgruppe 1 (XP-endo Finisher) und Testgruppe 2 (EDDY) und auch zwischen der Testgruppe 1 und Testgruppe 3 (Ultraschallspitzen) einen p-Wert kleiner als 0,05. Bei den Stichproben mit den Gruben lag der $p$-Wert bei 0,006 und bei denen mit Vertiefungen bei 0,043. Somit liegt bei diesen Vergleichen ein signifikanter Unterschied vor.

Zwischen den Testgruppen 2 und 3 lag der p-Wert für beide Vertiefungen bei 1,0. Das Ergebnis zeigt, dass zwischen diesen beiden Gruppen, EDDY und Ultraschall, kein signifikanter Unterschied festgestellt werden kann.

\subsubsection{Einfluss des Vertiefungstyps}

Um festzustellen, ob die Art der Vertiefung eine Auswirkung auf die jeweilige Spülmethode hat, wurde zur Bestimmung der Signifikanzunterschiede innerhalb jeder einzelnen Spülmethode der Wilcoxon-Test durchgeführt.

Nach Durchführung des Wilcoxon-Tests ergab sich für die Testgruppen 1 und 3 das Ergebnis, die Nullhypothese abzulehnen. Die Nullhypothese besagt, dass kein Unterschied zwischen den Vertiefungen in Bezug auf die Reinigungswirkung vorliegt. Durch die Ablehnung der Nullhypothese zeigt sich zwischen den Gruppen XP-endo Finisher und den Ultraschallspitzen ein signifikanter Unterschied hinsichtlich der Reinigungserfolge in Gruben und Rillen.

In der Testgruppe 2 wurde nach Durchführung des Tests die Nullhypothese beibehalten. In der Gruppe EDDY konnte somit kein signifikanter Unterschied in der Reinigungswirkung zwischen den Zahnhälften mit den Gruben und denen mit den Rillen festgestellt werden.

Das bedeutet, dass die Art der Vertiefungen für die Testgruppen 1 und 3 einen Unterschied hinsichtlich der Reinigungserfolge darstellt. Die Rillen waren signifikant besser gereinigt als die halbkugelförmigen Gruben. In der Testgruppe 2 wurden beide Vertiefungen gleich gut gereinigt. 


\subsection{Absolute und relative Häufigkeit}

Die Verteilung der absoluten Score-Häufigkeiten wird in Tabelle 8 gezeigt, die relativen Score-Häufigkeiten sind in Abbildung 7 dargestellt.

Insgesamt wurde Score 0 am häufigsten vergeben, gefolgt von Score 1. Der Score-Wert 2 wurde lediglich in der Gruppe XP-endo Finisher und den Zahnhälften mit den Gruben vergeben. Score 3 wurde ebenfalls nur in der Gruppe XP-endo Finisher vergeben, jedoch sowohl in den Zahnhälften mit den Rillen als auch in denen mit Gruben.

Die Ultraschallspitzen und EDDY erzielten größtenteils Score-Werte von 0, wobei als schlechtester Score-Wert der Wert 1 vergeben wurde. Dies bedeutet, dass die Ledermixrückstände höchstens im Bereich von $>25 \%$ bis $50 \%$ lagen.

Einzig die beiden Gruppen mit dem XP-endo Finisher als Spülmethode zeigten Ledermixrückstände von $50 \%$ bis $75 \%$ (Score 2 ) und bis zu $100 \%$ (Score 3 ).

Tabelle 8: Übersicht der absoluten Häufigkeit bei der Verteilung der Score-Werte

\begin{tabular}{|l|c|c|c|c|}
\hline Gruppe & Score 0 & Score 1 & Score 2 & Score 3 \\
\hline $\begin{array}{l}\text { XP-endo Finisher }+ \\
\text { Rillen }\end{array}$ & 6 & 7 & 0 & 2 \\
\hline $\begin{array}{l}\text { XP-endo Finisher }+ \\
\text { Gruben }\end{array}$ & 1 & 9 & 2 & 3 \\
\hline $\begin{array}{l}\text { EDDY }+ \\
\text { Rillen }\end{array}$ & 14 & 1 & 0 & 0 \\
\hline $\begin{array}{l}\text { EDDY }+ \\
\text { Gruben }\end{array}$ & 12 & 3 & 0 & 0 \\
\hline $\begin{array}{l}\text { Ultraschall }+ \\
\text { Rillen }\end{array}$ & 14 & 1 & 0 & 0 \\
\hline $\begin{array}{l}\text { Ultraschall }+ \\
\text { Gruben }\end{array}$ & 10 & 5 & 0 & 0 \\
\hline
\end{tabular}




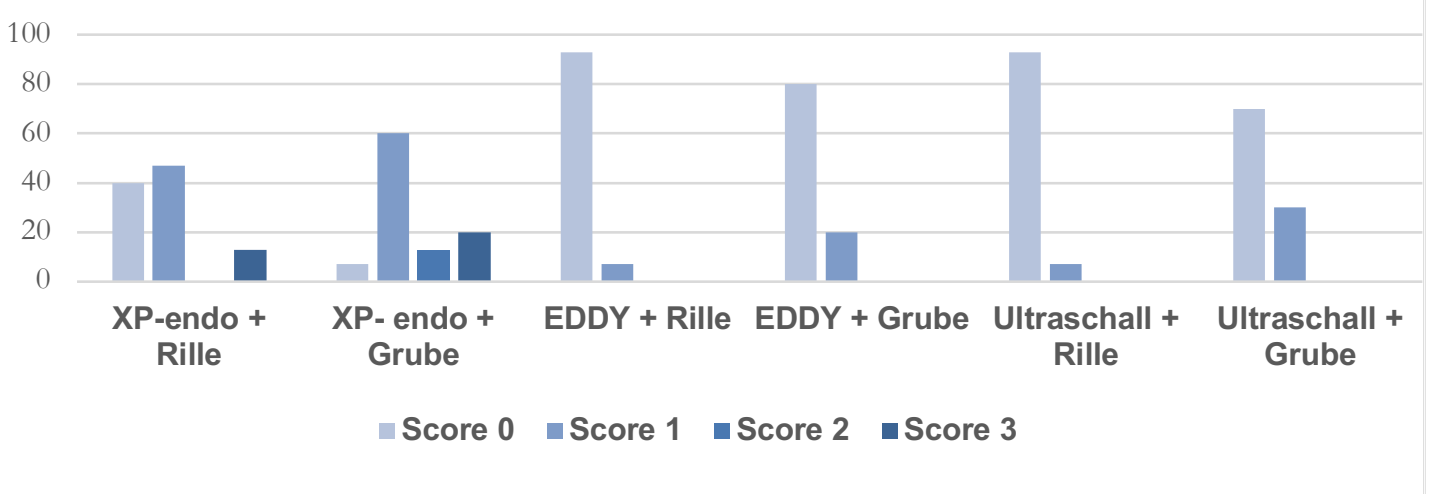

Abbildung 7: Übersicht der relativen Häufigkeit bei der Verteilung der Score-Werte

Im Hinblick auf die relativen Häufigkeiten der Score-Werte lässt sich feststellen, dass für die Zahnhälften mit den Rillen die besseren Spülergebnisse erzielt werden konnten. So erzielten die Ultraschallspitzen und EDDY in $93 \%$ einen Ledermixrückstand von unter $25 \%$ (Score 0 ), wobei die fehlenden $7 \%$ jeweils auf den Score-Wert 1 entfielen. Ähnlich stellt sich die Verteilung bei den Zahnhälften mit den halbkugelförmigen Gruben dar. Hier erreichte EDDY zu $80 \%$, die Ultraschallspitzen zu 67\% Score 0 und mit 20\% bzw. 33\% den Score 1.

Der XP-endo Finisher erhielt bei den Zahnhälften mit den Rillen in 40\% Score 0 , in $47 \%$ Score 1 und in 13\% Score 3. Bei den Zahnhälften mit den Gruben verteilten sich die Score-Werte mit $7 \%$ auf Score 0 , mit $60 \%$ auf Score 1, mit $13 \%$ auf Score 2 und mit $20 \%$ auf Score 3.

Dies bedeutet, dass EDDY in der Gesamtheit die besten Spülergebnisse erzielen konnte, wobei es keinen signifikanten Unterschied zu den Spülergebnissen der Ultraschallspitzen gab. Der XP-endo Finisher zeigte eine deutlich andere absolute und relative Verteilung der Score-Häufigkeiten. 


\section{Diskussion}

\subsection{Diskussion der Methode}

Das verwendete Studiendesign ist angelehnt an den Versuchsaufbau von Lee et al. (2004a). Bisher wurde dieser Versuchsaufbau hauptsächlich verwendet, um die Effektivität der Entfernung von Kalziumhydroxid oder Debris aus dem Wurzelkanal zu untersuchen (van der Sluis et al. 2005b; van der Sluis et al. 2006; Wigler et al. 2017). Für die Entfernung von Ledermix-Einlagen liegt bislang nur eine Studie vor, in der dieses Studiendesign verwendet wurde. Die Studie vergleicht die Entfernbarkeit von Kalziumhydroxid und Ledermix (Rödig et al. 2011). Da Kalziumhydroxid aufgrund unterschiedlicher Viskosität schwerer zu entfernen ist als Ledermix, ist ein Vergleich der Studien zur Entfernung von Kalziumhydroxid mit der vorliegenden Studie nur begrenzt möglich.

Lee et al. (2004a) präparierten für ihren Versuchsaufbau runde und längliche Vertiefungen mit standardisierten Maßen in die apikalen Bereiche einer Wurzelkanalhälfte. Die Präparation apikaler Rillen soll der Imitation nicht direkt der Spülung zugänglicher Bereiche dienen und die Präparation apikaler Gruben der Imitation von Seitenkanälen. Jedoch ist es auch mit Hilfe der präparierten Vertiefungen schwer, die gesamte Komplexität eines Wurzelkanalsystems widerzuspiegeln.

Es ist nicht auszuschließen, dass mechanisch hergestellte Vertiefungen einfacher zu reinigen sind als anatomisch bedingte Isthmen, Seitenkanäle und ovale Kanalbereiche. Dies würde zu besseren Reinigungserfolgen führen, als es in vivo der Fall wäre und sollte daher in vergleichenden Studien überprüft werden.

Um vergleichbare Ausgangsbedingungen herzustellen, wurden lediglich Zähne mit geradem Wurzelkanallumen gewählt, welche weiter auf eine Einheitslänge von 19 mm eingekürzt wurden. Dies spiegelt jedoch nur die einfachste Form der Kanalgeometrie wider und lässt die komplexeren Formen, wie es bei gekrümmten Kanälen der Fall wäre, außer Acht. Da die Reinigung gekrümmter Kanäle möglicherweise schwieriger wäre und es zu Begradigungen der Wurzelkanäle kommen kann (Goldberg et al. 2004), wurden wie in vielen anderen Studien Zähne mit geradem Wurzelverlauf gewählt (Lee et al. 2004a; Rödig et al. 2010a; Arslan et al. 2015; Pabel und Hülsmann 2017). Andere In-vitro-Studien nutzen 
Plastik- oder Kunstharzblöcke (Lee et al. 2004b; van der Sluis et al. 2005a). Hier ist eine realistische Imitierung der Wurzelmorphologie nicht möglich, da die Eigenschaften des Wurzeldentins und mögliche Interaktionen zwischen Dentin und medikamentöser Einlage nicht reproduziert werden können. Da Studien mit extrahierten Zähnen einer In-vivo-Situation am nächsten kommen, haben diese klinisch eine höhere Relevanz als solche mit künstlich geschaffenen Wurzelkanälen.

Um positive Verfälschungen der Reinigungserfolge zu verhindern, wurde anhand von Röntgenbildern das vollständige und blasenfreie Befüllen der Wurzelkanäle überprüft. Dies ist nötig, um zu gewährleisten, dass jeder Wurzelkanal gleich stark mit Ledermix gefüllt ist.

Für ein gleichmäßiges Reinigungsverhalten wurde durch den Verschluss des Apex mit Hilfe von Klebewachs verhindert, dass während des Spülvorgangs Spülflüssigkeit über den Apex hinaus austreten kann. Ebenfalls sollte so auch im koronalen Wurzelbereich ein adäquates Spülverhalten erzielt werden. Dies ist durch das Einkürzen der Zähne auf eine Einheitslänge jedoch nur bedingt möglich, da die damit oft einhergehende Entfernung der Zahnkrone, und somit eines Spülreservoirs, ein verändertes Spülverhalten bewirkt.

Das Ziel der Versuche war es, zu bestimmen, welche Methode die beste Reinigungswirkung besitzt. Da dies unabhängig vom Spülmedium und dessen chemischer Wirkung beurteilt werden sollte, wurde aqua dest. als Spüllösung gewählt. Aqua dest. alleine ist nicht in der Lage, anorganische oder organische Bestandteile der medikamentösen Einlage aufzulösen. Ein ähnliches Fließverhalten zwischen aqua dest. und $\mathrm{NaOCl}$ konnte nachgewiesen werden (Guerisoli et al. 1998). Somit ist eine gute Vergleichbarkeit mit Studien gegeben, die $\mathrm{NaOCl}$ als Spülmedium verwenden.

Es wurde nach einem Spülprotokoll mit standardisierten Angaben für Menge der Spülflüssigkeit und Dauer des Spülvorgangs gearbeitet. So konnte eine Verfälschung der Ergebnisse innerhalb der drei Gruppen während des Reinigungsvorgangs ausgeschlossen werden.

Die Auswertung wurde anhand digitaler Bilder vorgenommen. Es wurden zum Einen Aufnahmen vor dem Befüllen erstellt, welche später bei der Auswertung der Ledermixrückstände als Orientierungshilfe dienen konnten. Zum Anderen 
wurden die Vertiefungen nach dem Reinigungsvorgang erneut digital erfasst, um die tatsächliche Bewertung der Reinigungserfolge vornehmen zu können. Beide Aufnahmen erfolgten unter standardisierten Bedingungen.

Wie in zahlreichen Studien zuvor angewandt (Rödig et al. 2010a; Keskin et al. 2017; Pabel und Hülsmann 2017; Donnermeyer et al. 2019), erfolgte die Einteilung des in den Vertiefungen verbliebenen Ledermix anhand eines ScoreSystems mit vier Bewertungseinheiten. Diese Art der Score-Einteilung ermöglicht exaktere Aussagen als beispielsweise eine rein dichotome Bewertung mit den Bewertungsmöglichkeiten ja oder nein. Eine Unterteilung in mehr als vier Bewertungseinheiten könnte zu größeren Verunsicherungen der Prüfer hinsichtlich der Zuordnung der Score-Werte führen, was in einer erhöhten Fehlerrate der Bewertungen resultieren könnte.

Das subjektive Empfinden eines Untersuchers oder dessen Vorliebe zu einem bestimmten Score-Wert ist natürlich nicht gänzlich auszuschließen. Um eine gute Reproduzierbarkeit der Ergebnisse zwischen den Untersuchern zu gewährleisten, wurde im Vorfeld der Auswertung eine Kalibrierung der an der Bewertung teilnehmenden Personen durchgeführt. Mit Kappa-Werten die im Durchschnitt bei $k=0,887$ liegen, ist eine gute Reproduzierbarkeit der angewandten Auswertungsmethode und somit der Ergebnisse gegeben.

Andere Studien ermitteln den Reinigungserfolg mit Hilfe eines Micro-CTs, was eine exaktere Volumenbestimmung der Rückstände ermöglicht (Ma et al. 2015; Yang et al. 2020). Jedoch wäre bei Anwendung eines Mikro-CTs eine Präparation der Bereich im apikalen Bereich des Wurzelkanals, welche einer besseren Standardisierung der Proben dienen, nicht möglich.

In dieser Studie wurden für die Hauptversuche pro Gruppe n= 15 Zähne und für die beiden Kontrollgruppen $n=5$ Zähne verwendet. Diese Größenordnung ist auch in weiteren Studien zu finden (Rödig et al. 2011; Topçuoğlu et al. 2015b; Gokturk et al. 2017).

\subsection{Diskussion der Ergebnisse}

Bei der Verwendung einer medikamentösen Einlage während einer Wurzelkanalbehandlung ist es wichtig, diese vollständig wieder aus dem Wurzelkanal zu entfernen. Dies sollte geschehen, bevor die Wurzelkanäle unter 
Verwendung von Sealer und Guttapercha definitiv gefüllt werden, da es sonst zu negativen Interaktionen zwischen Sealer und der medikamentösen Einlage (Margelos et al. 1997; Hosoya et al. 2004) und zu Undichtigkeiten in der Wurzelkanalfüllung kommen kann (Calt und Serper 1999; Kim und Kim 2002; Contardo et al. 2007).

Es wurde gezeigt, dass auch bei der Entfernung der medikamentösen Einlage aus dem Wurzelkanal mehrere Faktoren eine Rolle spielen. So ist der Erfolg abhängig von den verwendeten Spülmedien, der Spüldauer und -menge, der apikalen Präparationsgröße sowie der Aktivierung der Spüllösung.

Die am häufigsten verwendeten Spülmedien sind zurzeit EDTA und $\mathrm{NaOCl}$ (Zehnder 2006). Diese verfügen nachweislich über die Fähigkeit, organische und anorganische Bestandteile einer medikamentösen Einlage aufzulösen und können somit den Reinigungserfolg verstärken. Um diese positiv verstärkende Eigenschaft von Spülflüssigkeiten vernachlässigen zu können, wurde in der vorliegenden Studie auf aqua dest. als Spülmedium zurückgegriffen. Aqua dest. ist nicht in der Lage, Bestandteile einer medikamentösen Einlage aufzulösen, besitzt dabei aber ähnliche Fließeigenschaften wie beispielsweise $\mathrm{NaOCl}$ (Guerisoli et al. 1998).

Spülmenge und -dauer wurden in einem Spülprotokoll festgelegt, welches für jede Methode gleichermaßen angewandt wurde. Das Spülvolumen umfasste jeweils $8 \mathrm{ml}$ bei einer aktivierten Spüldauer von einer Minute. Die apikale Präparation der Wurzelkanäle wurde mit einer Aufbereitungsgröße von 40/.04 so gewählt, dass eine ausreichende Spülleistung möglich war (Ram 1977).

Da schon in vorherigen Studien gezeigt wurde, dass die Reinigung von Wurzelkanälen bei einer Aktivierung der Spülflüssigkeit deutlich erfolgreicher ist als bei der alleinigen manuellen Spülung, wurde auf Letztere in dieser Studie zu Vergleichszwecken verzichtet (Rödig et al. 2010a; Rödig et al. 2010c; Uygun et al. 2017).

\subsubsection{Reinigungswirkung EDDY}

Bei EDDY handelt es sich um eine Polyamidspitze, welche in einem Frequenzbereich von 5000 bis $6000 \mathrm{~Hz}$ arbeitet und somit zu den schallbetriebenen Aktivierungsmethoden gehört. Durch die Materialeigenschaften werden die 
erzeugten Schwingungen mit dem Ergebnis einer oszillierenden Bewegung mit starker Amplitudenauslenkung auf die Polymerspitze übertragen. Dies führt zu den Effekten von Kavitation und Verwirbelung der Spülflüssigkeit, wodurch eine verbesserte Reinigungskraft erreicht wird.

EDDY erzielte in der vorliegenden Studie die besten Reinigungsergebnisse: Lediglich in 4 von 30 Fällen wurde der Score-Wert 1 vergeben, welcher einen Ledermixrückstand von $<25 \%$ bis $50 \%$ anzeigt. Die restlichen 26 Fälle erreichten den Score-Wert 0, was bedeutet, dass im Großteil der Fälle eine Reinigungsleistung von über $75 \%$ bis $100 \%$ erzielt werden konnte. Auch war EDDY als einzige Methode in der Lage, die beiden Vertiefungen, sowohl die Gruben als auch die Rillen, gleich gut von Ledermix zu befreien. In der Reinigungswirkung gab es keinen signifikanten Unterschied zur Gruppe PUI, jedoch zur Gruppe XP-endo Finisher.

Zur Entfernung von Ledermix mit Hilfe des EDDY liegt derzeit keine Studie vor, zur Entfernung von Kalziumhydroxid aus standardisierten Gruben gibt es zwei Studien (Reus 2018; Donnermeyer et al. 2019). Reus (2018) untersuchte die Reinigungsleistungen von PUI, EDDY, EndoActivator und der konventionellen Handspülung. EDDY und PUI waren den anderen beiden Methoden in der Gesamtheit signifikant überlegen. Dabei konnte jedoch kein signifikanter Unterschied in der Reinigungseffizienz der apikalen Rillen zwischen EDDY, PUI und dem EndoActivator gezeigt werden. Auch Donnermeyer et al. (2019) wiesen eine vergleichbare Effizienz hinsichtlich der Säuberung apikaler Rillen nach. Der XP-endo Finisher war in diesem Bereich signifikant unterlegen. Diese Unterschiede waren für die Rillen im koronalen Wurzelbereich nicht nachzuweisen. Die Ergebnisse hinsichtlich der Effizienz von PUI und EDDY stimmen mit den Ergebnissen der vorliegenden Studie überein. Ebenso decken sich die Erkenntnisse bezüglich der schlechteren Reinigungseffektivität des XP. endo Finisher.

Weiter wurde die Effektivität von EDDY bei der Entfernung von Debris und smear layer untersucht. So verglichen Urban et al. (2017) die Reinigungsleistung von PUI, EndoActivator und EDDY und kamen zu dem Ergebnis, dass alle drei der manuellen Spülung deutlich überlegen sind und gleich gute Ergebnisse bei der Entfernung von Debris aufwiesen. Diese Ergebnisse decken sich mit denen von 
Haupt et al. (2020), wobei PUI lediglich bei der Entfernung von smear layer aus gekrümmten Kanälen der konventionellen Handspülung überlegen war, nicht jedoch bei der Beseitigung von Debris.

Auch Conde et al. (2017) zeigten bei der Entfernung von Gewebe aus dem Wurzelkanal, dass keine Unterschiede zwischen PUI, EA und EDDY vorlagen. Plotino et al. (2019) stellten bei der Entfernung von Debris aus künstlichen Wurzelkanälen eine signifikante Überlegenheit von EDDY gegenüber PUI fest.

Die Ergebnisse der vorliegenden Studie hinsichtlich der vergleichbaren Reinigungseffektivität des EDDY mit PUI werden durch die Erkenntnisse der oben genannten Studien bestätigt. Zum XP-endo Finisher liegt momentan nur eine vergleichende Studie vor, welche jedoch zu ähnlichen Beobachtungen kommt (Donnermeyer et al. 2019).

Der EndoActivator (EA) arbeitet wie EDDY im schallaktivierten Bereich und kann in drei Frequenzbereichen von 2000, 6000 und $10000 \mathrm{~Hz}$ eingesetzt werden. Auch der EA arbeitet mit Polymeransätzen und ist daher in Funktions- und Anwendungsweise dem EDDY sehr ähnlich und lässt aufgrund einer größeren Anzahl an Studien zumindest bedingt eine Aussage hinsichtlich der Reinigungsleistung des XP-endo Finisher gegenüber schallbetriebenen Aktivierungsmethoden zu.

Elnaghy et al. (2017) zeigten, dass EA und XP-endo Finisher bei der Entfernung von Debris und smear layer gleich gute Resultate erzielen. Auch bei der Entfernung des Kalziumhydroxidpräparates Pulpdent aus Resorptionskavitäten war der EA in der Reinigungswirkung ebenso effizient wie XP-endo Finisher (Nasab Mobarakeh et al. 2020). Alakshar et al. (2020) zeigten eine Überlegenheit des EA bei der Entfernung von Debris und smear layer auf. Diese Ergebnisse decken sich mit denen dieser Studie zur Entfernung von Ledermix. Keskin et al. (2017) ermittelten bei der Entfernung von $\mathrm{Ca}(\mathrm{OH})_{2}$ aus Resorptionskavitäten hingegen eine Überlegenheit des XP-endo Finisher gegenüber dem EA.

Eine Dominanz des XP-endo Finishers steht im Widerspruch zu den Resultaten der vorliegenden Studie, in welcher EDDY signifikant sauberere Wurzelkanäle erreichen konnte als der XP-endo Finisher. 
Es wird deutlich, dass weitere Studien zur Entfernung der medikamentösen Einlage mit Hilfe des EDDY notwendig sind, ebenso wie Vergleichsstudien zwischen EDDY und dem XP-endo Finisher, um die Ergebnisse dieser Studie hinsichtlich der Reinigungsleistung des EDDY besser einordnen zu können.

Ein weiteres schallbasiertes Instrument zur Aktivierung von Spüllösungen ist Vibringe. Vibringe arbeitet bei einer Frequenz von $150 \mathrm{~Hz}$ und ermöglicht die Zufuhr und die Aktivierung des Spülmediums in einem Schritt. Die speziell angefertigte $10 \mathrm{ml}$ Luer-Lock-Spritze ist mit gängigen Spülnadeln kombinierbar. Der deutlich niedrigere Frequenzbereich sowie die gemeinsame Zufuhr und Aktivierung der Spülflüssigkeit stellen einen großen Unterschied in Funktionsund Anwendungsweise gegenüber EDDY und dem EA dar.

Gokturk et al. (2017) zeigten bei der Entfernung von $\mathrm{Ca}(\mathrm{OH})_{2}$ eine deutliche Unterlegenheit von Vibringe gegenüber PUI. Auch bei der Entfernung von double antibiotic paste konnten Gokturk et al. (2016) diese Ergebnisse bestätigen, wobei es keinen signifikanten Unterschied zwischen Vibringe und der konventionellen Handspülung gab. Der XP-endo Finisher erreichte eine verbesserte Reinigung der Rillen, jedoch ebenfalls ohne signifikanten Unterschied zur Handspülung.

Rödig et al. (2010a) untersuchten die Effizienz von Vibringe, PUI und der Handspülung in der Entfernung von Debris. PUI war den beiden anderen Methoden signifikant überlegen, wobei Vibringe die Rillen signifikant besser reinigte als die konventionelle Handspülung.

Es lassen sich innerhalb der schallbasierten Aktivierungsmethoden deutliche Unterschiede hinsichtlich der Reinigungsleistung feststellen, wobei Vibringe am wenigsten effizient zu sein scheint.

Hier sollten weitere Studien zum Vergleich der Effizienz in der Entfernung von medikamentösen Einlagen aus dem Wurzelkanal mit Hilfe schallbasierter Aktivierungssysteme folgen.

\subsubsection{Reinigungswirkung PUI}

Die passive ultraschallgestützte Spülung arbeitet in einem Frequenzbereich zwischen $25 \mathrm{kHZ}$ und $1 \mathrm{GHz}$, wobei sich die meisten neueren Instrumente um die $30 \mathrm{kHz}$ bewegen. Bei der PUI oszilliert das Instrument frei und ohne 
Dentinkontakt im Wurzelkanal. Dabei entstehen Schwingungen in Form aneinandergereihter Achten, welche eine Kette von Schallbäuchen und Schallknoten entstehen lassen. Dieses führt zu den gewünschten Phänomenen des acoustic streaming und der Mikrokavitationen.

Die in dieser Studie angewandte Ultraschallfeile IRRI S 21/25 ermöglicht aufgrund ihrer Größe und Anwendbarkeit einen Vergleich zu EDDY und zum XPendo Finisher. Auch die IRRI S-Feile arbeitet mit einer ISO-Größe von 25 und sieht das periodische Applizieren der Spülflüssigkeit vor.

PUI erzielte nach EDDY die besten Ergebnisse. So wurde hier in 24 von 30 Fällen der Score 0 und in den restlichen vier Fällen lediglich der Score 1 vergeben. Ein signifikanter Unterschied in Bezug auf die Reinigungswirkung lag lediglich gegenüber dem XP-endo Finisher vor.

Eine ähnliche Verteilung der Score-Werte bei der Entfernung von Ledermix mit Hilfe von Ultraschall zeigten Rödig et al. (2011). So wurden hier bei einer Gesamtprobenanzahl von $n=15$ die Scores 0 und 1 gleichmäßig vergeben, was die guten Ergebnisse in Bezug auf die PUI in dieser Studie stützt. Es wurde jedoch ein signifikanter Unterschied hinsichtlich der Reinigungsleistung der Gruben und Rillen festgestellt, wobei die Rillen signifikant besser gereinigt wurden. Dieses lässt sich möglicherweise auf den größeren Durchmesser der Rillen im Vergleich zu den Gruben zurückführen. Es könnte bei einer größeren Angriffsfläche einfacher sein, das Ledermix aus den Vertiefungen herauszulösen. Ma et al. (2015) untersuchten in einer Mikro-CT-Studie die Entfernung von $\mathrm{Ca}(\mathrm{OH})_{2}$ aus den Wurzelkanälen zweiter Unterkiefermolaren. Im apikalen Bereich wurden durch die Ultraschallspitze 31\% und durch den EndoActivator $28 \%$ des Wurzelkanals nicht von der medikamentösen Einlage befreit. Auch hier wurde kein signifikanter Unterschied zwischen der schallaktivierten und der ultraschallaktivierten Methode festgestellt. Dies stützt tendenziell die Ergebnisse der vorhandenen Studie, kann aufgrund der unterschiedlich verwendeten Instrumente und des Einsatzes von $\mathrm{Ca}(\mathrm{OH})_{2}$ als medikamentöse Einlage aber nur bedingt übertragen werden.

Gokturk et al. (2017) verglichen unter anderem die Reinigungsleistung von PUI und XP-endo Finisher. Sie zeigten, dass die PUI im apikalen Wurzelkanalbereich bei der Entfernung von Kalziumhydroxid dem XP-endo Finisher signifikant 
überlegen war. Dies stimmt mit den Ergebnissen dieser Studie überein. Jedoch ist zu berücksichtigen, dass als Spülmedium $\mathrm{NaOCl}$ und als medikamentöse Einlage Kalziumhydroxid dienten. Bei einem ähnlichen Versuchsaufbau wiesen Wigler et al. (2017) nach, dass PUI und XP-endo Finisher die Rillen apikal gleichermaßen gut reinigen konnten. Momentan liegt in der Literatur keine Studie vor, welche einen Vergleich der Reinigungswirkung von XP-endo Finisher und PUI bei der Verwendung von Ledermix und aqua dest. untersuchte.

Dies lässt eine genaue Einordnung der in dieser Studie vorhandenen Überlegenheit der PUI gegenüber dem XP-endo Finisher nicht zu.

\subsubsection{Reinigungswirkung XP-endo Finisher}

Der XP-endo Finisher gehört zu der Gruppe der Nickel-Titan-Instrumente, welche sich durch die Fähigkeit der Formerinnerung (memory shape) auszeichnen. Bei der Herstellung wird eine MaxWire-Legierung verwendet, welche es dem Instrument ermöglicht, auf unterschiedliche Temperaturen mit einer Formänderung zu reagieren. So ist der XP-endo Finisher bei Raumtemperatur gerade und nimmt bei Körpertemperatur eine Sichelform an. Wird diese Sichel in Rotation versetzt, schwingt das Instrument bis zum Wandkontakt lateralwärts und passt sich so der Wurzelkanalanatomie an. Der XP-endo Finisher arbeitet bei einer optimalen Drehzahl von 800 bis $1000 \mathrm{~min}^{-1}$.

In der vorliegenden Studie erzielte der XP-endo Finisher die schlechtesten Werte. So wurden lediglich in dieser Gruppe die Score-Werte 2 und 3 vergeben. EDDY und PUI erzielten dagegen nur die Scores 0 und 1.

Dies zeigt eine signifikant schlechtere Reinigungsleistung des XP-endo Finishers gegenüber PUI und EDDY. Auch wurden die Gruben signifikant schlechter von Ledermixrückständen befreit als die Rillen. Ein entsprechendes Ergebnis erzielten auch Gokturk et al. (2017).

Der Großteil der momentan verfügbaren Studien zeigt jedoch ähnlich gute Reinigungserfolge des XP-endo Finishers im Vergleich zu PUI und schallbasierten Instrumenten.

Wigler et al. (2017) und Kfir et al. (2018) stellten bei apikalen Rillen keinen signifikanten Unterschied in der Reinigungswirkung zwischen XP-endo Finisher 
und PUI fest. Weiterhin zeigten Keskin et al. (2017), dass XP-endo Finisher und PUI manuell angelegte Resorptionskavitäten gleichermaßen gut reinigten. Lediglich die schallbasierte Methode des EA schnitt signifikant schlechter als die beiden anderen genannten Methoden ab.

Hamdan et al. (2017) stellten eine Überlegenheit des XP-endo Finishers gegenüber der PUI bezüglich des apikalen Reinigungserfolges fest. Jedoch wurden die Wurzelkanäle hier nicht mit Vertiefungen versehen, was einen Vergleich mit den Ergebnissen der vorliegenden Studie nur begrenzt zulässt.

Im direkten Vergleich des XP-endo Finishers mit EDDY und PUI bei der Entfernung von Kalziumhydroxid war der XP-endo Finisher den beiden anderen Aktivierungsmethoden jedoch signifikant unterlegen, was sich mit den Erkenntnissen der hier vorliegenden Studie deckt (Donnermeyer et al. 2019).

Es lässt sich feststellen, dass ein Vergleich der Ergebnisse dieser Studie mit den Daten aus der der aktuellen Literatur nur bedingt möglich ist, da derzeit keine weitere Studie zur Entfernung von Ledermix mit dem XP-endo Finisher vorliegt. Weiter verwendet keine der Studien aqua dest. als Spülflüssigkeit, sondern zumeist $\mathrm{NaOCl}$ oder EDTA. Auch wird in der vorliegenden Studie eine dauerhafte Temperatur von $37^{\circ} \mathrm{C}$ während der Versuchsdurchführung des XP-endo Finisher lediglich angestrebt, um die Fähigkeiten der MaxWire-Legierung ausnutzen zu können. Da dieses durch Arbeiten in einem Wasserbad umgesetzt wurde, kann es hier zu situationsbedingten Temperatur-schwankungen gekommen sein, welche die Leistung des XP-endo Finishers möglicherweise beeinträchtigten.

Es liegen weitere Studien vor, in denen der XP-endo Finisher mit anderen NickelTitan-Aktivierungsmethoden hinsichtlich der Reinigungsleistung verglichen wird. Uygun et al. (2017) führten eine vergleichende Studie von XP-endo Finisher, TRUShape 3D conforming file, PUI und der konventionellen Handspülung hinsichtlich der Entfernung von $\mathrm{Ca}(\mathrm{OH})_{2}$ durch. Die TRUShape 3D conforming file ist ein S-förmiges Nickel-Titan-Instrument. Es wurde gezeigt, dass XP-endo Finsher, PUI und TRUShape 3D gleichermaßen erfolgreich und signifikant besser als die Handspülung in der Entfernung von $\mathrm{Ca}(\mathrm{OH})_{2}$ arbeiteten.

Auch die self-adjusting file ist ein Nickel-Titan-Instrument, welches zur Entfernung der medikamentösen Einlage aus dem Wurzelkanal genutzt werden kann. Sie besteht aus einem hohlen und somit komprimierbaren Netz aus Nickel- 
Titan. Die SAF passt sich der Kanalgeometrie an und wurde zur Präparation und zeitgleichen Spülung des Wurzelkanals entwickelt (Kfir et al. 2018).

Jedoch wurde schon in einigen Studien die Effektivität der SAF hinsichtlich der Entfernung von $\mathrm{Ca}(\mathrm{OH})_{2}$ untersucht. Capar et al. (2014) zeigten, dass die SAF in Kombination mit 2,5\% NaOCl und 17\% EDTA gleich gute Ergebnisse wie die PUI erzielte. Beide waren dabei der Entfernung mit Hilfe der konventionellen Handspülung und EndoVac signifikant überlegen. Jedoch reinigte PUI in Kombination mit 2,5\% $\mathrm{NaOCl}$ die Rillen signifikant besser als die anderen genannten Methoden.

Topçuoğlu et al. (2015b) und Kfir et al. (2018) untersuchten die Effizienz der SAF in der Entfernung von $\mathrm{Ca}(\mathrm{OH})_{2}$. Beide konnten die Ergebnisse von Capar et al. (2014) bestätigen. PUI und SAF reinigten die Rillen signifikant besser als die zu vergleichenden Methoden. Topçuoğlu et al. (2015b) zeigten eine signifikante Überlegenheit der SAF gegenüber CanalBrush, EndoVac, EA und der konventionellen Handspülung bei der Reinigung simulierter Resorptionskavitäten.

Kfir et al. (2018) verglichen die Reinigungserfolge von SAF, PUI, XP-endo Finisher und der Handspülung. SAF, PUI und XP-endo Finisher befreiten die standardisierten Rillen signifikant besser von $\mathrm{Ca}(\mathrm{OH})_{2}$ als die Handspülung.

Zur Entfernung der medikamentösen Einlage wurden in der Literatur noch weitere Methoden untersucht, welche sich in Funktions- und Anwendungsweise von den bisher beschrieben unterscheiden.

\subsubsection{Reinigungswirkung weiterer Aktivierungsmethoden}

\subsubsection{EndoVac}

EndoVac ist ein Spülsystem, welches durch Erzeugen von apikalem Unterdruck arbeitet. So entsteht eine kontinuierliche Sogwirkung, welche die Spülflüssigkeit aus dem Wurzelkanal herauszieht und zeitgleich über das angeschlossene Absaugsystem entfernt.

Capar et al. (2014) überprüften die Reinigungswirkung des EV bezüglich der Entfernung von $\mathrm{Ca}(\mathrm{OH})_{2}$ aus standardisierten Rillen im apikalen Wurzelbereich. 
EV war PUI signifikant unterlegen und erreichte keine signifikant bessere Reinigungsleistung gegenüber der konventionellen Handspülung.

Topçuoğlu et al. (2015b) untersuchten die Effizienz in der Entfernung von $\mathrm{Ca}(\mathrm{OH})_{2}$ aus simulierten Resorptionskavitäten und konnten die Ergebnisse von Capar et al. (2014) bestätigen. PUI und SAF waren dem EV signifikant überlegen, wobei kein signifikanter Unterschied zu CB, EA und der konventionellen Handspülung festgestellt wurde.

Es sollten weitere Studien folgen, welche auch die in dieser Studie nicht berücksichtigten Aktivierungsmethoden hinsichtlich der Entfernung von Ledermix aus standardisierten halbkugelförmigen Gruben und Rillen untersuchen und vergleichen.

Zusammenfassend lässt sich feststellen, dass keine der in dieser Studie geprüften Methoden in der Lage ist, Ledermix vollständig aus dem Wurzelkanal zu entfernen. 


\section{Zusammenfassung}

Ziel dieser Studie war es, die Effektivität der Reinigung von mit Ledermix gefüllten Wurzelkanälen mit Hilfe einer schallgestützten Spültechnik, einer ultraschallgestützten Spülmethode und eines neuartigen Nickel-TitanInstrumentes zu erproben, sowie die angewandten Spültechniken untereinander zu vergleichen.

In der vorliegenden Studie wurden 55 extrahierte, einwurzelige Zähne in drei Versuchsgruppen zu je 15 Zähnen und zwei Kontrollgruppen zu je fünf Zähnen aufgeteilt. Alle Zähne wurden auf eine Einheitslänge von 19 mm gekürzt, bevor sie mit Hilfe von Nickel-Titan-Instrumenten maschinell bei einer Arbeitslänge von 18 mm auf eine Größe von 40/.04 präpariert wurden.

Nach jeder Instrumentierung folgte eine manuelle Spülung des Wurzelkanals. Für die Zwischenspülungen wurden mit einer $5 \mathrm{ml}$-Handspritze und einer 30 gaugeKanüle je $2 \mathrm{ml}$ 3\%-iges $\mathrm{NaOCl}$ in den Wurzelkanal eingebracht. Nach Erreichen der Zielgröße erfolgte auf gleichem Wege eine Abschlussspülung mit je $5 \mathrm{ml}$ 17\%-igem EDTA und 3\%-igem NaOCl.

Mit einer Trennscheibe wurden alle Zähne entlang der mesialen und distalen Längsachsen in zwei Zahnhälften aufgespalten. In jeder Hälfte wurden im apikalen Wurzelbereich halbkugelförmige Gruben von 0,3 mm Durchmesser oder Rillen mit einer Länge von $4 \mathrm{~mm}$ angelegt.

Beide Vertiefungen wurden einzeln mit Ledermix befüllt und die Zahnhälften wieder zusammengesetzt. Anschließend folgten ein komplettes Befüllen des Wurzelkanals mit Ledermix und ein Verschluss der Zahnhälften apikal und lateral mit Hilfe von Zervikalwachs und koronal mit Cavit.

Die anschließende aktivierte Spülung der Wurzelkanäle zur Entfernung von Ledermix erfolgte entweder mit EDDY, IRRI S Ultraschallspitzen oder XP-endo Finisher. Die Gesamtspülzeit betrug jeweils 60 Sekunden, aufgeteilt in drei Spülzyklen von je 20 Sekunden.

Für die Beurteilung der Ergebnisse wurden die Zahnhälften wieder voneinander getrennt und digitale Fotoaufnahmen jeder Zahnhälfte angefertigt. Diese wurden 
von zwei unabhängigen Untersuchern anhand eines vierstufigen Score-Systems ausgewertet.

Die statistische Analyse der Ergebnisse erfolgte anhand nichtparametrischer Verfahren.

Keine der verwendeten Spülmethoden konnte die Vertiefungen vollständig von Ledermix befreien. PUI und EDDY erzielten die besten Ergebnisse, ohne dabei einen signifikanten Unterschied aufzuweisen.

PUI reinigte die halbkugelförmigen Gruben und Rillen gleichermaßen gut. EDDY und XP-endo Finisher befreiten die Rillen signifikant besser von der medikamentösen Einlage als die Gruben.

Der XP-endo Finisher erzielte die schlechtesten Reinigungsergebnisse und war den beiden anderen Spülmethoden dabei signifikant unterlegen.

Für die Reinigung von mit Ledermix gefüllten Wurzelkanälen eignen sich sowohl schall- als auch ultraschallbasierte Aktivierungssysteme. Das neuartige NickelTitan-Instrument XP-endo Finisher schnitt signifikant schlechter ab. Kein System konnte die Einlage vollständig entfernen. 


\section{Anhang}

Tabelle A.1: Übersicht aller vergebenen Score-Werte beider Untersucher

\begin{tabular}{|c|c|c|c|c|}
\hline & Untersucher & & Untersucher & \\
\hline $\begin{array}{l}\text { Proben- } \\
\text { nummer }\end{array}$ & Rille & Gruben & Rille & Gruben \\
\hline 1 & 0 & 0 & 1 & 1 \\
\hline 2 & 0 & 0 & 0 & 0 \\
\hline 3 & 0 & 0 & 0 & 0 \\
\hline 4 & 0 & 0 & 0 & 0 \\
\hline 5 & 1 & 1 & 1 & 1 \\
\hline 6 & 1 & 1 & 2 & 1 \\
\hline 7 & 0 & 0 & 1 & 1 \\
\hline 8 & 0 & 0 & 1 & 1 \\
\hline 9 & 1 & 1 & 2 & 2 \\
\hline 10 & 1 & 0 & 0 & 0 \\
\hline 11 & 0 & 0 & 0 & 0 \\
\hline 12 & 0 & 0 & 1 & 0 \\
\hline 13 & 0 & 0 & 0 & 0 \\
\hline 14 & 0 & 0 & 0 & 0 \\
\hline 15 & 3 & 3 & 2 & 2 \\
\hline 16 & 0 & 0 & 0 & 0 \\
\hline 17 & 0 & 0 & 0 & 0 \\
\hline 18 & 0 & 0 & 1 & 1 \\
\hline 19 & 1 & 1 & 3 & 3 \\
\hline 20 & 0 & 0 & 0 & 0 \\
\hline 21 & 0 & 0 & 0 & 0 \\
\hline 22 & 0 & 0 & 0 & 0 \\
\hline 23 & 3 & 3 & 3 & 3 \\
\hline
\end{tabular}




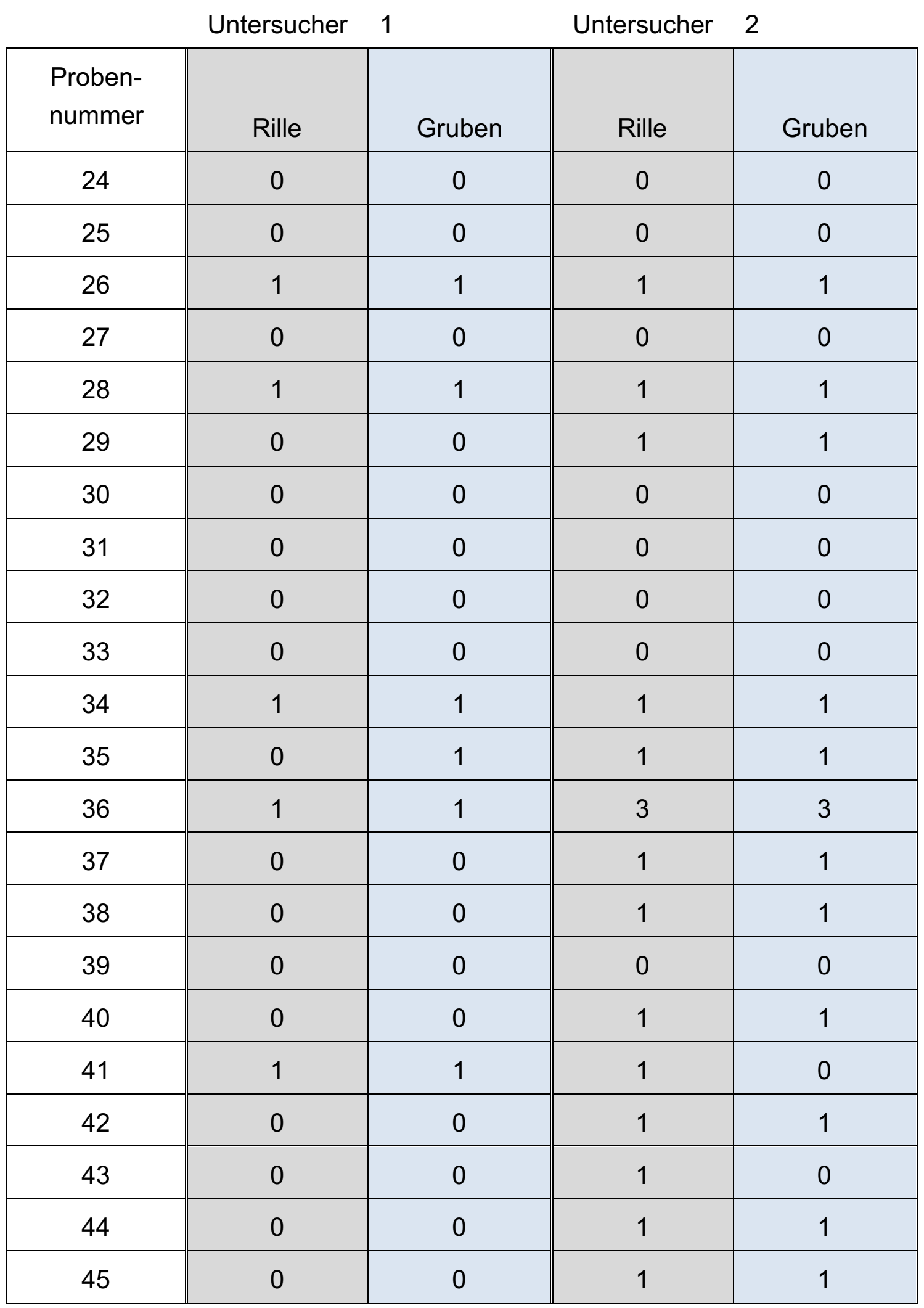


Tabelle A.2: Materialliste

\begin{tabular}{|l|l|}
\hline Produkt & Hersteller \\
\hline Acrylrohr & Alt- intech, Neresheim, Deutschland \\
\hline Aqua dest. & B. Braun, Melsungen, Deutschland \\
\hline Auflichtmikroskop Stemi SV 11 & Carl Zeiss, Jena, Deutschland \\
\hline Cavit & 3M ESPE, Neuss, Deutschland \\
\hline Dental- Mikroskop: OPMI pico & Carl Zeiss, Jena, Deutschland \\
\hline Diamantierte Trennscheibe & Horico, Berlin, Deutschland \\
\hline Diamantierter Schallaufsatz & $\begin{array}{l}\text { KaVo Dental GmbH, Biberach/Riß, } \\
\text { Deutschland }\end{array}$ \\
\hline Diamantschleifkörper & Komet Dental, Lemgo, Deutschland \\
\hline Digitales Röntgengerät Heliodent Plus & $\begin{array}{l}\text { Sirona Dental, Bensheim, } \\
\text { Deutschland }\end{array}$ \\
\hline EDDY Endo Irrigation Tip & VDW GmbH, München, Deutschalnd \\
\hline EDTA (17\%) & $\begin{array}{l}\text { Lege artis Pharma, Dettenhausen, } \\
\text { Deutschland }\end{array}$ \\
\hline Endo IT Motor & VDW GmbH, München, Deutschland \\
\hline Fingerspreader ISO 35 & VDW GmbH, München, Deutschland \\
\hline Gates Glidden Bohrer Größe II und III & Komet Dental, Lemgo, Deutschland \\
\hline Geo Klebewachs & $\begin{array}{l}\text { Renfert GmbH, Hilzingen, } \\
\text { Deutschland }\end{array}$ \\
\hline Geo Zervikalwachs & $\begin{array}{l}\text { Renfert GmbH, Hilzingen, } \\
\text { Deutschland }\end{array}$ \\
\hline Guttapercha- Stifte 40/.02 & VDW GmbH, München, Deutschland \\
\hline Injektionskanüle & $\begin{array}{l}\text { Ultradent Products, Inc., South } \\
\text { Jordan, Utah, USA }\end{array}$ \\
\hline Inkubator Climacell 111 & $\begin{array}{l}\text { MMM Medcenter, München, } \\
\text { Deutschland }\end{array}$ \\
\hline Leica Camera AG, Wetzlar, \\
Deutschland
\end{tabular}




\begin{tabular}{|c|c|}
\hline Produkt & Hersteller \\
\hline Ledermix & $\begin{array}{l}\text { RIEMSER Pharma GmbH, } \\
\text { Greifswald, Deutschland }\end{array}$ \\
\hline Mtwo-Feilen bis 40/.04 & VDW GmbH, München, Deutschland \\
\hline Mtwo-SystemBox & VDW GmbH, München, Deutschland \\
\hline $\mathrm{NaOCl}(3 \%)$ & Hedinger, Stuttgart, Deutschland \\
\hline Papierspitzen (color) & ORBIS Dental, Münster, Deutschland \\
\hline Reamer ISO 10 & VDW GmbH, München, Deutschland \\
\hline Rosenbohrer & Komet Dental, Lemgo, Deutschland \\
\hline Scaler & $\begin{array}{l}\text { HLW, Wernerberg-Köblitz, } \\
\text { Deutschland }\end{array}$ \\
\hline Silaplast Futur & Detax, Ettlingen, Deutschland \\
\hline SONICflex Handstück 2003L & $\begin{array}{l}\text { KaVo Dental GmbH, Biberach/Riß, } \\
\text { Deutschland }\end{array}$ \\
\hline Spritze „BD Discardit II“ $5 \mathrm{ml}$ & $\begin{array}{l}\text { Becton, Dickinson and Company, } \\
\text { Franklin Lake, USA }\end{array}$ \\
\hline Spülnadel VMK EndoNeedle & Vedefar N.V., Mechelen, Belgien \\
\hline Thermometer WA 1030 & Technoline, Wildau, Deutschland \\
\hline $\begin{array}{l}\text { Ultraschallgerät VDW. Ultra - Dental } \\
\text { ultrasonic generator }\end{array}$ & VDW GmbH, München, Deutschland \\
\hline Ultraschallspitze IRRI S 21/25 & VDW GmbH, München, Deutschland \\
\hline Nichtdiamantierter Schallaufsatz & $\begin{array}{l}\text { KaVo Dental GmbH, Biberach/Riß, } \\
\text { Deutschland }\end{array}$ \\
\hline Wachsmesser & $\begin{array}{l}\text { Henry Schein Dental Deutschland } \\
\text { GmbH, Langen, Deutschland }\end{array}$ \\
\hline Wattekugel & $\begin{array}{l}\text { Pluradent GmbH \& Co. KG, } \\
\text { Offenbach, Deutschland }\end{array}$ \\
\hline Winkelstück (grün/rot) & NSK, Nakanishi Inc., Tochigi, Japan \\
\hline XP-endo Finisher & $\begin{array}{l}\text { FKG Dentaire SA, } \\
\text { La Chaux-de-Fonds, Schweiz }\end{array}$ \\
\hline
\end{tabular}




\section{$7 \quad$ Literaturverzeichnis}

Abbott PV, Heithersay GS, Hume WR (1988): Release and diffusion through human tooth roots in vitro of corticosteroid and tetracycline trace molecules from Ledermix paste. Endod Dent Traumatol $\underline{4}, 55-62$

Abou-Rass M, Piccinino MV (1982): The effectiveness of four clinical irrigation methods on the removal of root canal debris. Oral Surg Oral Med Oral Pathol $\underline{54}$, 323-328

Ahmetoğlu F, Şımşek N, Keleş A, Ocak MS, Er K (2013): Efficacy of self-adjusting file and passive ultrasonic irrigation on removing calcium hydroxide from root canals. Dent Mater J $\underline{32}, 1005-1010$

Alakshar A, Saleh ARM, Gorduysus MO (2020): Debris and smear layer removal from oval root canals comparing XP-Endo Finisher, EndoActivator, and manual irrigation: a SEM evaluation. Eur J Dent 14, 626-633

Al-Ali M, Sathorn C, Parashos P (2012): Root canal debridement efficacy of different final irrigation protocols. Int Endod J $\underline{45}$, 898-906

Alturaiki S, Lamphon H, Edrees H, Ahlquist M (2015): Efficacy of 3 different irrigation systems on removal of calcium hydroxide from the root canal: a scanning electron microscopic study. J Endod 41, 97-101

Arslan H, Capar ID, Saygili G, Gok T, Akcay M (2014): Effect of photon-initiated photoacoustic streaming on removal of apically placed dentinal debris. Int Endod J 47, 1072-1077

Arslan H, Akcay M, Capar ID, Saygili G, Gok T, Ertas H (2015): An in vitro comparison of irrigation using photon-initiated photoacoustic streaming, ultrasonic, sonic and needle techniques in removing calcium hydroxide. Int Endod J 4ㅇ, 246-251

Athanassiadis B, Abbott PV, George N, Walsh LJ (2010): An in vitro study of the antimicrobial activity of some endodontic medicaments against Enteroccus faecalis biofilms. Aust Dent J $\underline{55}, 150-155$

Athanassiadis M, Jacobsen N, Parashos P (2011): The effect of calcium hydroxide on the steroid component of Ledermix and Odontopaste. Int Endod J 44, 1162-1169

Athanassiadis M, Jacobsen N, Nassery K, Parashos P (2013): The effect of calcium hydroxide on the antibiotic component of Odontopaste and Ledermix paste. Int Endod J $\underline{46}, 530-537$

Ballal V, Kundabala M, Acharya S, Ballal M (2007): Antimicrobial action of calcium hydroxide, chlorhexidine and their combination on endodontic pathogens. Aust Dent J $\underline{52}, 118-121$ 
Barbosa CA, Gonçalves RB, Siqueira JF, de Uzeda M (1997): Evaluation of the antibacterial activities of calcium hydroxide, chlorhexidine, and camphorated paramonochlorophenol as intracanal medicament. A clinical and laboratory study. J Endod $\underline{23}, 297-300$

Barker BC, Lockett BC (1972): Reaction of dog pulp and periapical tissue to two glucocorticosteroid preparations. Oral Surg Oral Med Oral Pathol $\underline{33}, 249$ 262

Basrani B, Santos JM, Tjäderhane L, Grad H, Gorduysus O, Huang J, Lawrence HP, Friedman S (2002): Substantive antimicrobial activity in chlorhexidinetreated human root dentin. Oral Surg Oral Med Oral Pathol Oral Radiol Endod 94, 240-245

Basrani B, Tjäderhane L, Santos JM, Pascon E, Grad H, Lawrence HP, Friedman $S$ (2003): Efficacy of chlorhexidine- and calcium hydroxide-containing medicaments against Enterococcus faecalis in vitro. Oral Surg Oral Med Oral Pathol Oral Radiol Endod $\underline{96}$, 618-624

Böttcher DE, Hirai VHG, Da Silva Neto UX, Grecca FS (2010): Effect of calcium hydroxide dressing on the long-term sealing ability of two different endodontic sealers: an in vitro study. Oral Surg Oral Med Oral Pathol Oral Radiol Endod 110, 386-389

Boutsioukis C, Lambrianidis T, Kastrinakis E (2009): Irrigant flow within a prepared root canal using various flow rates: a computational fluid dynamics study. Int Endod J 42, 144-155

Boutsioukis C, Verhaagen B, Versluis M, Kastrinakis E, Wesselink PR, van der Sluis LWM (2010a): Evaluation of irrigant flow in the root canal using different needle types by an unsteady computational fluid dynamics model. J Endod $\underline{36}$, 875-879

Boutsioukis C, Gogos C, Verhaagen B, Versluis M, Kastrinakis E, van der Sluis LWM (2010b): The effect of apical preparation size on irrigant flow in root canals evaluated using an unsteady computational fluid dynamics model. Int Endod J 누, 874-881

Boutsioukis C, Lambrianidis T, Verhaagen B, Versluis M, Kastrinakis E, Wesselink PR, van der Sluis LWM (2010c): The effect of needle-insertion depth on the irrigant flow in the root canal: evaluation using an unsteady computational fluid dynamics model. J Endod $\underline{36}, 1664-1668$

Boutsioukis C, Kastrinakis E, Lambrianidis T, Verhaagen B, Versluis M, van der Sluis LWM (2014): Formation and removal of apical vapor lock during syringe irrigation: a combined experimental and computational fluid dynamics approach. Int Endod J ㄴ7, 191-201

Brandt P, Sonntag D (2016): Aktivierung von Spüllösungen Eine Literaturübersicht. Endodontie 25, 7-19 
Bystrom A, Sundqvist G (1985): The antibacterial action of sodium hypochlorite and EDTA in 60 cases of endodontic therapy. Int Endod J 18, 35-40

Bystrom A, Claesson R, Sundqvist G (1985): The antibacterial effect of camphorated paramonochlorophenol, camphorated phenol and calcium hydroxide in the treatment of infected root canals. Endod Dent Traumatol 1, 170-175

Calt S, Serper A (1999): Dentinal tubule penetration of root canal sealers after root canal dressing with calcium hydroxide. J Endod 25, 431-433

Capar ID, Ozcan E, Arslan H, Ertas H, Aydinbelge HA (2014): Effect of different final irrigation methods on the removal of calcium hydroxide from an artificial standardized groove in the apical third of root canals. J Endod $\underline{40}$, 451-454

Carrotte P (2004): Endodontics: Part 9. Calcium hydroxide, root resorption, endoperio lesions. Br Dent J 197, 735-743

Chang JWW, Cheung AWT, Cheung GSP (2015): Effect of root canal dimensions, injection rate, and needle design on the apical extrusion of an irrigant: an in vitro study. J Investig Clin Dent $\underline{6}, 221-227$

Chen BK-J, George R, Walsh LJ (2012): Root discolouration following short-term application of steroid medicaments containing clindamycin, doxycycline or demeclocycline. Aust Endod J $\underline{38}, 124-128$

Chen H, Teixeira FB, Ritter AL, Levin L, Trope M (2008): The effect of intracanal anti-inflammatory medicaments on external root resorption of replanted dog teeth after extended extra-oral dry time. Dent Traumatol $\underline{24}, 74-78$

Chou K, George R, Walsh LJ (2014): Effectiveness of different intracanal irrigation techniques in removing intracanal paste medicaments. Aust Endod J 누, 21-25

Chow TW (1983): Mechanical effectiveness of root canal irrigation. J Endod $\underline{9}$, 475-479

Conde AJ, Estevez R, Loroño G, Valencia de Pablo Ó, Rossi-Fedele G, Cisneros $R$ (2017): Effect of sonic and ultrasonic activation on organic tissue dissolution from simulated grooves in root canals using sodium hypochlorite and EDTA. Int Endod J $\underline{50}$, 976-982

Contardo L, de Luca M, Bevilacqua L, Breschi L, Di Lenarda R (2007): Influence of calcium hydroxide debris on the quality of endodontic apical seal. Minerva Stomatol $\underline{56}, 509-517$

Cunningham WT, Martin H, Forrest WR (1982): Evaluation of root canal débridement by the endosonic ultrasonic synergistic system. Oral Surg Oral Med Oral Pathol $\underline{53}, 401-404$

Davies GE, Francis J, Martin AR, Rose FL, Swain G (1954): 1:6-Di-4'chlorophenyldiguanidohexane (hibitane); laboratory investigation of a new 
antibacterial agent of high potency. Br J Pharmacol Chemother $\underline{9}, 192-$ 196

De-Deus G, Belladonna FG, de Siqueira Zuolo A, Perez R, Carvalho MS, Souza EM, Lopes RT, Silva EJNL (2019): Micro-CT comparison of XP-endo Finisher and passive ultrasonic irrigation as final irrigation protocols on the removal of accumulated hard-tissue debris from oval shaped-canals. Clin Oral Investig 23, 3087-3093

Desai P, Himel V (2009): Comparative safety of various intracanal irrigation systems. J Endod 35, 545-549

Devi AA, Abbott PV (2012): Comparison of the flow characteristics of irrigants with standard and Max-i-Probe needles. Aust Endod J $\underline{38}, 50-54$

Donnermeyer D, Wyrsch H, Bürklein S, Schäfer E (2019): Removal of calcium hydroxide from artificial grooves in straight root canals: sonic activation using EDDY versus Passive Ultrasonic Irrigation and XPendo Finisher. J Endod $\underline{45}, 322-326$

Eftekhar B, Moghimipour E, Pourakbar Jahandideh P, Jalali S, Mahmoudian M (2013): Analgesic effect of odontopaste and a compound intracanal medicament between root canal therapy appointments. Jundishapur J Nat Pharm Prod $\underline{8}, 169-174$

Ehrmann EH, Messer HH, Adams GG (2003): The relationship of intracanal medicaments to postoperative pain in endodontics. Int Endod J $\underline{36}$, 868875

Ehrmann EH, Messer HH, Clark RM (2007): Flare-ups in endodontics and their relationship to various medicaments. Aust Endod J $\underline{33}, 119-130$

Ellerbruch ES, Murphy RA (1977): Antimicrobial activity of root canal medicament vapors. J Endod $\underline{3}, 189-193$

Elnaghy AM, Mandorah A, Elsaka SE (2017): Effectiveness of XP-endo Finisher, EndoActivator, and File agitation on debris and smear layer removal in curved root canals: a comparative study. Odontology $\underline{105}, 178-183$

Estrela C, Sydney GB, Bammann LL, Felippe Júnior O (1995): Mechanism of action of calcium and hydroxyl ions of calcium hydroxide on tissue and bacteria. Braz Dent J $\underline{6}$, 85-90

Estrela C, Pimenta FC, Ito IY, Bammann LL (1998): In vitro determination of direct antimicrobial effect of calcium hydroxide. J Endod 24, 15-17

Farhad A, Mohammadi Z (2005): Calcium hydroxide: a review. Int Dent J $\underline{55}$, 293301

Fatori Popovic S, Lübbers H-T, von Mandach U (2016): Pregnancy and lactation period: Which antibiotic and rinsing solutions? Swiss Dent J $\underline{126}, 598-599$ 
Fava LR, Saunders WP (1999): Calcium hydroxide pastes: classification and clinical indications. Int Endod J $\underline{32}, 257-282$

Gade VJ, Sedani SK, Lokade JS, Belsare LD, Gade JR (2013): Comparative evaluation of debris removal from root canal wall by using EndoVac and conventional needle irrigation: An in vitro study. Contemp Clin Dent $\underline{4}$, 432-436

Georgopoulou M, Kontakiotis E, Nakou M (1993): In vitro evaluation of the effectiveness of calcium hydroxide and paramonochlorophenol on anaerobic bacteria from the root canal. Endod Dent Traumatol $\underline{9}$, 249-253

Gokturk H, Ozkocak I, Buyukgebiz F, Demir O (2016): An in vitro evaluation of various irrigation techniques for the removal of double antibiotic paste from root canal surfaces. J Appl Oral Sci 24, 568-574

Gokturk H, Ozkocak I, Buyukgebiz F, Demir O (2017): Effectiveness of various irrigation protocols for the removal of calcium hydroxide from artificial standardized grooves. J Appl Oral Sci 25, 290-298

Goldberg F, Alfie D, Roitman M (2004): Evaluation of the incidence of transportation after placement and removal of calcium hydroxide. J Endod $\underline{30}, 646-648$

Gomes BPF de A, Ferraz CCR, Garrido FD, Rosalen PL, Zaia AA, Teixeira FB, de Souza-Filho FJ (2002): Microbial susceptibility to calcium hydroxide pastes and their vehicles. J Endod $\underline{28}, 758-761$

Gomes BPFA, Souza SFC, Ferraz CCR, Teixeira FB, Zaia AA, Valdrighi L, Souza-Filho FJ (2003a): Effectiveness of $2 \%$ chlorhexidine gel and calcium hydroxide against Enterococcus faecalis in bovine root dentine in vitro. Int Endod J $\underline{36}, 267-275$

Gomes BPFA, Sato E, Ferraz CCR, Teixeira FB, Zaia AA, Souza-Filho FJ (2003b): Evaluation of time required for recontamination of coronally sealed canals medicated with calcium hydroxide and chlorhexidine. Int Endod J $\underline{36}, 604-609$

Grischke J, Müller-Heine A, Hülsmann M (2014): The effect of four different irrigation systems in the removal of a root canal sealer. Clin Oral Investig $\underline{18}, 1845-1851$

Gu L, Kim JR, Ling J, Choi KK, Pashley DH, Tay FR (2009): Review of contemporary irrigant agitation techniques and devices. J Endod $\underline{35}$, 791804

Guerisoli DMZ, Silva RS, Pécora JD (1998): Evaluation of some physicochemical properties of different concentrations of sodium hypochlorite solutions. Braz Endod J $\underline{3}, 21-3$

Hamdan R, Michetti J, Pinchon D, Diemer F, Georgelin-Gurgel M (2017): The XPEndo Finisher for the removal of calcium hydroxide paste from root canals and from the apical third. J Clin Exp Dent $\underline{9}$, e855-e860 
Hasselgren G, Olsson B, Cvek M (1988): Effects of calcium hydroxide and sodium hypochlorite on the dissolution of necrotic porcine muscle tissue. $\mathrm{J}$ Endod $\underline{14}, 125-127$

Haupt F, Meinel M, Gunawardana A, Hülsmann M (2020): Effectiveness of different activated irrigation techniques on debris and smear layer removal from curved root canals: a SEM evaluation. Aust Endod J 뜨, 40-46

Heithersay GS (1975): Calcium hydroxide in the treatment of pulpless teeth with associated pathology. J Br Endod Soc $\underline{8}, 74-93$

Heling I, Pecht M (1991): Efficacy of Ledermix paste in eliminating Staphylococcus aureus from infected dentinal tubules in vitro. Endod Dent Traumatol $\underline{7}, 251-254$

Hennessey TS (1973): Some antibacterial properties of chlorhexidine. J Periodontal Res Suppl $\underline{12}, 61-67$

Hermann B: Calciumhydroxid als Mittel zum Behandeln und Füllen von Wurzelkanälen. Med. Diss. Würzburg 1920

Hermann B (1930): Dentinobliteration der Wurzelkanale nach der Behandlung mit Kalcium. Zahnärztliche Rundsch $\underline{39}, 888$

Hosoya N, Kurayama H, lino F, Arai T (2004): Effects of calcium hydroxide on physical and sealing properties of canal sealers. Int Endod J $\underline{37}, 178-184$

Hsieh YD, Gau CH, Kung Wu SF, Shen EC, Hsu PW, Fu E (2007): Dynamic recording of irrigating fluid distribution in root canals using thermal image analysis. Int Endod J $\underline{40}, 11-17$

Huang TY, Gulabivala K, Ng YL (2008): A bio-molecular film ex-vivo model to evaluate the influence of canal dimensions and irrigation variables on the efficacy of irrigation. Int Endod J $\underline{41}, 60-71$

Hülsmann M, Rödig T (2005): Die medikamentöse Einlage in der Endodontie. Endodontie 14, 281-301

Jezeršek M, Lukač N, Lukač M (2020): Measurement of simulated debris removal rates in an artificial root canal to optimize laser-activated irrigation parameters. Lasers Surg Med (im Druck; doi 10.1002/lsm.23297)

Jiang LM, Verhaagen B, Versluis M, van der Sluis LWM (2010): Evaluation of a sonic device designed to activate irrigant in the root canal. J Endod $\underline{36}$, 143-146

Johnson M, Sidow SJ, Looney SW, Lindsey K, Niu L, Tay FR (2012): Canal and isthmus debridement efficacy using a sonic irrigation technique in a closed-canal system. J Endod $\underline{38}, 1265-1268$

Keskin C, Sariyilmaz E, Sariyilmaz Ö (2017): Efficacy of XP-endo Finisher File in removing calcium hydroxide from simulated internal resorption cavity. $J$ Endod 43, 126-130 
Kfir A, Blau-Venezia N, Goldberger T, Abramovitz I, Wigler R (2018): Efficacy of self-adjusting file, XP-endo finisher and passive ultrasonic irrigation on the removal of calcium hydroxide paste from an artificial standardized groove. Aust Endod J 44, 26-31

Kim SK, Kim YO (2002): Influence of calcium hydroxide intracanal medication on apical seal. Int Endod J $\underline{35}$, 623-628

Kim ST, Abbott P (2000): The effects of Ledermix paste as an intracanal medicament on the discolouration of teeth. Aust Endod J $\underline{26}, 86-87$

Kim ST, Abbott PV, McGinley P (2000): The effects of Ledermix paste on discolouration of mature teeth. Int Endod J $\underline{33}, 227-232$

Kirar DS, Jain P, Patni P (2017): Comparison of different irrigation and agitation methods for the removal of two types of calcium hydroxide medicaments from the root canal wall: an in-vitro study. Clujul Med $\underline{90}, 327-332$

Küçükkaya Eren S, Aksel H, Parashos P (2017): A novel model for testing the efficiency of removal of calcium hydroxide from complex root canal anatomies. Aust Endod J $\underline{43}, 5-10$

Lee SJ, Wu MK, Wesselink PR (2004a): The effectiveness of syringe irrigation and ultrasonics to remove debris from simulated irregularities within prepared root canal walls. Int Endod J 37, 672-678

Lee SJ, Wu MK, Wesselink PR (2004b): The efficacy of ultrasonic irrigation to remove artificially placed dentine debris from different-sized simulated plastic root canals. Int Endod J $\underline{37}, 607-612$

Lenherr P, Allgayer N, Weiger R, Filippi A, Attin T, Krastl G (2012): Tooth discoloration induced by endodontic materials: a laboratory study. Int Endod J 45, 942-949

Leoni GB, Versiani MA, Silva-Sousa YT, Bruniera JFB, Pécora JD, Sousa-Neto MD (2017): Ex vivo evaluation of four final irrigation protocols on the removal of hard-tissue debris from the mesial root canal system of mandibular first molars. Int Endod J $\underline{50}$, 398-406

Li D, Jiang S, Yin X, Chang JWW, Ke J, Zhang C (2015): Efficacy of needle, ultrasonic, and Endoactivator irrigation and photon-induced photoacoustic streaming in removing calcium hydroxide from the main canal and isthmus: an in vitro micro-computed tomography and scanning electron microscopy study. Photomed Laser Surg $\underline{33}, 330-337$

Lin S, Levin L, Peled M, Weiss El, Fuss Z (2003): Reduction of viable bacteria in dentinal tubules treated with clindamycin or tetracycline. Oral Surg Oral Med Oral Pathol Oral Radiol Endod $\underline{96}$, 751-756

Lloyd A, Uhles JP, Clement DJ, Garcia-Godoy F (2014): Elimination of intracanal tissue and debris through a novel laser-activated system assessed using high-resolution micro-computed tomography: a pilot study. J Endod $\underline{40}$, 584-587 
Lloyd A, Navarrete G, Marchesan MA, Clement D (2016): Removal of calcium hydroxide from Weine Type II systems using photon-induced photoacoustic streaming, passive ultrasonic, and needle irrigation: a microcomputed tomography study. J Appl Oral Sci $\underline{24}, 543-548$

Ma JZ, Shen Y, Al-Ashaw AJ, Khaleel HY, Yang Y, Wang ZJ, Peng B, Haapasalo M (2015): Micro-computed tomography evaluation of the removal of calcium hydroxide medicament from C-shaped root canals of mandibular second molars. Int Endod J $\underline{48}, 333-341$

Macedo R, Verhaagen B, Rivas DF, Versluis M, Wesselink P, van der Sluis L (2014): Cavitation measurement during sonic and ultrasonic activated irrigation. J Endod 40, 580-583

Margelos J, Eliades G, Verdelis C, Palaghias G (1997): Interaction of calcium hydroxide with zinc oxide-eugenol type sealers: a potential clinical problem. J Endod 23, 43-48

McGill S, Gulabivala K, Mordan N, Ng Y-L (2008): The efficacy of dynamic irrigation using a commercially available system (RinsEndo) determined by removal of a collagen „bio-molecular film“ from an ex vivo model. Int Endod J 41, 602-608

Metzger Z, Teperovich E, Zary R, Cohen R, Hof R (2010a): The self-adjusting file (SAF). Part 1: respecting the root canal anatomy--a new concept of endodontic files and its implementation. J Endod $\underline{36}, 679-690$

Metzger Z, Teperovich E, Cohen R, Zary R, Paqué F, Hülsmann M (2010b): The self-adjusting file (SAF). Part 3: removal of debris and smear layer-A scanning electron microscope study. J Endod $\underline{36}, 697-702$

Mitchell RP, Yang S-E, Baumgartner JC (2010): Comparison of apical extrusion of $\mathrm{NaOCl}$ using the EndoVac or needle irrigation of root canals. J Endod 36, 338-341

Möller K: Lehrbuch der Pharmakologie für Zahnärzte. JF Lehmanns-Verlag, München 1934

Moser JB, Heuer MA (1982): Forces and efficacy in endodontic irrigation systems. Oral Surg Oral Med Oral Pathol $\underline{53}, 425-428$

Mozo S, Llena C, Chieffi N, Forner L, Ferrari M (2014): Effectiveness of passive ultrasonic irrigation in improving elimination of smear layer and opening dentinal tubules. J Clin Exp Dent $\underline{6}$, e47-e52

Naenni N, Thoma K, Zehnder M (2004): Soft tissue dissolution capacity of currently used and potential endodontic irrigants. J Endod $\underline{30}, 785-787$

Nasab Mobarakeh NM, Taheri A, Rahmanian H, Jafarpour D, Rahmanian S (2020): Effect of various irrigating devices on the removal of two different forms of calcium hydroxide from internal resorption cavities. Int J Dent $\underline{2020}, 8881177$ 
Neuhaus KW, Liebi M, Stauffacher S, Eick S, Lussi A (2016): Antibacterial efficacy of a new sonic irrigation device for root canal disinfection. J Endod $\underline{42}, 1799-1803$

Orstavik D, Haapasalo M (1990): Disinfection by endodontic irrigants and dressings of experimentally infected dentinal tubules. Endod Dent Traumatol $\underline{6}, 142-149$

Ozbay Y, Erdemir A (2018): Effect of several laser systems on removal of smear layer with a variety of irrigation solutions. Microsc Res Tech $\underline{81}, 1214$ 1222

Pabel AK, Hülsmann M (2017): Comparison of different techniques for removal of calcium hydroxide from straight root canals: an in vitro study. Odontology 105, 453-459

Peters OA (2004): Current challenges and concepts in the preparation of root canal systems: a review. J Endod $\underline{30}, 559-567$

Plotino G, Pameijer CH, Grande NM, Somma F (2007): Ultrasonics in endodontics: a review of the literature. J Endod $\underline{33}, 81-95$

Plotino G, Grande N, Melo M, Bahia M, Somma F (2009): Mechanical properties and dimensional characterisation of Roeko CanalBrush. Int Endod $\mathrm{J} \underline{42}$, 1159, Abstract R112

Plotino G, Grande NM, Mercade M, Cortese T, Staffoli S, Gambarini G, Testarelli $L$ (2019): Efficacy of sonic and ultrasonic irrigation devices in the removal of debris from canal irregularities in artificial root canals. J Appl Oral Sci $\underline{27}$, e20180045

Plutzer B, Zilm P, Ratnayake J, Cathro P (2018): Comparative efficacy of endodontic medicaments and sodium hypochlorite against Enterococcus faecalis biofilms. Aust Dent J $\underline{63}, 208-216$

Podbielski A, Spahr A, Haller B (2003): Additive antimicrobial activity of calcium hydroxide and chlorhexidine on common endodontic bacterial pathogens. J Endod 29, 340-345

Ram Z (1977): Effectiveness of root canal irrigation. Oral Surg Oral Med Oral Pathol 44 , 306-312

Reus A: Vergleichende Studie zur Entfernung von Kalziumhydroxid aus dem Wurzelkanal mit Hilfe unterschiedlicher Techniken. Med. Diss. Göttingen 2018

Ribeiro EM, Silva-Sousa YTC, Souza-Gabriel AE, Sousa-Neto MD, Lorencetti KT, Silva SRC (2012): Debris and smear removal in flattened root canals after use of different irrigant agitation protocols. Microsc Res Tech $\underline{75}$, $781-790$

Richman R (1957): The use of ultrasonics in root canal therapy and root resection. J Med 12, 12-18 
Roach RP, Hatton JF, Gillespie MJ (2001): Prevention of the ingress of a known virulent bacterium into the root canal system by intracanal medications. $J$ Endod 27, 657-660

Rödig T, Bozkurt M, Konietschke F, Hülsmann M (2010a): Comparison of the Vibringe system with syringe and passive ultrasonic irrigation in removing debris from simulated root canal irregularities. J Endod $\underline{36}, 1410-1413$

Rödig T, Döllmann S, Konietschke F, Drebenstedt S, Hülsmann M (2010b): Effectiveness of different irrigant agitation techniques on debris and smear layer removal in curved root canals: a scanning electron microscopy study. J Endod $\underline{36}$, 1983-1987

Rödig T, Sedghi M, Konietschke F, Lange K, Ziebolz D, Hülsmann M (2010c): Efficacy of syringe irrigation, RinsEndo and passive ultrasonic irrigation in removing debris from irregularities in root canals with different apical sizes. Int Endod J 누, 581-589

Rödig T, Hirschleb M, Zapf A, Hülsmann M (2011): Comparison of ultrasonic irrigation and RinsEndo for the removal of calcium hydroxide and Ledermix paste from root canals. Int Endod J 444, 1155-1161

Rosenthal S, Spångberg L, Safavi K (2004): Chlorhexidine substantivity in root canal dentin. Oral Surg Oral Med Oral Pathol Oral Radiol Endod 98, 488492

Salman MI, Baumann MA, Hellmich M, Roggendorf MJ, Termaat S (2010): SEM evaluation of root canal debridement with Sonicare CanalBrush irrigation. Int Endod J 느, 363-369

Sassone LM, Fidel R, Fidel S, Vieira M, Hirata R (2003): The influence of organic load on the antimicrobial activity of different concentrations of $\mathrm{NaOCl}$ and chlorhexidine in vitro. Int Endod J $\underline{36}$, 848-852

Schäfer E, Bössmann K (2005): Antimicrobial efficacy of chlorhexidine and two calcium hydroxide formulations against Enterococcus faecalis. J Endod $\underline{31}, 53-56$

Schlichting R (2018): PIPS: Die laseraktivierte Spülung in der Endodontie. Endodontie 27, 407-413

Schroeder A, Triadan H (1962): The pharmacotherapy of pulpitis. Oral Surg Oral Med Oral Pathol 15, 345-350

Sedgley CM, Nagel AC, Hall D, Applegate B (2005): Influence of irrigant needle depth in removing bioluminescent bacteria inoculated into instrumented root canals using real-time imaging in vitro. Int Endod J $\underline{38}, 97-104$

Senia ES, Marshall FJ, Rosen S (1971): The solvent action of sodium hypochlorite on pulp tissue of extracted teeth. Oral Surg Oral Med Oral Pathol $\underline{31}$, 96-103 
Seow WK (1990): The effects of dyadic combinations of endodontic medicaments on microbial growth inhibition. Pediatr Dent 12, 292-297

Silva EJNL, Carvalho CR, Belladonna FG, Prado MC, Lopes RT, De-Deus G, Moreira EJL (2019): Micro-CT evaluation of different final irrigation protocols on the removal of hard-tissue debris from isthmus-containing mesial root of mandibular molars. Clin Oral Investig 23, 681-687

Siqueira J, Lopes H (2002): Kalziumhydroxid als antimikrobielle Einlage in der Endodontie - Wirkungsmechanismen, Vorteile und Grenzen. Endodontie 11, 333-347

Siqueira JF, de Uzeda M (1996): Disinfection by calcium hydroxide pastes of dentinal tubules infected with two obligate and one facultative anaerobic bacteria. J Endod 22, 674-676

Sjögren U, Figdor D, Spångberg L, Sundqvist G (1991): The antimicrobial effect of calcium hydroxide as a short-term intracanal dressing. Int Endod J 24, 119-125

Soekanto A, Kasugai S, Mataki S, Ohya K, Ogura H (1996): Toxicity of camphorated phenol and camphorated parachlorophenol in dental pulp cell culture. J Endod 22, 284-289

Spångberg L: Intracanal medication. In: Endodontics; Ingle JI, Bakland LK. 4. Auflage.; Williams \& Wilkins, Baltimore 1994, 627-671

Spångberg L: Instruments materials and devices. In: Pathways of the Pulp; Cohens,S; Burns,RC. 8. Auflage; Mosby Inc., St Louis, MO, USA 2002, 521-572

Stuart KG, Miller CH, Brown CE, Newton CW (1991): The comparative antimicrobial effect of calcium hydroxide. Oral Surg Oral Med Oral Pathol $\underline{72}, 101-104$

Sukawat C, Srisuwan T (2002): A comparison of the antimicrobial efficacy of three calcium hydroxide formulations on human dentin infected with Enterococcus faecalis. J Endod 28, 102-104

Tanomaru JMG, Pappen FG, Tanomaru Filho M, Spolidorio DMP, Ito IY (2007): In vitro antimicrobial activity of different gutta-percha points and calcium hydroxide pastes. Braz Oral Res 21, 35-39

Tanriverdi F, Esener T, Erganiş O, Belli S (1997): An in vitro test model for investigation of disinfection of dentinal tubules infected with Enterococcus faecalis. Braz Dent J $\underline{8}, 67-72$

Tay FR, Gu LS, Schoeffel GJ, Wimmer C, Susin L, Zhang K, Arun SN, Kim J, Looney SW, Pashley DH (2010): Effect of vapor lock on root canal debridement by using a side-vented needle for positive-pressure irrigant delivery. J Endod $\underline{36}, 745-750$ 
Taylor MA, Humen WR, Heithersay GS (1989): Some effects of Ledermix paste and Pulpdent paste on mouse fibroblasts and on bacteria in vitro. Endod Dent Traumatol $\underline{5}, 266-273$

Tepel J, Darwisch el Sawaf M, Hoppe W (1994): Reaction of inflamed periapical tissue to intracanal medicaments and root canal sealers. Endod Dent Traumatol $\underline{10}$, 233-238

Thomson AD, Athanassiadis B, Kahler B, Walsh L (2012): Tooth discolouration: staining effects of various sealers and medicaments. Aust Endod J $\underline{38}, 2-$ 9

Topçuoglu HS, Akti A, Düzgün S, Ceyhanli KT, Topçuoglu G (2015a): Effectiveness of different irrigation procedures for removal of dentin debris from a simulated internal resorption cavity. Int J Artif Organs $\underline{38}, 165-169$

Topçuoğlu HS, Düzgün S, Ceyhanlı KT, Aktı A, Pala K, Kesim B (2015b): Efficacy of different irrigation techniques in the removal of calcium hydroxide from a simulated internal root resorption cavity. Int Endod J $\underline{48}, 309-316$

Tronstad L: Clinical Endodontics. Thieme-Verlag, Stuttgart 1991

Trope M (1990): Relationship of intracanal medicaments to endodontic flare-ups. Endod Dent Traumatol $\underline{6}, 226-229$

Urban K, Donnermeyer D, Schäfer E, Bürklein S (2017): Canal cleanliness using different irrigation activation systems: a SEM evaluation. Clin Oral Investig $\underline{21}, 2681-2687$

Uygun AD, Gündoğdu EC, Arslan H, Ersoy İ (2017): Efficacy of XP-endo finisher and TRUShape 3D conforming file compared to conventional and ultrasonic irrigation in removing calcium hydroxide. Aust Endod $\mathrm{J} \underline{43}$, 8993

Uzunoglu-Özyürek E, Erdoğan Ö, Aktemur Türker S (2018): Effect of calcium hydroxide dressing on the dentinal tubule penetration of 2 different root canal sealers: a confocal laser scanning microscopic study. J Endod $\underline{44}$, 1018-1023

van der Sluis LWM, Wu M-K, Wesselink PR (2005a): A comparison between a smooth wire and a K-file in removing artificially placed dentine debris from root canals in resin blocks during ultrasonic irrigation. Int Endod J 38, 593596

van der Sluis LWM, Wu M-K, Wesselink PR (2005b): The efficacy of ultrasonic irrigation to remove artificially placed dentine debris from human root canals prepared using instruments of varying taper. Int Endod J $\underline{38}$, 764768

van der Sluis LWM, Gambarini G, Wu MK, Wesselink PR (2006): The influence of volume, type of irrigant and flushing method on removing artificially placed dentine debris from the apical root canal during passive ultrasonic irrigation. Int Endod J $\underline{39}$, 472-476 
van der Sluis LWM, Versluis M, Wu MK, Wesselink PR (2007): Passive ultrasonic irrigation of the root canal: a review of the literature. Int Endod J $\underline{40}, 415$ 426

Venumbaka NR, Baskaran P, Mungara J, Chenchugopal M, Elangovan A, Vijayakumar $P$ (2018): Comparative evaluation of Endovac and conventional irrigating syringe on apical extrusion in primary molars. an in vitro study. J Clin Pediatr Dent $\underline{42}$, 355-360

Vianna ME, Gomes BPFA, Berber VB, Zaia AA, Ferraz CCR, de Souza-Filho FJ (2004): In vitro evaluation of the antimicrobial activity of chlorhexidine and sodium hypochlorite. Oral Surg Oral Med Oral Pathol Oral Radiol Endod 97, 79-84

Vivan RR, Bortolo MV, Duarte MAH, Moraes IG de, Tanomaru-Filho M, Bramante CM (2010): Scanning electron microscopy analysis of RinsEndo system and conventional irrigation for debris removal. Braz Dent J 21, 305-309

Walkhoff O: Lehrbuch der konservierenden Zahnheilkunde. 3. Auflage; 1928

Wall GL, Dowson J, Shipman C (1972): Antibacterial efficacy and cytotoxicity of three endodontic drugs. Oral Surg Oral Med Oral Pathol 33, 230-241

Walmsley AD, Williams AR (1989): Effects of constraint on the oscillatory pattern of endosonic files. J Endod 15, 189-194

Walmsley AD, Lumley PJ, Laird WR (1989): Oscillatory pattern of sonically powered endodontic files. Int Endod J 22, 125-132

Walmsley AD, Lea SC, Felver B, King DC, Price GJ (2013): Mapping cavitation activity around dental ultrasonic tips. Clin Oral Investig 17, 1227-1234

Walters MJ, Baumgartner JC, Marshall JG (2002): Efficacy of irrigation with rotary instrumentation. J Endod 28, 837-839

Waltimo TM, Orstavik D, Sirén EK, Haapasalo MP (1999): In vitro susceptibility of Candida albicans to four disinfectants and their combinations. Int Endod J $\underline{32}, 421-429$

Walton RE (1984): Intracanal medicaments. Dent Clin North Am 28, 783-796

Wauters T, Wauters J (2000): Should the dentin smear layer be preserved or eliminated? (Review of the literature). Rev Belge Med Dent 55, 93-103

Weller RN, Brady JM, Bernier WE (1980): Efficacy of ultrasonic cleaning. J Endod 6, $740-743$

White RR, Hays GL, Janer LR (1997): Residual antimicrobial activity after canal irrigation with chlorhexidine. J Endod 23, 229-231

Wigler R, Dvir R, Weisman A, Matalon S, Kfir A (2017): Efficacy of XP-endo finisher files in the removal of calcium hydroxide paste from artificial 
standardized grooves in the apical third of oval root canals. Int Endod $\mathrm{J}$ 50, 700-705

Willershausen B, Willershausen I, Ehlers V, Azaripour A, Briseño B (2012): A prospective clinical trial on the influence of a triamcinolone /demeclocycline and a calcium hydroxide based temporary cement on pain perception. Head Face Med $\underline{8}, 9$

Wu MK, Wesselink PR (1995): Efficacy of three techniques in cleaning the apical portion of curved root canals. Oral Surg Oral Med Oral Pathol Oral Radiol Endod $\underline{79}$, 492-496

Yang Q, Liu MW, Zhu LX, Peng B (2020): Micro-CT study on the removal of accumulated hard-tissue debris from the root canal system of mandibular molars when using a novel laser-activated irrigation approach. Int Endod $\mathrm{J} \underline{53}, 529-538$

Yücel AÇ, Gürel M, Güler E, Karabucak B (2013): Comparison of final irrigation techniques in removal of calcium hydroxide. Aust Endod J $\underline{39}, 116-121$

Zehnder M (2006): Root canal irrigants. J Endod 32, 389-398 


\section{Danksagung}

Mein größter Dank gilt Herrn Prof. Dr. Michael Hülsmann für die Ermöglichung meiner Promotion, sowie der Überlassung des Themas meiner Doktorarbeit. Die stetige und immer motivierende Unterstützung trug maßgeblich zur Fertigstellung dieser Arbeit bei. Eine solch freundliche Betreuung sowie schnelle und konstruktive Korrekturen sind keinesfalls selbstverständlich und gebühren daher besonderer Erwähnung und Dank. Vielen Dank.

Auch möchte ich mich an dieser Stelle bei Anne Reus und Christoph Beckmann bedanken, die mir in der Zeit der klinischen Versuche zur Seite standen. 